NATIONAL GENTER | Series 10

FOT HEALTH STATISTICS| Number 34

VITAI and ITEATTIT STATISTICS

DATA FROM THE NATIONAL HEALTH SURVEY

\title{
Cigarette Smoking and Health Characteristics
}

\section{United States- July 1964 - June 1965}

Statistics on the prevalence of selected chronic conditions, incidence of selected acute conditions, and days of disability by cigarette smoking habits, sex, and age. Based on data collected in household interviews during the period July 1964-June 1965.

Washington, D. C.

May 1967

U.S. DEPARTMENT OF

HEALTH, EDUCATION, AND WELFARE

Public Health Service

John W. Gardner

Secretary

William H. Stewart

Surgeon General 


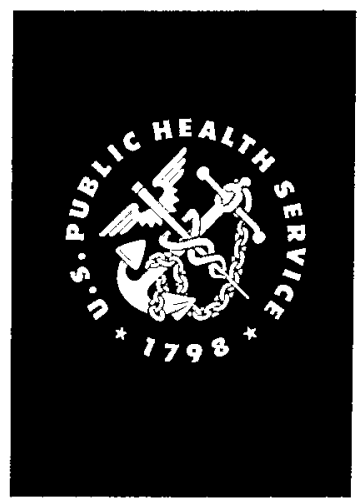

Public Health Service Publication No. 1000-Series 10, No. at 


\title{
NATIONAL CENTER FOR HEALTH STATISTICS
}

\author{
FORREST E. LINDER, PH.D., Director \\ THEODORE D. WOOLSEY, Deputy Director \\ OSWALD K. SAGEN, PH.D., Assistant Director for State Relations \\ WALT R. SIMMONS, M.A., Statistical Advisor \\ PHILIP S. LAWRENCE, Sc.D., Planning Officer \\ ALICE M. WATERHOUSE, M.D., Medical Consultant \\ JAMES E. KELLY, D.D.S., Dental Advisor \\ LOUIS R. STOLCIS, M.A., Executive Officer \\ DONALD GREEN, Information Officer
}

\section{DIVISION OF HEALTH INTERVIEW STATISTICS}

\author{
ELIJAH L. WhITE, A.M., Director \\ ROBERT R. FUCHSBERG, Chief, Survey Methods Branch \\ Geraldine A. Gleeson, Chief, Analysis and Reports Branch
}

COOPERATION OF THE BUREAU OF THE CENSUS

Under the legislation establishing the National Health Survey, the Public Health Service is authorized to use, insofar as possible, the services or facilities of other Federal, State, or private agencies.

In accordance with specifications established by the National Health Survey, the Bureau of the Census, under a contractual arrangement, participates in most aspects of survey planning, selects the sample, collects the data, and carries out certain parts of the statistical processing.

Public Health Service Publication No. 1000-Series 10-No. 34 


\section{CONTENTS}

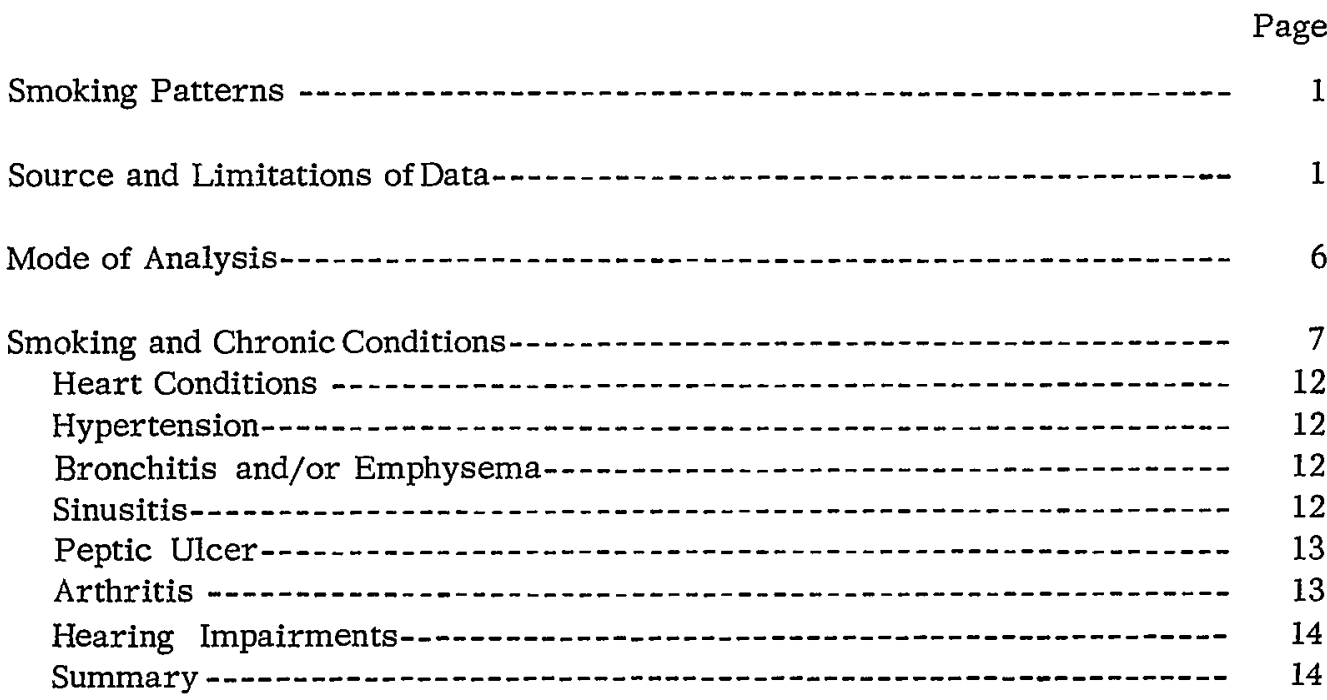

Smoking and Acute Conditions-m-14

Upper Respiratory Conditions-1.- 16

Other Respiratory Conditions-_. 16

Infective and Parasitic Diseases-_._. 16

Influenza -..-. 16

Injuries - -

Disability Days -

Restricted-Activity Days-1-16 16

Bed-Days -......- 18

Work-Loss Day-_. 18

Interval Since Last Smoked and Morbidity and Disability Days Among Male

Former Smokers - 20

References-- 20

Detailed Tables-_. 21 
Appendix I. Technical Notes on Methods- 56

Background of This Report-_. 56

Statistical Design of the Health Interview Survey-_-_._. 56

General Qualifications-...... 57

Reliability of Estimates-_-_._- 58

Guide to Use of Relative Standard Error Charts__. 59

Appendix II. Definitions of Certain Terms Used in This Report-_...- 62

Terms Related to Cigarette Smoking

Terms Relating to Chronic Conditions

Terms Relating to Acute Conditions-... 63

Terms Relating to Disability Days-_. 63

Demographic and Economic Terms -..... 64 
IN THIS REPORT, statistics are presented on selected health characteristics and cigarette smoking habits of the civilian, noninstitutional population 17 years and over in the United States during the period July 1964June 1965. Estimates of prevalence rates of selected chronic conditions, incidence rates of selected acute conditions, and the number of days of disability for males and females are shoun by a combination of smoking characteristics which include present smoking status, the number of cigarettes smoked per day when smoking the heaviest, and the present cigarette consumption. The data permit comparisons of health characteristics for persons who are or had been cigarette smokers with those who had never smoked cigarettes.

In general, persons who had ever smoked cigarettes reported higher rates of heart conditions, bronchitis and/or emphysema, sinusitis, and peptic ulcers; more acute conditions; and more days of disability than persons who had never smoked cigarettes. The proportion of persons who reported chronic conditions was usually higher among former smokers than among present smokers taken as a group. Where a relationship existed between a given condition and cigarette smoking, the relationship tended to increase as cigarette consumption increased.

\section{SYMBOLS}

Data not available-...-- -

Category not applicable---

Quantity zero-1.-

Quantity more than 0 but less than $0.05-----\quad 0.0$

Figure does not meet standards of reliability or precision-..- 


\title{
CIGARETTE SMOKING AND HEALTH CHARACTERISTICS
}

\author{
Ronald W. Wilson, Division of Health Interview Statistics
}

This is a report of one of a number of studies undertaken by the Public Health Service to further investigate the relationship between smoking and health subsequent to the report of the Surgeon General's Advisory Committee on Smoking and Health. ${ }^{1}$ The data presented here were collected as a part of the continuing Health Interview Survey which included several questions on cigarette smoking habits in addition to questions on health characteristics.

\section{SMOKING PATTERNS}

The average number of civilian, noninstitutionalized persons in the population 17 years and over during the period, July 1964-June 1965 was estimated at 122,086,000; consisting of 57,585,000 men and $64,501,000$ women (table 1). About $29,341,000$, or 51.0 percent, of the males were classified as present cigarette smokers as compared with $21,400,000$, or 33.2 percent, of the females (fig. 1). An estimated 19.2 percent of the males were former smokers, while 29.6 percent had never smoked as many as 100 cigarettes. Only 7.8 percent of the females reported that they were former smokers while 58.5 percent of the females had never smoked 100 cigarettes. About 72.6 percent of all men who had ever smoked were still smoking during the interview period as compared with 80.9 percent of the women. Figure 1 and tables 1 and 2 also show smoking status by age groups and demonstrate the marked differences in smoking habits between the sexes. As shown in figure 2 and in more detail in tables 1 and 2, the number of cigarettes smoked per day varies by age. There was a tendency toward higher smoking rates at the middle age groups in both sexes, although the level of the rates for females was considerably lower. The lower smoking rates reported among the older age groups were not entirely due to the persons who had cut down on their smoking, but also reflected lower overall smoking rates among older persons.

\section{SOURCE AND LIMITATIONS OF DATA}

The information contained in this publication is derived from household interviews conducted by the Health Interview Survey in cooperation with the U.S. Bureau of the Census in a probability sample of the civilian, noninstitutional population of the United States. The sample is designed so that interviews are conducted during every week of the year. During the 52-week period from July 1964 through June 1965, the sample was composed of approximately 42,000 households containing about 134,000 persons living at the time of the interview.

A description of the design of the survey, the methods used in estimation, and general qualifications of the data obtained from surveys is presented in Appendix I. Since the estimates shown in this report are based on a sample of the population rather than on the entire population, they are subject to sampling error. Therefore, particular attention should be paid to the section entitled "Reliability of Estimates." Sampling errors for most of the estimates are of relatively low magnitude. However, where an estimated num- 


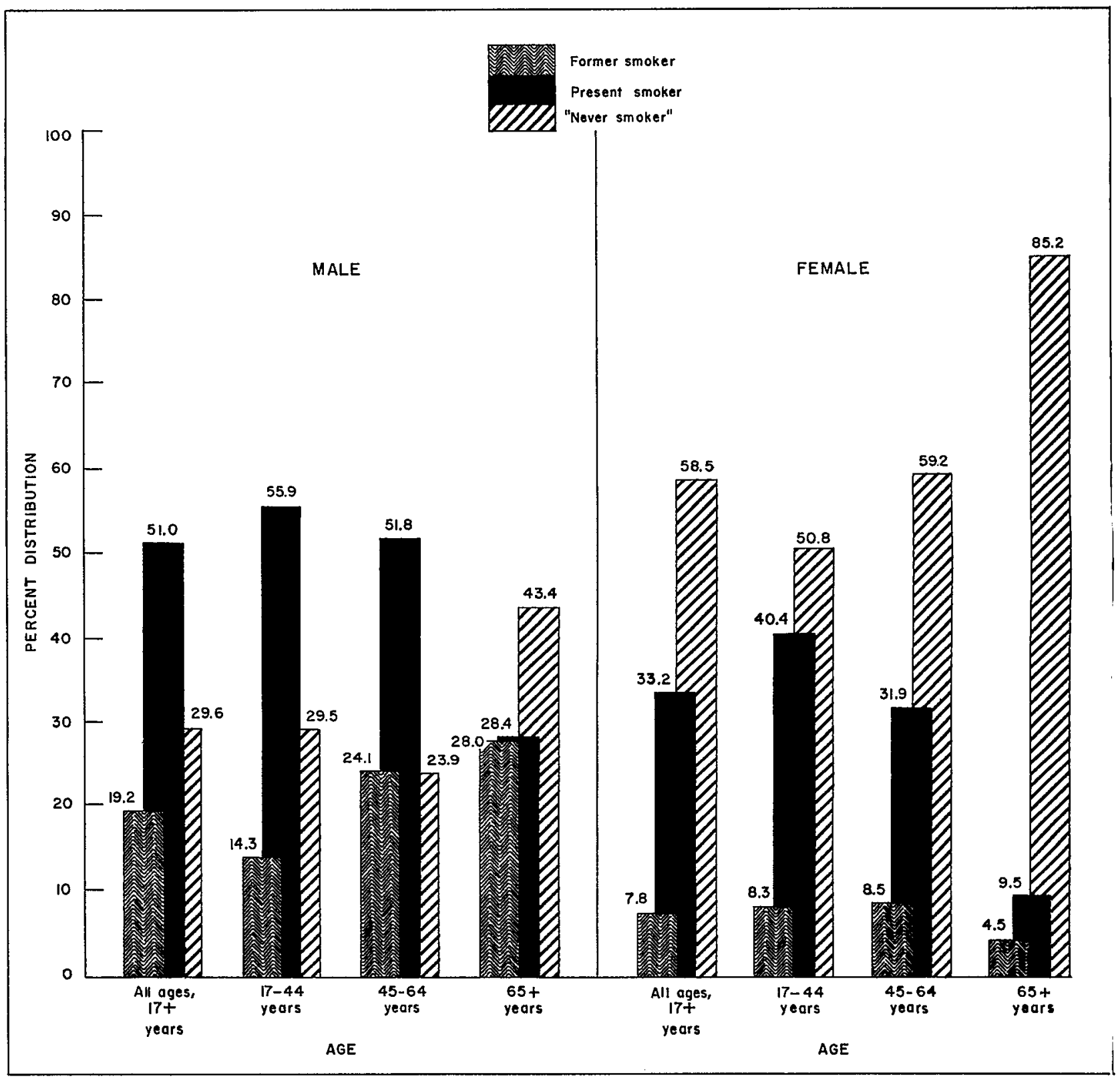

Figure 1. Percent distribution of the population 17 years and over, by smoking status according to sex and age.

ber or the numerator or the denominator of a rate or percentage is small, the sampling error may be high. Charts of relative sampling errors and instructions for their use are shown in Appendix I.

The questionnaire used during the period July 1964-June 1965 appears in "Current Estimates," (Vital and Health Statistics, Series
10, No. 25). The estimates on cigarette smoking were obtained from questions 18-20, which are reproduced from the questionnaire in figure 3. The respondents did not know that they would be asked questions on their cigarette smoking habits until after the health data were obtained. In this manner a possible source of respondent bias was eliminated. 


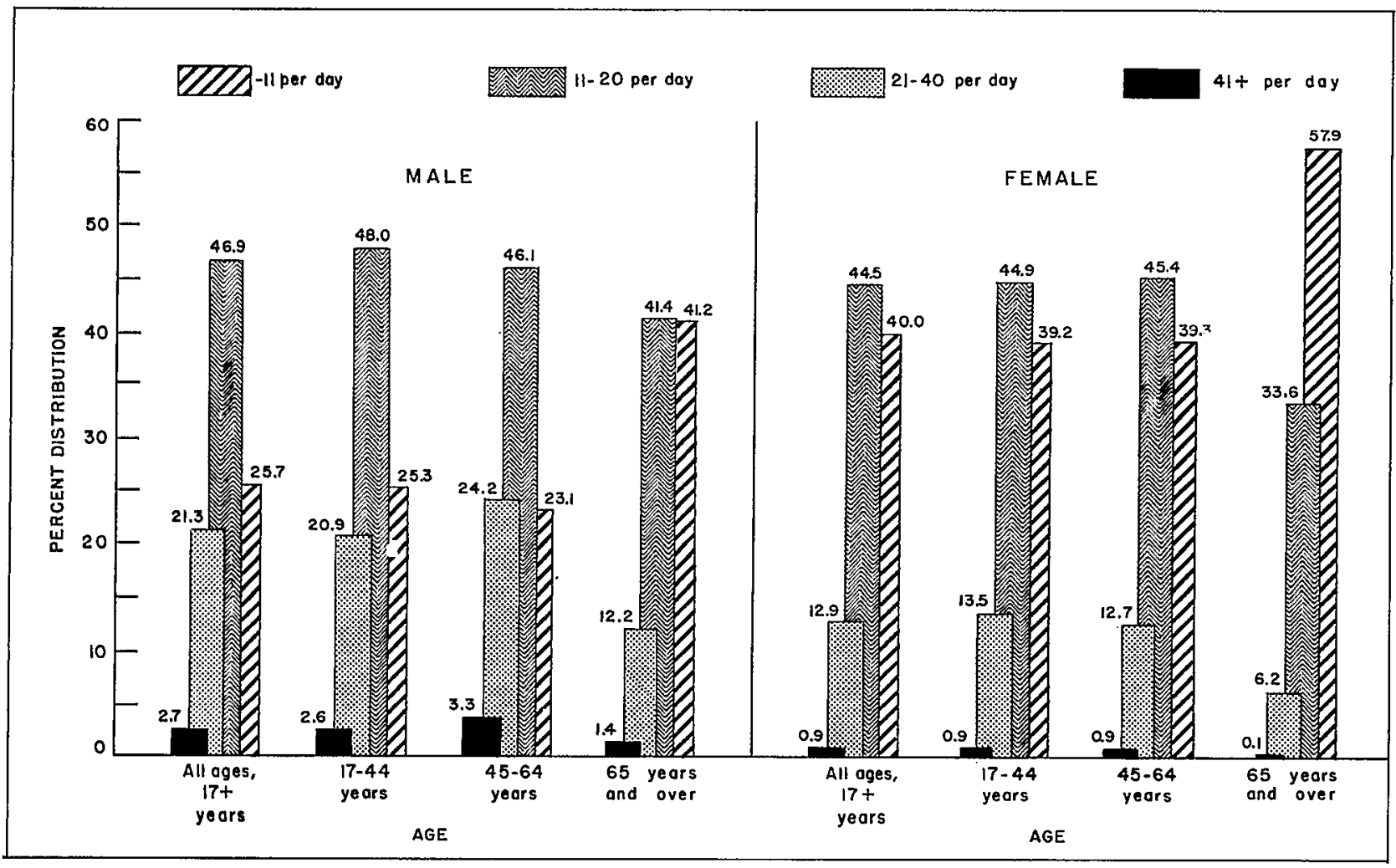

Figure 2. Percent distribution of present smokers, by number of cigarettes smoked per day according to sex and age.

The smoking characteristics of all persons aged 17 years and over are examined in terms of three basic measures: (1) current smoking habits, (2) the number of cigarettes smoked per day at the present time and, (3) the number of cigarettes smoked per day when smoking the heaviest. Thus, the population can be divided into groups of persons who had never smoked cigarettes, and persons who have ever smoked cigarettes, with the latter group subdivided into

Now I have o fow questions about smoking - -

For each person 17 years old or over, ask:

18. a. Have you smoked at least one hundred eigarattex during your entire lifo?

If "Yes," ask:

b. During the period when you ware smoking the most, how many cigarettes a doy did you usually smoke?

19. a. Do you smoke el garetten now?

If "Yes," ask questions $19 \mathrm{~b}$ AND 19c. If "No," go to question 20:

b. On the average, about how many cigaroties a day do you moke?

e. Twelve monthe ago, how many elgarettes a day were you smoking?

If "No" to question 19a, ask BOTH questions 20a AND 20b.

20. a. On the averoge, about how many elgarattes a day were you smoking 12 month: ago?

b. How long has it been sinee you smoked cigareftes fairly regularly?

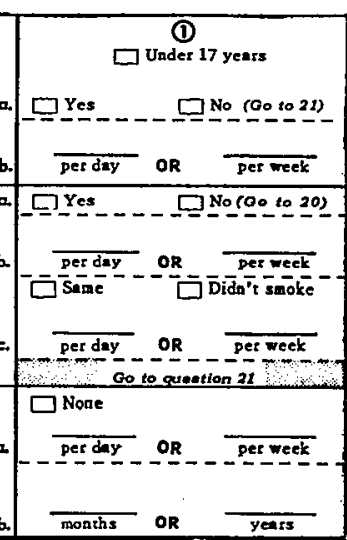

Figure 3. 


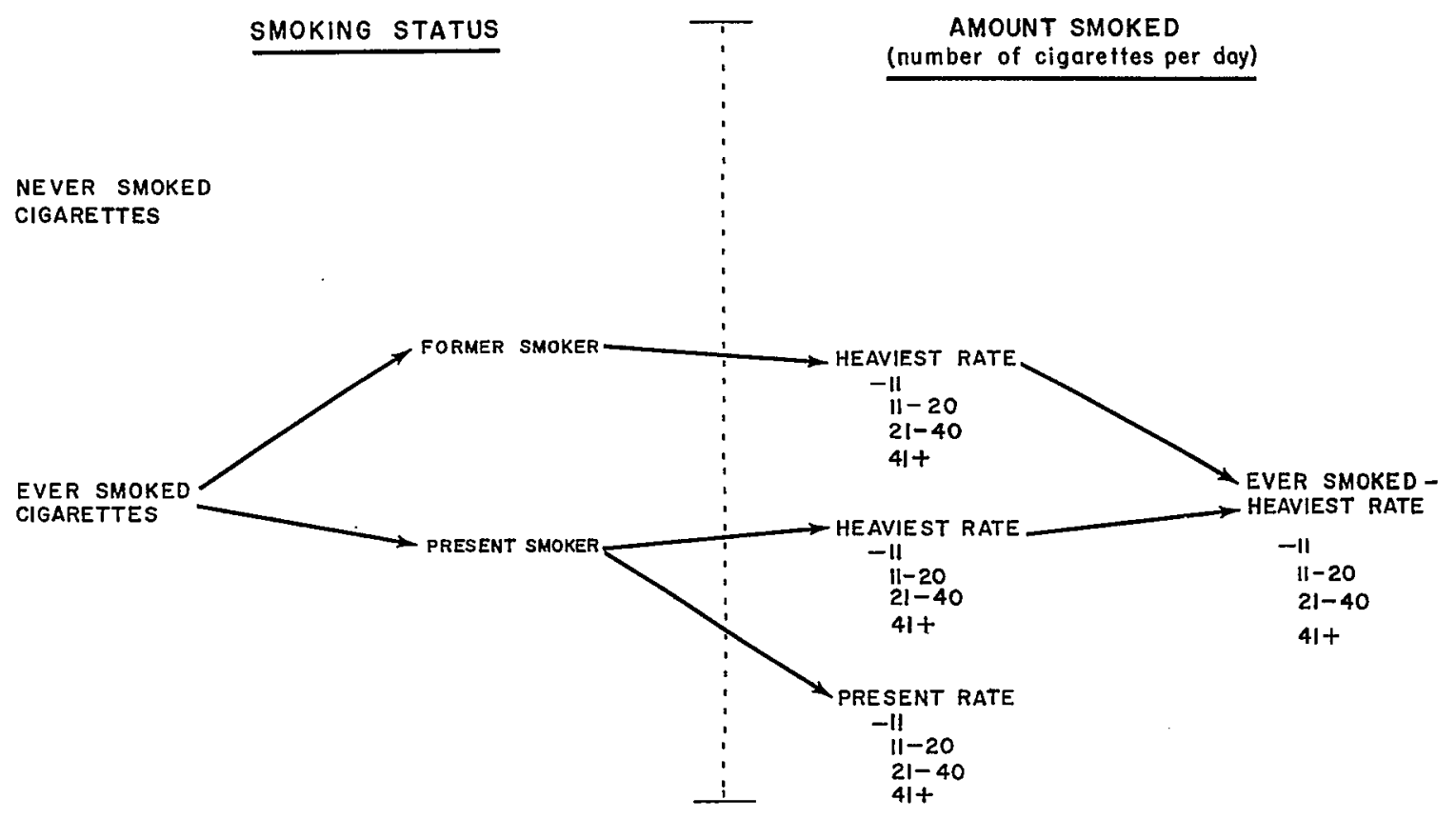

Figure 4. Schematic presentation of cigarette smoking categories.

present and former smokers. Hereafter, these three groups will be identified in the discussion as "never smokers," a "present smokers," and "former smokers."

The smoking amounts were obtained in terms of the actual number of cigarettes smoked, but for purposes of analysis these data were divided into four categories (under 11, 11-20, 21-40, and 41 cigarettes and over per day). These four categories were established to correspond with limits imposed by cigarette packaging practices, and range from a half a pack or less to more than two packs per day. Although the estimates for the category, more than two packs a day, are

aAmong those males who reported that they had not smoked at least 100 cigarettes in their entire life, 59.6 percent reported that they had smoked at least 10 cigars and/or at least 3 packages of pipe tobacco. In addition, 18.0 percent of the male "never smokers" were pipe and/or cigar smokers at the time of the survey and 19.9 percent of these reported smoking 5 or more cigars a day and/or 10 or more pipefuls of tobacco a day. Also, 25.7 percent of the male former cigarette smokers were cigar and,'or pipe smokers at the time of the survey, and 30.4 percent of these smoked 5 or more cigars or 10 or more pipefuls a day. small, it was retained as a separate category as indicative of extreme smoking behavior. By utilizing the present and heaviest smoking amounts, it was then possible to make the follow ing groupings: (1) ever smoked-heaviest amount, (2) former smoker-heaviest amount, (3) present smoker-heaviest amount, and (4) present smoker-present amount. These four categories comprise the major groupings used in this report to describe the smoking habits of the population. In figure 4 a schematic outline of the smoking categories is presented. Definitions of smoking and other terms used in this report are found in Appendix II.

There are several other factors affecting interpretation that should be kept in mind when reading this report. While the data give a measure of current and heaviest cigarette smoking amounts, there is no measure of how long a respondent was smoking at a given rate, or how long ago the rate prevailed. For example, a 50year-old man who reported his heaviest amount 
as two packs a day could have smoked at that rate from 20 to 45 years of age, or only for 1 year in his twenties. Another possible source of bias was best described in an earlier Public Health Service report ${ }^{2}$ on smoking patterns as follows:

It should be stressed that the questions were designed to classify people and not to estimate the amount of tobacco consumed. For the latter purpose the proper approach would have been to include questions on recent purchases or on the number of units consumed in a given day. Couching smoking questions in terms of "on the average" probably exerts a downward bias. The respondent may be encouraged to think of some smoking pattern which he rarely falls below and to neglect amounts in excess of this figure in his response. Since the primary objective of this survey was to classify groups of people for purposes of comparisons, such biases would not be important so long as they were not large nor selective in character.

Self- and proxy-response differences also result in some reporting biases. Both males and females are more likely to report themselves as former smokers than to report other family members (proxy respondents) as former smokers. Self-respondents who do report present smoking amounts, report smoking slightly higher amounts than proxy respondents. This will result in some underreporting of smoking rates for males in particular, since data on 60.0 percent of the males who had ever smoked were obtained from other persons as compared with only 17.2 percent of the female smokers who had proxy respondents. There were also some differences between selfand proxy-respondents in terms of having never smoked. Among the male self-respondents 26.2 percent had never smoked at least 100 cigarettes with 31.7 percent among the proxy respondents. Corresponding figures for female self- and proxy-respondents were 56.7 and 65.5 percent, respectively.

The prevalence estimates of chronic conditions used in this report are subject to special limitations inherent in data collected in household health interviews. Chronic conditions reported in interviews may be described as those of which the respondent is aware, and is willing to report to the interviewer. The diagnostic accuracy of reported conditions is dependent on the information the attending physician has passed on to the family, or, in the absence of medical attendance, on the previous experience or education of the family. For these reasons, the prevalence estimates produced from interview data will, for some conditions, differ markedly from estimates based on medical reports or clinical examinations.

It should be noted that respondents were not asked for information on how their health was affected by smoking. Rather, the findings represent a cross tabulation of health data reported in the regular interview with the reported smoking habits.

Data on chronic conditions in this report are for selected condition groups shown below with their equivalent code numbers from the 1955 revision of the International Classification of Diseases. These eight condition categories were selected for their probable relationships with smoking, accuracy of reporting, and the sufficient number of cases they offered for analysis.
Condition group

Heart conditions (excluding
rheumatic heart disease)--.--

Theumatic heart disease)-

Arteriosclerotic heart disease, including coronary disease -...-.-.--.--.-.-

Hypertension without heart

involvement -.-.--.--

Chronic bronchitis and/or

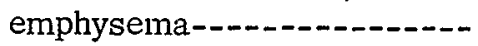

Chronic sinusitis -.-.--.---

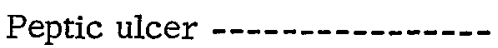

Arthritis

Hearing impairments -..---.--

All other chronic conditions --
Code number

$420-443,782.1$, $782.2,782.4$

$444-447$

$502,527.1$

513

540-542

720-725

X06-X09b

Residual

\footnotetext{
$\mathrm{b}_{\text {Impairments are classified by means of a special supple- }}$ mentary code which is used to group them according to the type of functional impairment and etiology. Health Statistics, Series B, No. 35, presents an explanation of this classification.
} 
The obvious omission of lung cancer from the list of chronic conditions in this report deserves comment since the relationship between cigarette smoking and lung cancer has been widely documented. The number of reported cases of lung cancer is very low in the Health Interview Survey sample, primarily because the reporting of cancer of all types in an interview survey is low and because the survey is restricted to a sample of persons living at the time of interview. The survival rate of persons diagnosed with lung cancer is low. For example, in a study in Connecticut (1935-51), it was found that the percent of males surviving 3,6 , and 12 months after a diagnosis of lung cancer was $44.7,26.1$, and 12.5 respectively (the survival rates were almost identical for females). ${ }^{3}$

The most these data can do is to demonstrate the lack of or the existence of a relationship between cigarette smoking and various health characteristics; it cannot establish any existing relationship as a causal one. If a relationship is found, there can be several possible explanations, for example: (1) smoking actually causes a certain condition (or is one of a number of causes), (2) the presence of a certain condition causes the person to smoke, or (3) some third factor, possibly psychologic or biologic, is causing both the condition and the smoking habit. (For a detailed discussion of causality in relation to cigarette smoking see reference 1 , ch. 3.)

One of the advantages of this study is that the data on relationships between cigarette smoking and health are based on responses from a probability sample which is representative of the civilian, noninstitutional population of the United States, thus allowing the data to be presented in the form of nutional estimatcs.

\section{MODE OF ANALYSIS}

The mode of analysis in this report consists of showing the relationships between various smoking habits and selected measures of morbidity, such as rates of selected acute and chronic conditions and disability days. The relationships between smoking and morbidity are not crossclassified by the demographic characteristics at this time. The main reason for restricting the analysis is the lack of sufficient cases to fill the appropriate cells in such cross-tabulations, particularly in terms of the number of cigarettes smoked per day.

All the data in this report are presented for each sex separately because of the marked differences in smoking practices by males and females, as well as sex differences in certain morbidity measures. Most of the incidence and prevalence rates shown in the detailed tables are age-adjusted by the indirect method (Appendix I) to the age distribution of the total population 17 years of age and over with three age categories (17-44, 45-64, and 65 years and over). Unless otherwise specified, all subsequent rates and numbers shown in the text are based on ageadjusted data. The age-adjusted rates do conceal some age differences with respect to cigarette smoking and certain types of conditions, but the more apparent of these differences are discussed as they arise. Age-adjusting to the total population allows direct comparisons of the estimates shown for males and females.

In addition, a number of ratios derived from these age-adjusted prevalence and incidence rates are presented using the rates of the "never smoked" category as the base. For example, the ratio of the rates of chronic bronchitis and/or emphysema for female present smokers (prevalence rate $=3.8$ cases per 100 persons), as compared with females who had never smoked (prevalence rate $=1.2 / 100$ persons), is $3.8 / 1.2$ or 3.17 , which means that female present smokers reported bronchitis and/or emphysema more than three times as often as those who had never smoked. In terms of percentages, the above ratio of 3.17 would mean that female present smokers had a prevalence rate of bronchitis and/or emphysema 217 percent higher than the "never smokers." The use of ratios in this form also removes the effect of sex differences and allows direct comparison between males and females on any variable. Since all rates are age adjusted to the total population 17 years and over, ratios can be computed using bases other than the "never smoked" population, such as the ratio of those who smoked more than two packs a day to those who smoked a half pack or less a day. There is a pattern which prevails in most of the tables 
of this report indicating that the former smokers had higher rates of morbidity and disability than did the present smokers. (However, present smokers whose heaviest smoking amount was over a pack a day showed a rather consistent pattern of higher rates of chronic conditions than the former smokers taken as a whole.) At first glance, this finding appears to be contradictory to the reports on the death rates among smokers which show that the former smokers have a better chance of survival than present smokers. ${ }^{4-6}$ One might draw the conclusion that a person who quits smoking will live somewhat longer but will be somewhat less healthy than the person who continues to smoke. However, these findings do not present the whole picture, since at least one important variable is not available in the data, i.e., the reason the former smoker stopped smoking. It could well be that most of the persons who quit smoking in the past, that is, prior to the Surgeon General's report, Smoking and Health, did so because of ill health. (For a detailed discussion see reference 7.) Had data been available on the reason for quitting, it mighthave been found that those smokers who stopped for nonmedical reasons or before their health was impaired have considerably lower rates of morbidity than present smokers, as well as having lower morbidity rates than persons who quit smoking after their health was impaired. The same studies that reported lower mortality among the former smokers also reported increased life expectancy as the interval "since last smoked" increased. The relationship between morbidity and the interval "since last smoked" is discussed later in this report.

The majority of the data in this report are in the form of ratios, rates, and percentages, which do not give an immediate picture of the number of persons on which these figures are based. Much of the original data can be readily approximated by multiplying the crude rates (not the age-adjusted rates) by the base population in table 1. For example, the estimated number of males 17 years or over who are presently smoking 21-40 cigarettes a day and report bronchitis and/or emphysema is $175,000(6,257,000 \mathrm{x}$ $2.8 / 100=175,000)$.

A number of the relationships found here between cigarette smoking and health character- istics lend further support to previous findings on smoking and mortality rates in which there is a direct relationship between smoking and certain conditions. However, the associations between smoking and other conditions are not so easily explained and the direction of any causal relationship is not readily apparent. It is with these latter conditions in particular, such as arthritis and injuries, that further data and investigations are needed to clarify the results of the present study.

\section{SMOKING AND CHRONIC CONDITIONS}

Both male and female cigarette smokers reported a higher rate of chronic conditions than did persons who had never smoked. Table A indicates that 58.0 percent of the male present smokers reported one or more chronic conditions, while only 53.5 percent of the male "never smokers" reported one or more chronic conditions. The corresponding figures for females are 64.4 percent for the present smokers and 60.0 percent for those who had never smoked. Although females reported more chronic conditions, the ratio of present smokers to "never smokers" is about the same for both sexes, i.e., 1.08 (58.0 percent/53.5 percent) for the male smokers, and 1.07 (64.4 percent/60.0 percent) for the female smokers. The differences between all present smokers and those who had neversmoked are not large. However, when the present smokers heaviest smoking amount is taken into consideration, there is a marked increase in the prevalence of chronic conditions as the number of cigarettes smoked per day increases. For example, of the males who smoked a half pack or less at their heaviest amount, 49.5 percent reported one or more chronic conditions while 72.1 percent of those who smoked over two packs a day had one or more chronic conditions, which is 35 percent higher than the percentage for the "never smokers." There is a similar increase in the percent of females with chronic conditions as the heaviest smoking amount increases with 57.1 percent of the light smokers and 85.3 percent of the heaviest smokers reporting one or more chronic conditions. Thus, the number of cigarettes smoked appears to be a major factor 
Table A. Age-adjusted ${ }^{1}$ percent and ratios ${ }^{2}$ of persons 17 years and over with one or more chronic conditions, by cigarette smoking status, number of cigarettes smoked per day for present smokersheaviest amount, sex, and number of chronic conditions: United States, July 1964-June 1965

\begin{tabular}{|c|c|c|c|c|c|c|c|c|c|}
\hline \multirow{3}{*}{$\begin{array}{l}\text { Sex and number of } \\
\text { chronic conditions }\end{array}$} & \multirow{3}{*}{$\begin{array}{l}\text { Tota1 } \\
\text { popu- } \\
\text { lation }\end{array}$} & \multicolumn{4}{|c|}{ Cigarette smoking status } & \multicolumn{4}{|c|}{ Present smokers } \\
\hline & & \multirow{2}{*}{$\begin{array}{l}\text { Persons } \\
\text { who } \\
\text { never } \\
\text { smoked }\end{array}$} & \multirow{2}{*}{$\begin{array}{l}\text { Persons } \\
\text { who } \\
\text { ever } \\
\text { smoked }\end{array}$} & \multirow{2}{*}{$\begin{array}{l}\text { Former } \\
\text { smokers }\end{array}$} & \multirow{2}{*}{$\begin{array}{l}\text { Present } \\
\text { smokers }\end{array}$} & \multicolumn{4}{|c|}{$\begin{array}{c}\text { Number of clgarettes } \\
\text { smoked per day-heaviest } \\
\text { amount }\end{array}$} \\
\hline & & & & & & $\begin{array}{l}\text { Under } \\
11\end{array}$ & $11-20$ & $21-40$ & $\begin{array}{l}41 \text { and } \\
\text { over }\end{array}$ \\
\hline Male & \multicolumn{9}{|c|}{ Age-adjusted percent } \\
\hline $\begin{array}{c}\text { 1t chronic conditions- } \\
\text { 3+ chronic conditions- } \\
\text { Female }\end{array}$ & $\begin{array}{l}57.5 \\
15.6\end{array}$ & $\begin{array}{l}53.5 \\
13.5\end{array}$ & $\begin{array}{l}59.3 \\
16.5\end{array}$ & $\begin{array}{l}62.5 \\
18.8\end{array}$ & $\begin{array}{l}58.0 \\
15.3\end{array}$ & $\begin{array}{l}49.5 \\
11.9\end{array}$ & $\begin{array}{l}55.1 \\
13.8\end{array}$ & $\begin{array}{l}64.7 \\
18.5\end{array}$ & $\begin{array}{l}72.1 \\
23.3\end{array}$ \\
\hline $\begin{array}{l}\text { 1t chronic conditions- } \\
3+\text { chronic conditions- }\end{array}$ & $\begin{array}{l}62.0 \\
21.3\end{array}$ & $\begin{array}{l}60.0 \\
20.2\end{array}$ & $\begin{array}{l}65.2 \\
23.3\end{array}$ & $\begin{array}{l}69.2 \\
26.6\end{array}$ & $\begin{array}{l}64.4 \\
22.4\end{array}$ & $\begin{array}{l}57.1 \\
16.5\end{array}$ & $\begin{array}{l}63.5 \\
21.7\end{array}$ & $\begin{array}{l}74.7 \\
30.6\end{array}$ & $\begin{array}{l}85.3 \\
49.1\end{array}$ \\
\hline Male & \multicolumn{9}{|c|}{ Ratio } \\
\hline $\begin{array}{c}\text { 1t chronic conditions- } \\
\text { 3+ chronic conditions- } \\
\text { Female }\end{array}$ & $\begin{array}{r}31.07 \\
1.16\end{array}$ & $\begin{array}{l}1.00 \\
1.00\end{array}$ & $\begin{array}{l}1.11 \\
1.22\end{array}$ & $\begin{array}{l}1.17 \\
1.39\end{array}$ & $\begin{array}{l}1.08 \\
1.13\end{array}$ & $\begin{array}{l}0.93 \\
0.88\end{array}$ & $\begin{array}{l}1.03 \\
1.02\end{array}$ & $\begin{array}{l}1.21 \\
1.37\end{array}$ & $\begin{array}{l}1.35 \\
1.73\end{array}$ \\
\hline $\begin{array}{l}\text { 1t chronic conditions- } \\
\text { 3t chronic conditions- }\end{array}$ & $\begin{array}{l}1.03 \\
1.05\end{array}$ & $\begin{array}{l}1.00 \\
1.00\end{array}$ & $\begin{array}{l}1.09 \\
1.15\end{array}$ & $\begin{array}{l}1.15 \\
1.32\end{array}$ & $\begin{array}{l}1.07 \\
1.11\end{array}$ & $\begin{array}{l}0.95 \\
0.82\end{array}$ & $\begin{array}{l}1.06 \\
1.07\end{array}$ & $\begin{array}{l}1.25 \\
1.51\end{array}$ & $\begin{array}{l}1.42 \\
2.43\end{array}$ \\
\hline
\end{tabular}

${ }^{1}$ Adjusted by the indirect method to the age distribution of the total civilian, noninstitutional population of the United States.

${ }^{2}$ Percent for given smoking category divided by percent for "never smokers."

${ }^{3}$ Example: $1.07=57.5 / 53.5$.

in the relationship between cigarette smoking and health, with the strongest relationship among the heaviest smokers. By comparing the ratios (table A) of percent of persons with one or more and three or more chronic conditions, it can be seen that smokers, at the higher levels of smoking, are more likely to report three or more chronic conditions than those who had never smoked. For example, among women who smoked 21-40 cigarettes a day at their heaviest rate, the number of those with one or more chronic conditions is 25 percent higher than that for "never smokers," while the number for those with three or more chronic conditions is 51 percent higher. This same pattern holds for the males.
Tables 3 and 4 show the relationship between both heaviest and present smoking amounts and the prevalence of one or more chronic conditions. Among former smokers there is a higher percent with one or more chronic conditions than among those who had never smoked or were present smokers. This could indicate that some smokers with chronic conditions tend to give up cigarettes, but, because of its chronic nature the condition still persists, giving the former smokers high prevalence rates. In the analysis the heaviest smoking amount is used in relation to chronic conditions since by definition the chronic conditions are of a continuing nature and thus coulci be affected by past smoking habits. Furthermore 
Table B. Ratios1 of present smokers to "never smokers" of precent of persons with one or more chronic conditions, by number of cigarettes smoked per day-heaviest amount, sex, and age: United States, July 1964-June 1965

\begin{tabular}{|c|c|c|c|c|c|}
\hline \multirow{3}{*}{ Sex and age } & \multirow{3}{*}{$\begin{array}{c}\text { Total } \\
\text { smokers }\end{array}$} & \multicolumn{4}{|c|}{ Present smokers } \\
\hline & & \multicolumn{4}{|c|}{$\begin{array}{c}\text { Number of cigarettes } \\
\text { smoked per day-heaviest } \\
\text { amount }\end{array}$} \\
\hline & & $\begin{array}{c}\text { Under } \\
11\end{array}$ & $11-20$ & $21-40$ & $\begin{array}{l}41 \text { and } \\
\text { over }\end{array}$ \\
\hline Male & \multicolumn{5}{|c|}{ Ratio } \\
\hline Al1 ages, 17 years and over & ${ }^{2} 1.03$ & 0.89 & 0.98 & 1.15 & 1.28 \\
\hline $\begin{array}{l}17-44 \text { years } \\
65-64 \text { years } \\
65 \text { Female }\end{array}$ & $\begin{array}{l}1.16 \\
1.05 \\
1.01\end{array}$ & $\begin{array}{l}0.91 \\
0.95 \\
0.98\end{array}$ & $\begin{array}{l}1.08 \\
1.01 \\
1.00\end{array}$ & $\begin{array}{l}1.35 \\
1.12 \\
1.07\end{array}$ & $\begin{array}{l}1.52 \\
1.25 \\
1.04\end{array}$ \\
\hline A11 ages, 17 years and over & 0.97 & 0.87 & 0.96 & 1.10 & 1.23 \\
\hline $\begin{array}{l}17-44 \text { years- } \\
45-64 \text { years } \\
65 \text { years and over- }\end{array}$ & $\begin{array}{l}1.15 \\
1.00 \\
0.98\end{array}$ & $\begin{array}{l}0.98 \\
0.93 \\
0.93\end{array}$ & $\begin{array}{l}1.13 \\
0.99 \\
1.00\end{array}$ & $\begin{array}{l}1.35 \\
1.11 \\
1.09\end{array}$ & $\begin{array}{r}1.56 \\
1.16\end{array}$ \\
\hline
\end{tabular}

${ }^{1}$ Ratlos of 1.00 = same as "never smoked."

Example: 1.03 = percent present smokers with one or more chronic conditions divided by percent "never smokers" with one or more chronic conditions.

of the present smokers, 72 percent of the males and 78 percent of the females had present smoking amounts similar to their heaviest smoking amounts. Because of this similarity, when the prevalence of chronic conditions is examined by the present smoking rate, the same pattern of increasing prevalence with increasing smoking rates is found, although differences in the prevalence of conditions between present light and heavy smoking rates are not as great as those shown when using the heaviest smoking rate. This could result from a reduction in the smoking amount because of a given chronic condition.

Although the age-adjusted prevalence rates are useful for comparative purposes, they do conceal certain patterns that exist in the agespecific data (even though some of the cells are small). One pattern that is found with almost all of the chronic conditions is that as age increases, the degree of the association between a given condition and smoking decreases. Many of the ratios of smokers to "never smokers" are largest for the 17-44 age group. This is shown in tables $B$ and $C$ which give the age-specific ratios of smokers to "never smokers" for persons with one or more chronic conditions and selected chronic conditions, respectively. (See tables 5 and 6 for age-specific rates.) One explanation of this finding is that the natural increase of most 
chronic conditions with age is also characteristic of persons who had never smoked, and for the older age groups results in a larger base for the ratio which in turn results in smaller ratios. There is also the problem of the effects of selected mortality on the ratios of the older age group, particularly with the higher mortality rates for certain conditions among cigarette smokers. Another important factor that is not taken into account in this analysis is the severity of the disease. Even though in most cases the ratios of smokers to "never smokers" decreases with age, it could be that conditions among smokers in the older age groups are more serious than those of the "never smokers." Some measure of severity might have been determined by comparing the number of disability days and/or activity limititions by condition for smokers and "never smokers." Unfortunately, the current data did not have sufficient cases for this more detailed analysis.

The relationship between smoking and the presence of chronic conditions varies considerably by condition. While the magnitude of this variation differs from condition to condition, the general pattern of relationships is quite similar, with the former smokers reporting higher rates

Table C. Age-specific ratios 1 of prevalence rates of chronic conditions for persons who had ever smoked to persons who had never smoked, by sex, age, and selected chronic conditions: United States, July 1964-June 1965

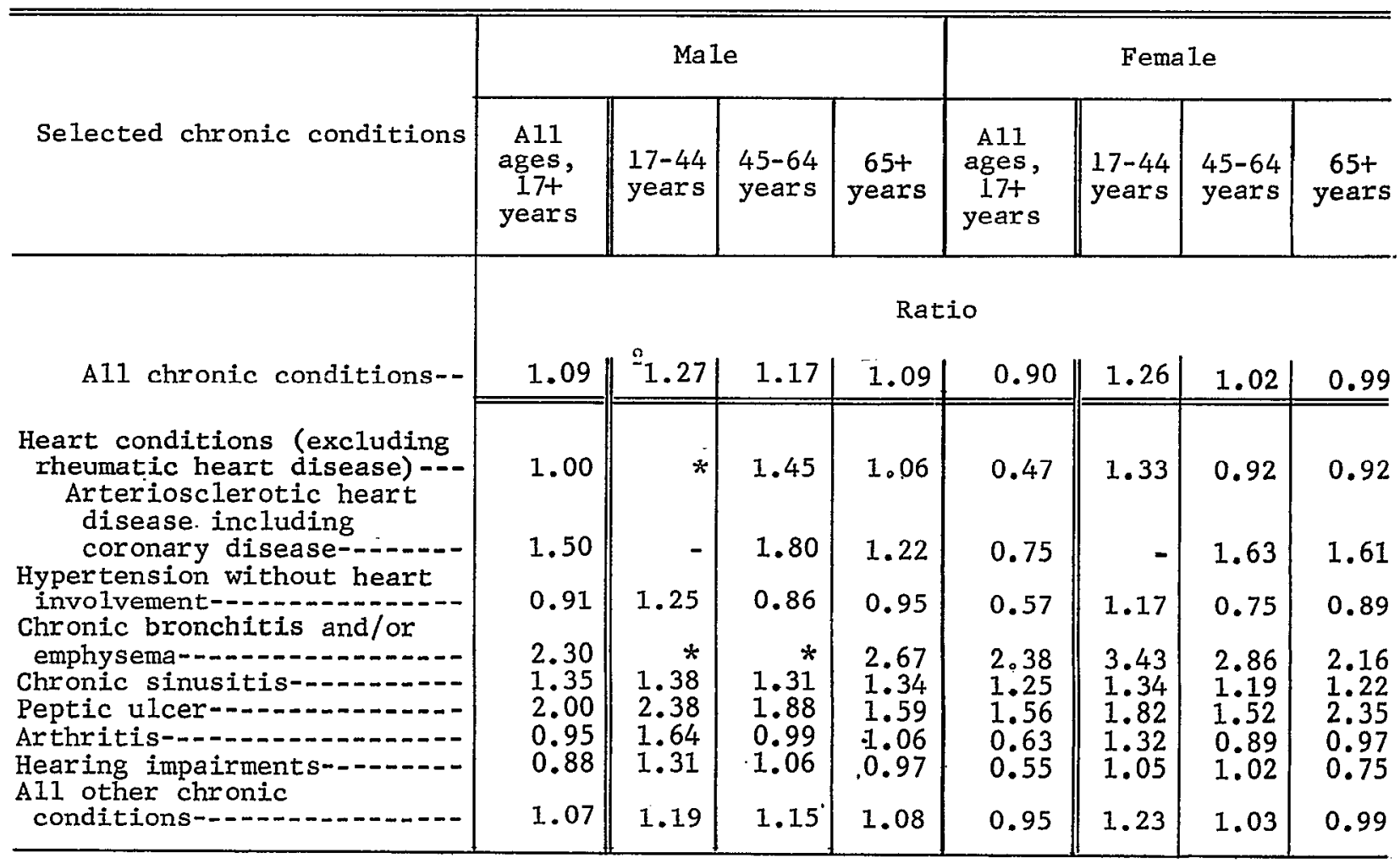

${ }^{1}$ Prevalence rate of "ever smokers" divided by prevalence rate of "never smokers."

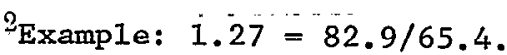


Table D. Ratios of age-adjusted ${ }^{1}$ prevalence rates of chronic conditions for persons 17 years and over who have ever smoked to persons who have never smoked, by cigarette smoking status, number of cigarettes smoked per day for present smokers-heaviest amount, sex, and selected chronic conditions: United States, July 1964-June 1965

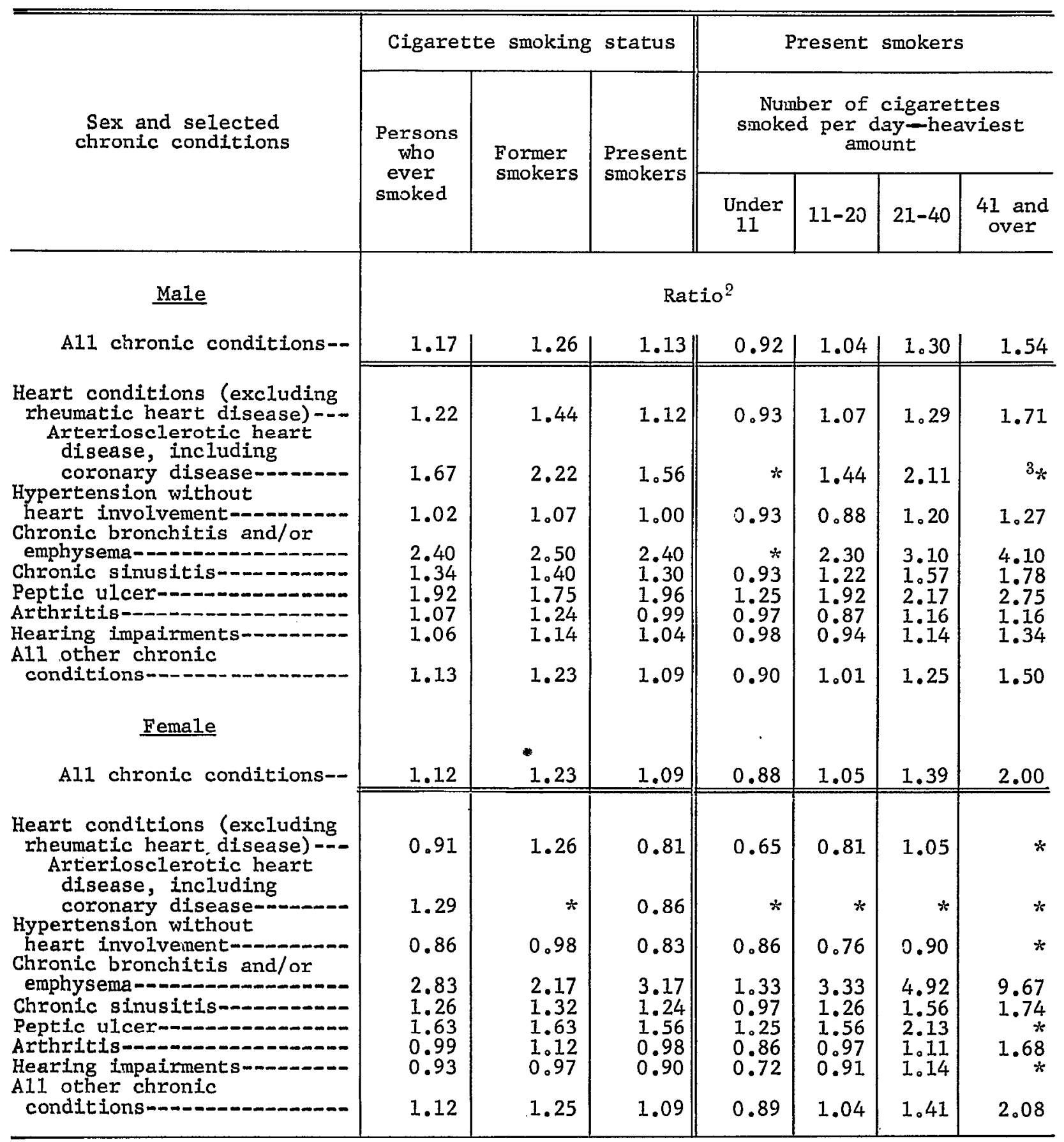

${ }^{1}$ Adjusted by the indirect method to the age distribution of the total civilian, nonInstitutional population of the United States.

"Prevalence rate for given smoking category divided by prevalence rate for "never

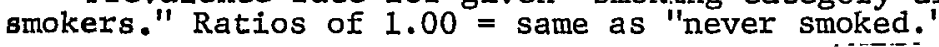

${ }^{3}$ Even though the asterisks in this column replace figures with large sampling errors, each of the six of the replaced ratios were larger than the ratios for the lower smoking amounts. 
than the present smokers and the prevalence rates of the present smokers increasing as their heaviest smoking rate increases (table 7). Unadjusted and age-adjusted prevalence rates for. selected chronic conditions for the several smoking categories are shown in tables 8-15. Ratios using the rate for "never smokers" as the base are shown in table $D$.

\section{Heart Conditions}

The prevalence rate of heart conditions (excluding rheumatic heart disease) among male former smokers was about 44 percent higher than among those who had never smoked. Although the present smokers who smoked up to a pack a day had a rate about the same as that for the "never smokers," men whose heaviest rate was over two packs a day reported prevalence rates for heart conditions about 70 percent higher than "never smokers" (see tables D and 8). The ratios are even higher for arteriosclerotic heart diseases, including coronary disease, being 2.22 (equivalent to $\mathbf{1 2 2}$ percent higher) for the former smokers and 2.11 for male present smokers who smoked 21-40 cigarettes a day. Thus, the positive relationship between cigarette smoking and heart disease seems to be strong among the males. Female former smokers reported about 25 percent higher rates of heart disease than those who never smoked, while the present smokers who smoked no more than a pack a day reported 1935 . percent lower rates than the "never smokers." It should be remembered that as long as the comparisons between males and females are made in terms of ratios, the original sex differences in prevalence rates can be ignored.

\section{Hypertension}

With the exception of males who smoked over a pack a day, the rates of hypertension without heart involvement were about the same for present cigarette smokers as for persons who had never smoked (tables D and 9). However, males 17-44 years who smoked $21-40$ cigarettes a day at their heaviest had an estimated rate of hypertension 75 percent higher than males of the same age who had never smoked; while males over 45 years had about the same prevalence rates of hypertension as the "never smokers" within the same age group.

\section{Bronchitis and/or Emphysema}

The strongest relationship is found between smoking habits and the presence of chronic bronchitis and/or emphysema. The estimated prevalence rate for male former smokers was 2.5 times greater than the rate for males who had never smoked, with the rate for present smokers 2.4 times higher (fig. 5 and tables $D$ and 10). Former smokers among women reported a rate over twice (ratio $=2.17$ ) as high as that for females who had never smoked, while the present female smokers had over three times (ratio = 3.17 ) as many reported cases of bronchitis and/or emphysema as "never smokers." This is one of the few instances where female former smokers had a lower morbidity rate than present smokers. Except for the former smokers, it will be noted that the ratios for females are higher than those for males. Males who smoked a pack a day when they were smoking the heaviest had a prevalence rate 2.30 times higher than that of the "never smokers," while the comparable ratio for females is 3.33. Corresponding ratios for those who smoked 21-40 cigarettes a day and over two packs a day at their heaviest are 3.10 and 4.10 respectively for males and 4.92 and 9.67 for females. It should be remembered, however, that bronchitis as reported in the household interview is not necessarily the same as a physician's diagnosis of bronchitis. It is quite possible that some of the self-diagnosed cases may in fact be "smokers' cough." If some of the reported bronchitis was indeed "smokers' cough," this might explain why female former smokers reported lower prevalence rates, since one would expect "smokers' cough" to decrease among former smokers.

\section{Sinusitis.}

Smokers among both sexes reported a higher prevalence rate of chronic sinusitis than did "never smokers," with the ratios about the same 


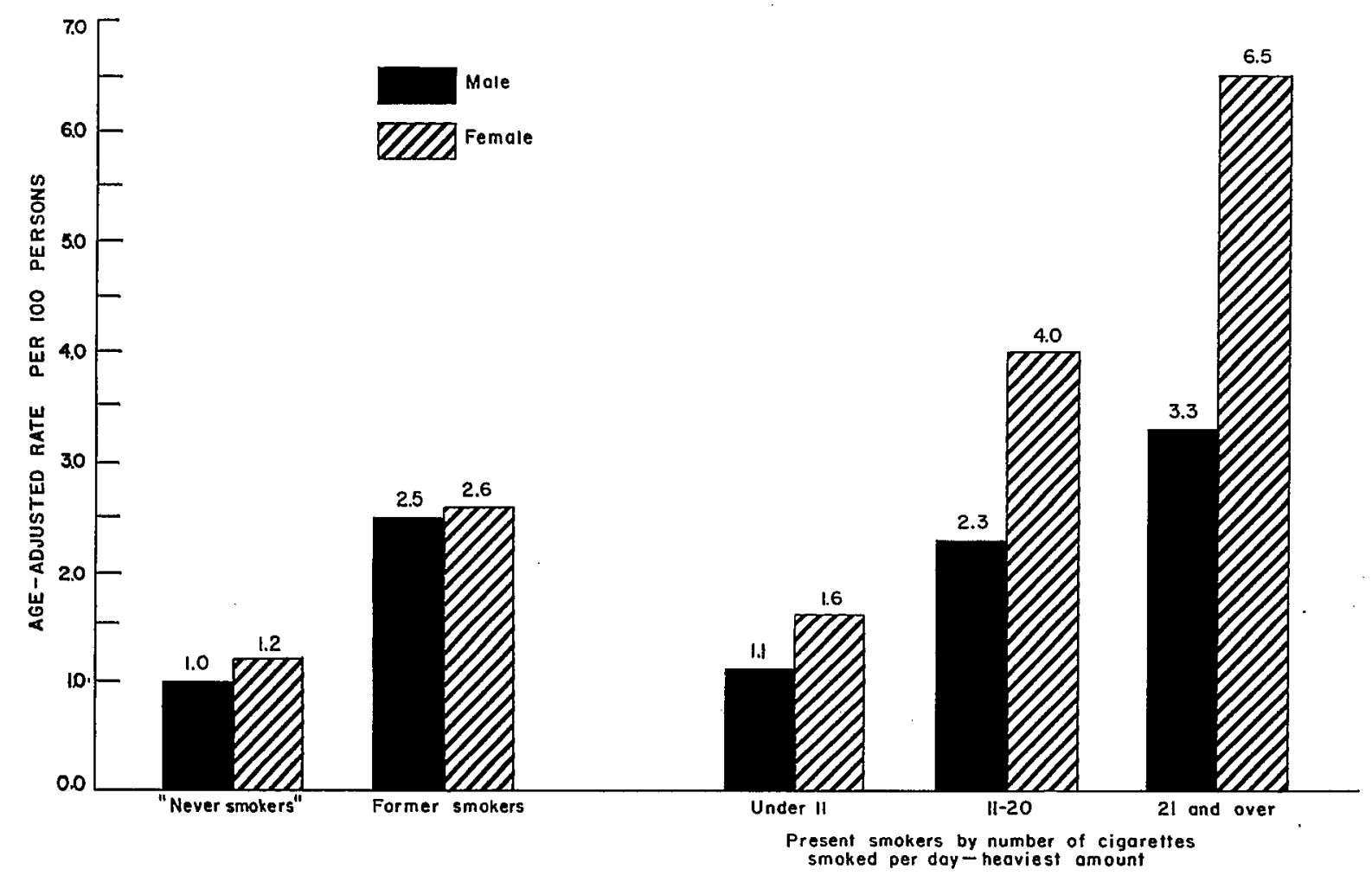

Figure 5. Age-adjusted rates of chronic bronchitis and/or emphysema per 100 persons 17 years and over, by sex, smoking status, and number of cigarettes smoked per day-heaviest amount.

for men and women. Smokers whose heaviest smoking was a half pack or less a day reported sinusitis at about the same rate as "never smokers," but as cigarette consumption increased to over two packs a day, the reported sinusitis increased to about 75 percent above those who had never smoked (tables $D$ and 11). While the age differences in prevalence of sinusitis among smokers is not as great as with most conditions, at the lower smoking levels (up to a pack a day), the relationship is strongest for persons 65 and over while at the higher smoking levels, it is strongest for the 17-44 age group.

\section{Peptic Ulcer}

The estimated prevalence rate of peptic ulcer was almost twice as high among male present smokers as among "never smokers" and over 50 percent higher for female smokers. The prevalence rate of both sexes increased as the heaviest smoking rate increased. However, among the males this was the only chronic condition studied for which former smokers had lower rates than present smokers (tables D and 12).

\section{Arthritis}

On the average, present cigarette smokers did not report higher rates of arthritis than those who had never smoked; however, male former smokers had a prevalence rate 24 percent higher than those who had never smoked (tables D and 13). Although the overall rates showed little if any relationship between smoking and arthritis, the age-specific rates indicated that while the prevalence of arthritis among smokers over 45 years of age was about the same as for persons who had never 
smoked, the rate for smokers 17-44 was considerably higher (64 percent for males and 29 percent for females) than for the "never smokers" (tables 5 and 6). This pattern of higher rates for the younger group was also found among the different smoking levels. For example, the prevalence of arthritis for male present smokers ages 17-44 who smoked over a pack a day at their heaviest was 2.4 times higher than for the "never smokers" in the same age group, while males over 45 years who smoked over a pack a day had prevalence rates similar to the "never smokers." A similar pattern prevailed for the females, but at a somewhat lower magnitude.

\section{Hearing Impairments}

Male present smokers, in general, reported the same rate of hearing impairments as did those who had never smoked (tables D and 14). However, men who had smoked over two packs a day had an estimated rate of hearing impairments 34 percent higher than the "never smokers" and, again, the biggest differences are among the 17-44 age groups. As the amount smoked among female smokers increased, the prevalence of hearing impairments also increased, although the increase began from a prevalence level considerably lower (28 percent) than that of women who had never smoked.

\section{Summary}

In summary, the data show that the age-adjusted prevalence rates of five of the eight specific chronic conditions listed on table D (all heart conditions, arteriosclerotic heart disease, bronchitis and/or emphysema, sinusitis, and peptic ulcer) were higher among males who had ever smoked cigarettes than among males who had never smoked. Among females, the prevalence rates among those who had ever smoked were higher than for the "never smokers" for only the last four of the above listed condition categories. Prevalence rates increased for almost all chronic conditions as the heaviest smoking rate increased among those smoking at the present time. Although obscured by the age-adjusted rates, for most conditions the largest differences between smokers and "never smokers" were in the 17-44 age groups. Very light smokers (less than 11 cigarettes a day) reported similar or slightly lower prevalence rates than did persons who had never smoked. For most conditions, former smokers showed higher prevalence rates than present smokers, although present smokers whose heaviest smoking rate was over a pack a day reported higher prevalence rates than all former smokers taken as a whole. The detailed tables also show that as the heaviest smoking rate of former smokers increased, there was also an increase in prevalence rates. Of the chronic conditions investigated, the strongest relationship with smoking habits among both males and females is found with bronchitis and/or emphysema.

\section{SMOKING AND ACUTE CONDITIONS}

Age-specific incidence rates for acute conditions are shown by smoking category in table 16; matching age-adjusted rates and ratios are presented in table 17. The age-adjusted incidence rate of acute conditions for persons who had ever smoked was 14 percent higher among men and 21 percent higher among women than the rates for "never smokers" (table E). Males who had never smoked reported 130.8 acute conditions per 100 men per year, while those who had smoked at one time or another reported 149.2 conditions; the corresponding figures for females were 167.1 and 203.0 (table 17). The number of reported conditions also tended to increase as the daily consumption of cigarettes increased. For example, among the males who had ever smoked, the number of conditions per 100 persons per year ranged from 129.5 for those whose heaviest rate was a half a pack or less up to 162.5 for those who smoked over two packs a day (table 17). This same pattern is characteristic of female smokers. As with chronic conditions, former smokers reported the highest rate of acut $\epsilon$ conditions, suggesting that they might have quit smoking because of their poorer health, regardless of whether or not their smoking directly affected their health.

Particular caution must be taken in interpreting the following results relating specific acute conditions to cigarette smoking because of the relatively large sampling error connected with the estimates for the several types of acute conditions. Although many of the ratios in table $E$ would seem to indicate a substantial difference 
Table E. Ratios of age-adjusted ${ }^{1}$ incidence of acute conditions for persons 17 years and over who have ever smoked to persons who have never smoked, by cigarette smoking status, number of cigarettes smoked per day for present smokers-present amount, sex, and selected acute conditions: United States, July 1964-June 1965

\begin{tabular}{|c|c|c|c|c|c|c|c|}
\hline \multirow{3}{*}{$\begin{array}{l}\text { Sex and selected } \\
\text { acute conditions }\end{array}$} & \multicolumn{3}{|c|}{ Cigarette smoking status } & \multicolumn{4}{|c|}{ Present smokers } \\
\hline & \multirow{2}{*}{$\begin{array}{l}\text { Persons } \\
\text { who } \\
\text { ever } \\
\text { smoked }\end{array}$} & \multirow{2}{*}{$\begin{array}{l}\text { Former } \\
\text { smokers }\end{array}$} & \multirow{2}{*}{$\begin{array}{l}\text { Present } \\
\text { smokers }\end{array}$} & \multicolumn{4}{|c|}{$\begin{array}{c}\text { Number of cigarettes } \\
\text { smoked per day-present } \\
\text { amount }\end{array}$} \\
\hline & & & & $\begin{array}{l}\text { Under } \\
11\end{array}$ & $11-20$ & $21-40$ & $\begin{array}{l}41 \text { and } \\
\text { over }\end{array}$ \\
\hline Male & \multicolumn{7}{|c|}{ Ratio ${ }^{2}$} \\
\hline A11 acute conditions---- & 1.14 & 1.23 & 1.11 & 1.02 & 1.11 & 1.23 & 1.21 \\
\hline Infective and parasitic & 1.21 & 1.36 & 1.16 & $*$ & 1.24 & 1.59 & * \\
\hline $\begin{array}{l}\text { Upper respiratory } \\
\text { conditions } \\
\text { Influenza- }\end{array}$ & $\begin{array}{l}1.03 \\
1.25\end{array}$ & $\begin{array}{l}1.22 \\
1.36\end{array}$ & $\begin{array}{l}0.96 \\
1.22\end{array}$ & $\begin{array}{l}0.98 \\
1.22\end{array}$ & $\begin{array}{l}0.98 \\
1.19\end{array}$ & $\begin{array}{l}0.92 \\
1.28\end{array}$ & $*$ \\
\hline $\begin{array}{l}\text { Other respiratory } \\
\text { conditions } \\
\text { Digestive system conditions- } \\
\text { Injuries- } \\
\text { Al1 other acute conditions-- }\end{array}$ & $\begin{array}{l}1.62 \\
1.05 \\
1.25 \\
1.06\end{array}$ & $\begin{array}{l}1.13 \\
1.03 \\
1.35\end{array}$ & $\begin{array}{l}1.54 \\
1.03 \\
1.32 \\
0.95\end{array}$ & $\begin{array}{r}* \\
* \\
1.00 \\
1.08\end{array}$ & $\begin{array}{l}* \\
0.90 \\
1.35 \\
0.85\end{array}$ & $\begin{array}{l}* \\
1.41 \\
1.56 \\
1.11\end{array}$ & $\begin{array}{l}* \\
* \\
* \\
*\end{array}$ \\
\hline Female & & & & & & & \\
\hline A11 acute conditions---- & 1.21 & 1.26 & 1.21 & 1.18 & 1.20 & 1.31 & * \\
\hline $\begin{array}{l}\text { Infective and parasitic } \\
\text { diseases- } \\
\text { Upper respiratory }\end{array}$ & 1.35 & 1.62 & 1.29 & 1.26 & 1.04 & 2.29 & - \\
\hline $\begin{array}{l}\text { Upper respiratory } \\
\text { conditions- }\end{array}$ & 1.26 & 1.20 & 1.27 & & 1.28 & 1.26 & $*$ \\
\hline $\begin{array}{l}\text { Influenza- } \\
\text { Other respiratory }\end{array}$ & 1.13 & 1.28 & 1.09 & 1.23 & 1.03 & 0.99 & $*$ \\
\hline $\begin{array}{l}\text { conditions } \\
\text { conditiony }\end{array}$ & 1.68 & * & 1.74 & & & $\star$ & * \\
\hline $\begin{array}{l}\text { Digestive system conditions- } \\
\text { Injuries } \\
\text { Al1 other acute conditions-- }\end{array}$ & $\begin{array}{l}1.07 \\
1.14 \\
1.22\end{array}$ & $\begin{array}{r}* \\
1.04 \\
1.31\end{array}$ & $\begin{array}{l}1.04 \\
1.17 \\
1.19\end{array}$ & $\begin{array}{l}0.78 \\
0.89 \\
1.29\end{array}$ & $\begin{array}{l}1.05 \\
1.40 \\
1.15\end{array}$ & 1.13 & $\begin{array}{l}* \\
* \\
*\end{array}$ \\
\hline
\end{tabular}

${ }^{1}$ Adjusted by the indirect method to the age distribution of the total civilian, noninstitutional population of the United States.

"Incidence rate for given smoking category divided by incidence rate for "never smokers."

between persons in the different smoking categories and the "never smokers," the actual number of reported cases involved were quite small and, in most cases, significant differences were not demonstrable. However, for most of the conditions shown, there is a general pattern of increasing ratios as cigarette consumption in- creased. If the observed differences are simplya reflection of sampling error, there should be more chance fluctuation in the ratios, i.e., above and below the value 1.00 . Thus it is probable that future studies will find the same patterns, although the rates may not be of the same magnitude. 


\section{Upper Respiratory Conditions}

In tables 18 and 19, the incidence rates for specific types of acute conditions are shown for the smoking categories. It is interesting to note the sex differential in the relationship between acute upper respiratory conditions and smoking. Present male smokers reported about the same rate of acute upper respiratory conditions as did males who had never smoked, while female present smokers reported 27 percent more upper respiratory conditions than females who had never smoked (table E). There is no apparent relationship for either sex between the number of cigarettes smoked and acute upper respiratory conditions. However, there is a marked relationship with the heaviest smoking rate among the male former smokers, with those who smoked over two packs a day as their heaviest amount reporting more than twice as many upper respiratory conditions as those who smoked less than a half a pack or none.

\section{Other Respiratory Conditions}

Other respiratory conditions, which includes acute bronchitis, shows the strongest relationship with smoking among both males and females. Present male smokers reported 54 percent more cases than males who had never smoked while he present female smokers reported 74 percent more than did females who had never smoked (table E). As with upper respiratory conditions, the ratio is considerably higher for females. However, there were not enough cases to allow examination of the occurrence of conditions of this type by the number of cigarettes smoked.

\section{Infective and Parasitic Diseases}

Smokers reported more cases of infective and parasitic diseases than did persons who had never smoked, with the relationship more apparent among the females. Current male smokers reported 11.4 cases per 100 or 16 percent more than those who had never smoked, while the females reported 18.4 cases per 100 which is 29 percent more than reported by females who had never smoked (tables E and 19).

\section{Influenza}

The relationship between cigarette smoking and influenza is somewhat stronger for males than for females. Current male smokers reported 22 percent more cases than did males who had never smoked, while the female smokers reported an excess of only 9 percent above the females who had never smoked.

\section{Injuries}

The ratios shown in table $E$ indicate that there is a relationship between smoking and injuries, with some differences between the sexes. Present male smokers have 32 percent more injuries than males who have never smoked; while present female smokers have 17 percent more injuries than those who had never smoked. The rate of all injuries among former smokers was almost the same as for persons who had never smoked (tables $E$ and 19). Again, it should be stressed that although a number of the ratios presented above for specific acute conditions are quite large, many of the differences are not significant since the actual number of cases involved is small.

\section{DISABILITY DAYS}

Persons who had ever smoked cigarettes experienced more days of disability than did those who had never smoked (tables $F$ and 23 ). In addition, heavy cigarette smokers had more disability days than light smokers. Among persons who smoked over two packs a day, the association is considerably more apparent among females. The usual increase in the rate of disability days with advancing age is apparent from tables 20-23, which show the age-specific rates by type of disability in the various smoking categories.

\section{Restricted-Activity Days}

Restricted-activity days occurred more frequently among persons who had ever smoked than among those who had never smoked cigarettes. Current male smokers (age-adjusted), reported 27 percent more restricted-activity days 
Table F. Ratios of age-adjusted ${ }^{1}$ number of days of disability per person 17 years and over per year who have ever smoked to persons who have never smoked, by number of cigarettes smoked per day for present smokers-heaviest amount, type of days of disability, smoking status, and sex: United States, July 1964-June 1965

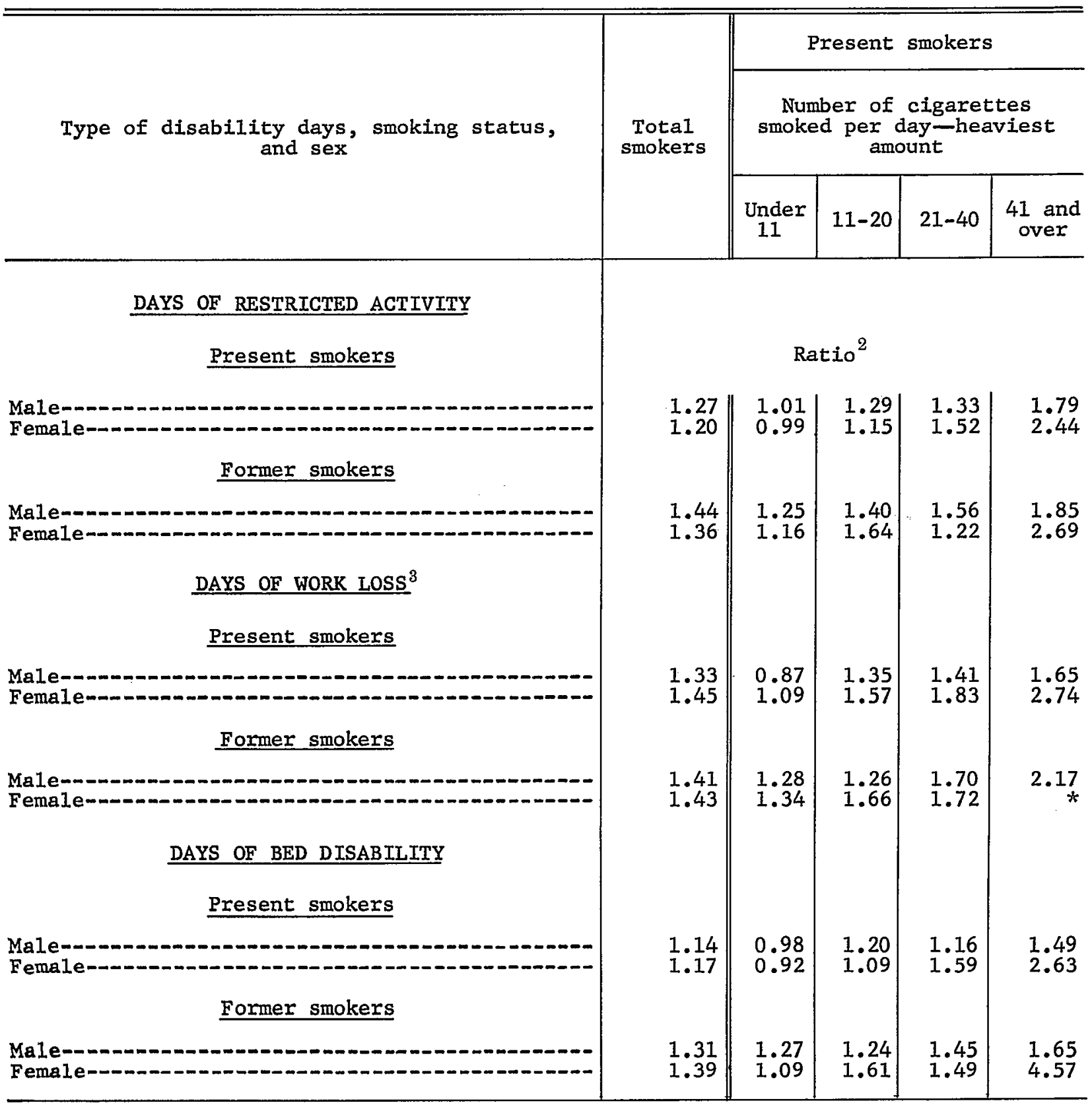

${ }^{1}$ Adjusted by the indirect method to the age distribution of the total civilian, noninstitutional population of the United States.

2Days of disability of given smoking category divided by days of disability of "never smokers."

${ }^{3}$ Days of work loss reported for currently employed persons only. 


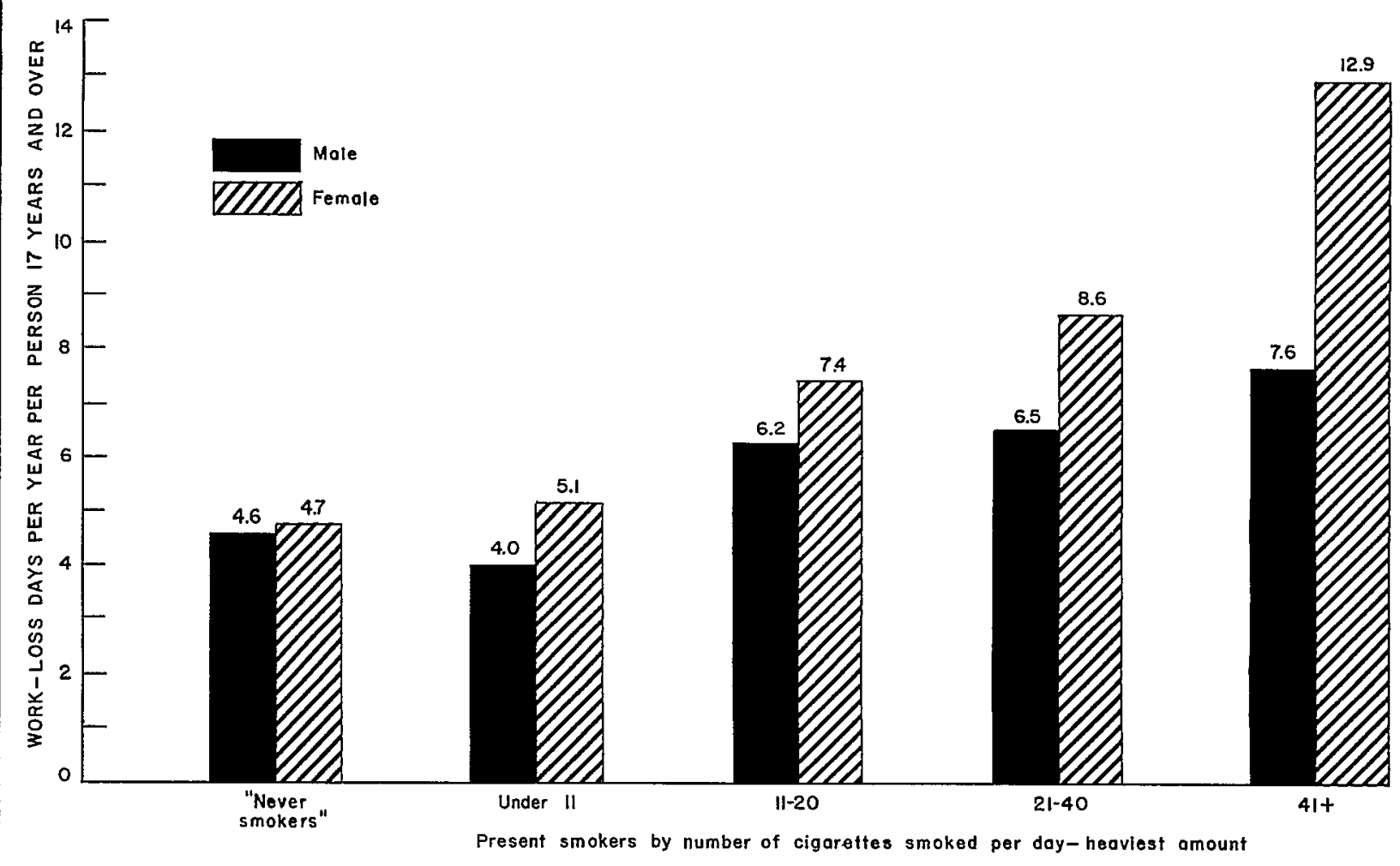

Figure 6. Number of age-adjusted work-loss days of currently employed "never smokers" and present smokers by sex and number of cigarettes smoked per day-heaviest amount.

and the female smokers had 20 percent more restricted days than did their counterparts who had never smoked. Present male smokers who smoked 41 cigarettes or more daily when they were smoking the heaviest reported 79 percent more restricted days while the women in this same group had about 2.5 times as many or 150 percent more restricted-activity days than the "never smokers." In most categories, former smokers reported higher rates of disability days than did present smokers.

\section{Bed-Days}

The relationship between bed-days and cigarette smoking followed much the same pattern as restricted-activity days. The ratio of the average number of bed-days per person among present smokers to that for "never smokers" is about
1.15 for both sexes or 15 percent more bed-days for present smokers. However, when the rat $\epsilon$ of bed-days for present smokers who at some period smoked more than two packs a day is compared with that for persons who had never smoked, the rate for males is 1.5 times higher among smokers, while the rate for female smokers is about 2.5 times that for nonsmokers.

\section{Work-Loss Day}

Cigarette smokers who were currently employed reported more work-loss days than employed persons who had never smoked. In addition, the number of work-loss days increasec consistently among present smokers in accordance with the number of cigarettes they hac smoked daily when smoking the heaviest. AE indicated in figure 6 , this pattern is characteris- 
tic of both men and women but is considerably more marked among women. Men in the heaviest smoking category (41 cigarettes and over per day) reported 3.6 more work-loss days per person per year than those in the lowest category (under 11 cigarettes), while females who smoked the heaviest reported 7.8 more work-loss days per year. Table $F$ shows the same relationship in the form of ratios, a measure which removes the effect of any sex difference in the number of work-loss days. The relationship between cigarette smoking and work loss, as with bed-days and restricted-activity days, is more apparent for females, with women in the "more than two packs a day" category having about 2.75 times more work-loss days than females who had never smoked. Among males, those who smoked 41 cigarettes or more per day have 1.65 times as many work-loss days as those who had never smoked.

It was stated earlier in the discussion of chronic conditions that much of the age-adjusted associations between conditions and smoking habits can be attributed to the 17-44 age group and that the association is less apparent in the 45-64 and 65 years and over age groups. However, the association between work loss and smoking among males stays at about the same level for both the 17-44 and 45-64 year categories.

Table G. Age-adjusted ${ }^{1}$ percent of males 17 years and over with one or more chronic conditions, incidence of all acute conditions per 100 persons per year, and number of days of restricted activity per person per year, by number of cigarettes smoked per day-heaviest amount, smoking status, and time interval since last smoked: United States, July 1964-June 1965

\begin{tabular}{|c|c|c|c|c|c|}
\hline \multirow{2}{*}{$\begin{array}{c}\text { Smoking status and interval } \\
\text { since last smoked }\end{array}$} & \multirow{2}{*}{$\begin{array}{l}\text { Total } \\
\text { smokers }\end{array}$} & \multicolumn{4}{|c|}{$\begin{array}{c}\text { Number of cigarettes smoked } \\
\text { per day - heaviest amount }\end{array}$} \\
\hline & & $\begin{array}{l}\text { Under } \\
11\end{array}$ & $11-20$ & $21-40$ & $\begin{array}{l}41 \text { and } \\
\text { over }\end{array}$ \\
\hline
\end{tabular}

A11 former smokers-_Quit within 1 year-n... Quit 5 years or more-nPresent smokers-m... "Never smokers"

A11 former smokers-Quit within 1 year-a-n Quit 5 years or morePresent smokers-_"Never smokers"-nam

\section{A11 former smokers-0-} Quit within 1 year-m-noQuit 5 years or more-n Present smokers-_"Never smokers"
Percent with 1+ chronic conditions

\begin{tabular}{r|r|r|r|r}
62.5 & 61.0 & 61.1 & 65.9 & 67.5 \\
63.6 & 61.4 & 63.8 & 65.5 & 65.5 \\
62.8 & 62.9 & 61.2 & 64.3 & 68.3 \\
58.0 & 49.5 & 55.1 & 64.8 & 72.1 \\
53.5 & $\ldots . .1$ & $\ldots .$. & $\ldots$ & $\ldots$
\end{tabular}

A11 acute conditions per 100 persons per year

\begin{tabular}{r||r|r|r|r}
161.5 & 152.6 & 146.2 & 180.6 & 195.4 \\
171.7 & 213.1 & 146.3 & 145.5 & $*$ \\
159.3 & 143.6 & 158.7 & 159.6 & $*$ \\
144.8 & 115.4 & 144.7 & 161.4 & 150.1 \\
130.8 & $\ldots .$. & $\ldots .$. & $\ldots .$. & $\ldots$
\end{tabular}

Restricted-activity days per person per year

\begin{tabular}{r||r|r|r|r}
19.9 & 17.3 & 19.3 & 21.5 & 25.5 \\
31.5 & 30.0 & 25.4 & 36.8 & 47.3 \\
18.7 & 14.3 & 18.3 & 18.8 & 26.1 \\
17.5 & 13.9 & 17.8 & 18.4 & 24.7 \\
13.8 & $\ldots$ & $\ldots$ & $\ldots$ & $\ldots$. \\
\hline
\end{tabular}

${ }^{1}$ Adjusted by the indirect method to the age distribution of the total civilian, noninstitutional population of the United States. 


\section{INTERVAL SINCE LAST SMOKED AND MORBIDITY AND DISABILITY DAYS AMONG MALE FORMER SMOKERS}

Earlier studies have shown that, in addition to former smokers having lower mortality rates than present smokers, former smokers have an increased life expectancy as the interval since last smoked increases. ${ }^{8}$ Although the relatively small number of female former smokers did not permit a complete analysis along these lines, table $G$ does present some comparisons of male former smokers. Comparisons can be made between males who quit within the past year and those who quit at least 5 years ago by percent with one or more chronic conditions, incidence of acute conditions, per 100 persons per year, and number of restricted-activity days per person per year.

Male former smokers reported the highest percentage with one or more chronic conditions, 62.5 percent, as compared with 58.0 percent for present smokers and 53.5 percent for "never smokers." However, as indicated in table G there appears to be no consistent pattern in the relationship between interval since last smoked and percent of persons with one or more chronic conditions. In fact, there are only relatively small differences between those who quit within the past year and those who quit at least 5 years before.

The second part of the table dealing with acute conditions also indicates no consistent pattern with amount smoked or length of time since last smoked, except that most former smokers, regardless of when they quit, have more acute conditions than do present smokers.

Overall, male former smokers reported 44 percent more restricted-activity days per person per year than did "never smokers," while present smokers reported 27 percent more than "never smokers." Data in table G show that those per- sons who quit smoking less than 1 year prior tc the interview had up to twice as many restrictedactivity days per person per year as those who quit at least 5 years before. The high number $o$ restricted-activity days for those who quit withir the past year might reflect restricted activity among persons who quit only temporarily for : specific health reason related to their restricted activity. (If the respondent stated specifically that he had stopped only temporarily, the inter.viewer was instructed to consider such a person as a present smoker.) However, persons whis quit smoking more than 5 years prior to this interview had about the same number of re. stricted-activity days per year as did the present smokers, at all levels of smoking.

\section{REFERENCES}

\footnotetext{
${ }^{1}$ Public Health Service: Smoking and Health, Report of th 3 Advisory Committee to the Surgeon General of the Publi : Health Service. PHS Pub. No. 1103. Washington. U.S. Goverr ment Printing Office, 1964.

${ }^{2}$ Haenszel, W., Shimkin, M. B., and Miller, H. P.: Tobaces smoking patterns in the United States. Public Health Monegraph. No. 45. PHS Pub. No. 463. Public Health Service. Washington. U.S. Government Printing Office, 1965. p. 9.

${ }^{3}$ Griswold, M. H., et al.: Cancer in Connecticut, 19,35-51. Connecticut State Department of Health. Hartford, Conn., 195 ! table 10.

${ }^{4}$ Public Health Service: op. cit., pp. 92-93.

${ }^{5}$ Best, F. W. R., Josie, G. H., and Walker, C. B.: A Can dian study of mortality in relation to smoking habits, a priliminary report. Canad.J.Pub.Health 52(3):99-106, 1961.p. 10 i.

${ }^{6}$ Hammond, E. C., and Horn, D.: Smoking and death rates report on forty-four months of follow-up of 187,783 men, Pt. I. Total mortality. J.A.M.A. 166(10):1159-1172, Mar. 1958. 1 . 1163.

${ }^{7}$ Hammond, E. C., and Garfinkel, L.: The influence $\mathrm{cf}$ health on smoking habits, in Haenszel, W., ed. Epideminlogical Approaches to the Study of Cancer and Other Chron c Diseases. National Cancer Institute Monograph. No. 19, 1963. pp. 269-285.

${ }^{8}$ Hammond and Horn: op. cit., p. 1163.
} 


\section{DETAILED TABLES}

Table 1. Distribution of the population 17 years and over, by smoking status, number of cigarettes smoked per day, sex, and age: United States, July 1964-June 1965 - ...m

Page

2. Percent distribution of smokers 17 years and over, by number of cigarettes smoked per day according to sex, smoking status, and age: United States, July 1964-June 1965 - J

3. Percent of persons 17 years and over with one or more chronic conditions, by smoking status, number of cigarettes smoked pex day, sex, and age: United States, July 1964-June 1965

4. Age-adjusted percent of persons 17 years and over with one or more chronic conditions and ratios of smokers to "never smokers," by smoking status, number of cigarettes smoked per day, and sex: United States, July 1964-June 1965-.....-

5. Age-speciflc prevalence rates of chronic conditions per 100 males, by cigarette smoking status, selected chronic conditions, and age: United States, July 1964June $1965-196$

6. Age-specific prevalence rates of chronic conditions per 100 females, by cigarette smoking status, selected chronic conditions, and age: United States, July 1964June 1965

7. Unadjusted and agemadjusted prevalence rates for a11 chronic conditions per 100 persons 17 years and over, by smoking status, number of cigarettes smoked per day, and sex: United States, July 1964-June 1965

8. Unadjusted and age-adjusted prevalence rates of heart conditions (excluding chronic rheumatic heart disease) per 100 persons 17 years and over, by smoking status, number of cigarettes smoked per day, and sex: United States, July 1964June 1965

9. Unadjusted and age-adjusted prevalence rates of hypertension without heart involvement per 100 persons 17 years and over, by smoking status, number of clgarettes smoked per day, and sex: United States, July 1964-June 1965 -

10. Unadjusted and age-adjusted prevalence rates of chronic bronchitis and/or emphysema per 100 persons 17 years and over, by smoking status, number of cigarettes smoked per day, and sex: United States, July 1964-June 1965-.......

11. Unadjusted and age-adjusted prevalence rates of chronic sinusitis per 100 persons 17 years and over, by smoking status, number of cigarettes smoked per day, and sex: United States, July 1964m June 1965

12. Unadjusted and age-adjusted prevalence rates of peptic ulcer per 100 persons 17 years and over, by smoking status, number of cigarettes smoked per day, and sex: United States, July 1964-June 1965-

13. Unadjusted and age-adjusted prevalence rates of arthritis per 100 persons 17 years and over, by smoking status, number of cigarettes smoked per day, and sex: United States, July 1964-June 1965-mon

14. Unadjusted and age-adjusted prevalence rates of hearing impairments per 100 persons 17 years and over, by smoking status, number of cigarettes smoked per day, and sex: United States, Iuly 1964-June 1965-

15. Unadjusted and age-adjusted prevalence rates of all other chronic conditions per 100 persons 17 years and over, by smoking status, number of cigarettes

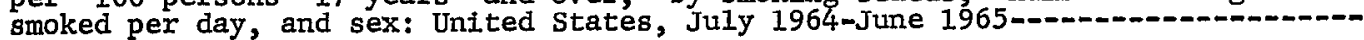


Table 16. Incidence of acute conditions per 100 persons 17 years and over per year, by smoking status, number of cigarettes smoked per day, sex, and age: United States, July 1964-June 1965-- J

17. Age-adjusted incidence of acute conditions per 100 persons 17 years and over per year and ratios of smokers to "never smokers," by smoking status, number of cigarettes smoked per day, and sex: United States, Ju1y 1964-June 1965 ..........

18. Unadjusted incidence of acute conditions per 100 persons 17 years and over pex year, by cigarette smoking status, selected acute conditions, and sex: United States, July 1964-June 1965-

19. Age-adjusted incidence of acute conditions per 100 persons 17 years and over per year, by cigarette smoking status, selected acute conditions, and sex: United States, July 1964-June 1965 - J

20. Number of restricted-activity days per person 17 years and over per year, by smoking status, number of cigarettes smoked per day, sex, and age: United States, July 1964-June 1965-

21. Number of bed-days per person 17 years and over per year, by smoking status, number of cigarettes smoked per day, sex, and age: United States, July 1964June 1965-

22. Number of work-1oss days per currently employed person 17 years and over per year, by smoking status, number of cigarettes smoked per day, sex, and age: United States, July 1964-June 1965-

23. Age-adjusted number of disability days per person 17 years and over per year, by smoking status, number of cigarettes smoked per day, type of disability day, and sex: United States, July 1964-June 1965- 
Table 1. Distribution of the population 17 years and over, by smoking status, number of cigarettes smoked per day. sex, and age: United States, July 1964-June 1965

[Data are based on household interviews of the civilian, noninstitutional population. The survey design, general qualifications, and information on the reliability of the estimates are given in Appendix I. Definitions of terms are given in Appendix II]

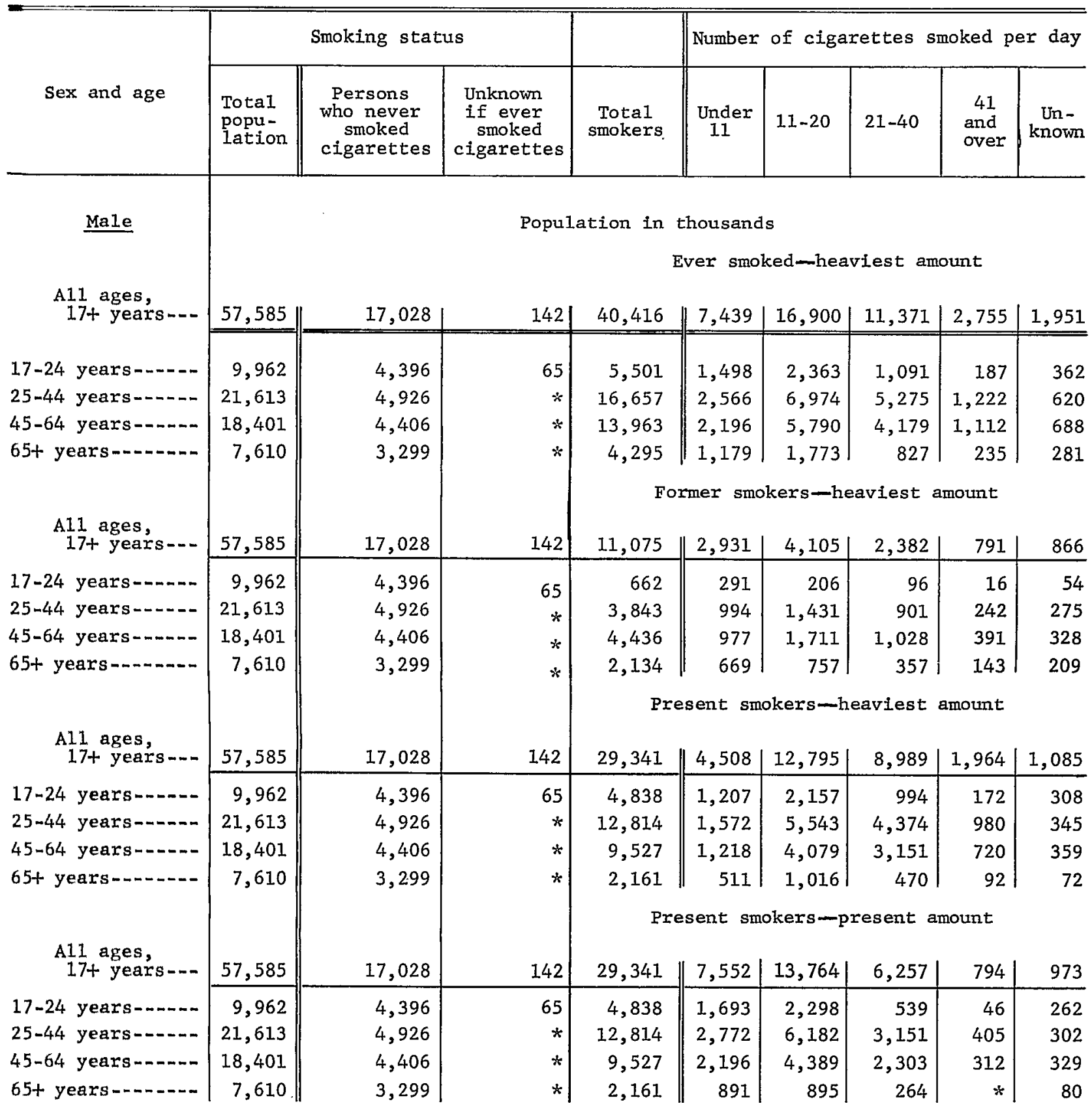


Table 1. Distribution of the population 17 years and over, by smoking status, number of cigarettes smoked per day, sex, and age: United States, July 1964-June 1965-Con.

[Data are based on household interviews of the civilian, noninstitutional population. The survey desigm, general cualifications, and information on the reliability of the estimates are given in Appendix I. Definitions of terms are given in Appendix II]

\begin{tabular}{|c|c|c|c|c|c|c|c|c|c|}
\hline \multirow[b]{2}{*}{ Sex and age } & \multicolumn{3}{|c|}{ Smoking status } & & \multicolumn{5}{|c|}{ Number of cigarettes smoked per day } \\
\hline & $\begin{array}{l}\text { Total } \\
\text { popu- } \\
\text { lation }\end{array}$ & $\begin{array}{l}\text { Persons } \\
\text { who never } \\
\text { smoked } \\
\text { cigarettes }\end{array}$ & $\begin{array}{l}\text { Unknown } \\
\text { if ever } \\
\text { smoked } \\
\text { cigarettes }\end{array}$ & $\begin{array}{l}\text { Total } \\
\text { smokers }\end{array}$ & $\underset{11}{\text { Under }}$ & $11-20$ & $21-40$ & $\begin{array}{l}41 \\
\text { and } \\
\text { over }\end{array}$ & $\begin{array}{l}\text { Un- } \\
\text { known }\end{array}$ \\
\hline \multirow[t]{2}{*}{ Female } & \multicolumn{9}{|c|}{ Population in thousands } \\
\hline & \multicolumn{9}{|c|}{ Ever smoked-heaviest amount } \\
\hline $\begin{array}{l}\text { AlI ages, } \\
17+\text { years }-.-\end{array}$ & 64,501 & 37,758 & 303 & 26,440 & 9,075 & 11,154 & 5,028 & 6621 & 520 \\
\hline $17-24$ years-...- & 11,337 & 6,765 & 112 & 4,460 & 1,662 & 1,824 & 753 & 104 & 117 \\
\hline $25-44$ years $-\ldots . .-$ & 23,686 & 11,019 & 55 & 12,612 & 3,899 & 5,384 & 2,775 & 394 & $1 \in 1$ \\
\hline 45-64 years--..-- & 19,795 & 11,723 & 57 & 8,015 & 2,831 & 3,485 & 1,345 & 159 & 1.6 \\
\hline $65+$ years & 9,683 & 8,250 & 79 & 1,354 & 684 & 460 & 157 & * & * \\
\hline & & & & \multicolumn{6}{|c|}{ Former smokers-heaviest amount } \\
\hline $\begin{array}{l}\text { A11 ages, } \\
17+\text { years - - }\end{array}$ & 64,501 & 37,758 & 303 & 5,040 & 2,796 & 1,428 & 562 & 87 & 16.6 \\
\hline 17-24 years...... & 11,337 & 6,765 & 112 & 621 & 359 & 191 & 55 & * & * \\
\hline $25-44$ years.$--\cdots$ & 23,686 & 11,019 & 55 & 2,291 & 1,220 & 687 & 277 & 52 & 55 \\
\hline 45-64 years-.--- & 19,795 & 11,723 & 57 & 1,691 & 952 & 446 & 193 & * & 71 \\
\hline $65+$ years $\ldots+\cdots---$ & 9,683 & 8,250 & 79 & 436 & 266 & 105 & $*$ & $\star$ & * \\
\hline & & & & \multicolumn{6}{|c|}{ Present smokers-heaviest amount } \\
\hline $\begin{array}{l}\text { A11 ages, } \\
17+\text { years--- }\end{array}$ & 64,501 & 37,758 & 303 & 21,400 & 6,279 & 9,125 & 4,466 & 575 & $3 ! 5$ \\
\hline $17-24$ years $-\ldots$ & 11,337 & 6,765 & 112 & 3,838 & 1,303 & 1,634 & 698 & 100 & 1014 \\
\hline $25-44$ years-..-- & 23,686 & 11,019 & 55 & 10,321 & 2,679 & 4,697 & 2,498 & 342 & 1015 \\
\hline 45-64 years $\ldots$ & 19,795 & 11,723 & 57 & 6,323 & 1,879 & 3,039 & 1,152 & 129 & $1: 5$ \\
\hline $65+$ years $-\ldots$ & 9,683 & 8,250 & 79 & 917 & 418 & 356 & 118 & * & * \\
\hline & & & & \multicolumn{6}{|c|}{ Present smokers-present amount } \\
\hline $\begin{array}{l}\text { Al1 ages, } \\
17+\text { years }--\end{array}$ & 64,501 & 37,758 & 303 & 21,400 & 8,568 & 9,531 & 2,771 & 189 & 342 \\
\hline $17-24$ years $-\cdots--$ & 11,337 & 6,765 & 112 & 3,838 & 1,836 & 1,578 & 308 & * & 97 \\
\hline $25-44$ years--.-- & 23,686 & 11,019 & 55 & 10,321 & 3,713 & 4,775 & 1,603 & 111 & $1: 20$ \\
\hline 45-64 years $\ldots-\ldots$ & 19,795 & 11,723 & 57 & 6,323 & 2,488 & 2,871 & 802 & 57 & 10)6 \\
\hline $65+$ years--..-- & 9,683 & 8,250 & 79 & 917 & 531 & 308 & 57 & * & * \\
\hline
\end{tabular}


Table 2. Percent distribution of smokers 17 years and over, by number of cigarettes smoked per day according to sex, smoking status, and age: United States, July 1964-June 1965

[Data are based on household interviews of the civilian, noninstitutional population. The survey design, general.qualifications, and information on the reliability of the estimates are given in Appendix I. Definitions of terms are given in Appendix II]

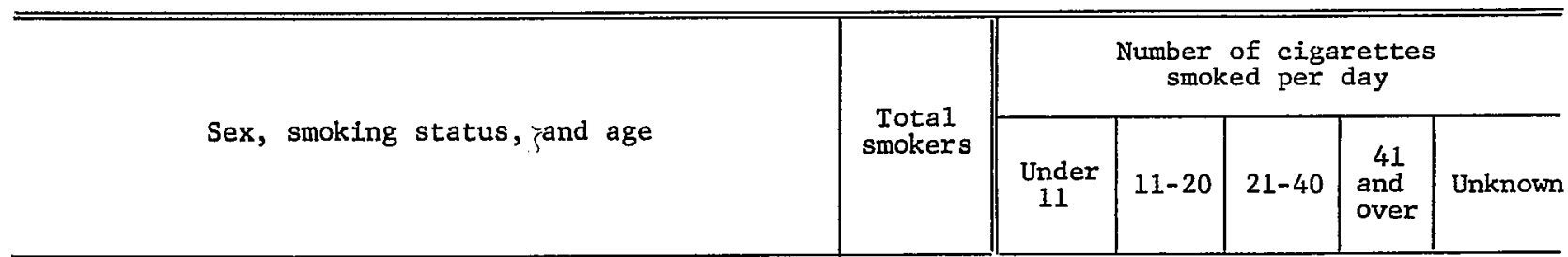

Male

A11 ages, 17 years and over-

17-24 years

25-44 years

45-64 years

65 years and over

A11 ages, 17 years and over-con

17-24 years

25-44 years

45-64 years

65 years and over

A11 ages, 17 years and over

17-24 years

25-44 years

45-64 years

65 years and over

A11 ages, 17 years and over-

17- 24 years

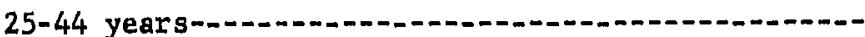

45-64 years

65 years and over
Percent distribution

Ever smoked-heaviest amount

\begin{tabular}{l||l|l|l|l|l}
100.0 & 18.4 & 41.8 & 28.1 & 6.8 & 4.8 \\
\hline \hline & & & & & \\
100.0 & 27.2 & 43.0 & 19.8 & 3.4 & 6.6 \\
100.0 & 15.4 & 41.9 & 31.7 & 7.3 & 3.7 \\
100.0 & 15.7 & 41.5 & 29.9 & 8.0 & 4.9 \\
100.0 & 27.5 & 41.3 & 19.3 & 5.5 & 6.5
\end{tabular}

Former smokers-heaviest amount

\begin{tabular}{l||l|l|l|l|l}
100.0 & 26.5 & 31.1 & 21.5 & 7.1 & 7.8 \\
\hline 100.0 & 44.0 & 31.1 & 14.5 & 2.4 & 8.2 \\
100.0 & 25.9 & 37.2 & 23.4 & 6.3 & 7.2 \\
100.0 & 22.0 & 38.6 & 23.2 & 8.8 & 7.4 \\
100.0 & 31.3 & 35.5 & 16.7 & 6.7 & 9.8
\end{tabular}

Present smokers-heaviest amount

\begin{tabular}{l||l|l|l|l|l}
100.0 & 15.4 & 43.6 & 30.6 & 6.7 & 3.7 \\
\hline 100.0 & 24.9 & 44.6 & 20.5 & 3.6 & 6.4 \\
100.0 & 12.3 & 43.3 & 34.1 & 7.6 & 2.7 \\
100.0 & 12.8 & 42.8 & 33.1 & 7.6 & 3.8 \\
100.0 & 23.6 & 47.0 & 21.7 & 4.3 & 3.3
\end{tabular}

Present smokers-present amount

\begin{tabular}{l||r|r|r|r|r}
100.0 & 25.7 & 46.9 & 21.3 & 2.7 & 3.3 \\
\hline 100.0 & 35.0 & 47.5 & 11.1 & 1.0 & 5.4 \\
100.0 & 21.6 & 48.2 & 24.6 & 3.2 & 2.4 \\
100.0 & 23.1 & 46.1 & 24.2 & 3.3 & 3.5 \\
100.0 & 41.2 & 41.4 & 12.2 & $*$ & 3.7
\end{tabular}


Table 2. Percent distribution of smokers 17 years and over, by number of cigarettes smoked per day according to sex, smoking status, and age: United States, July 1964-June 1965-Con.

[Data are based on household interviews of the civilian, noninstitutional population. The survey design, general qualifications, and information on the reliability of the estimates are given in Appendix I. Definitions of terms are given in Appendix II]

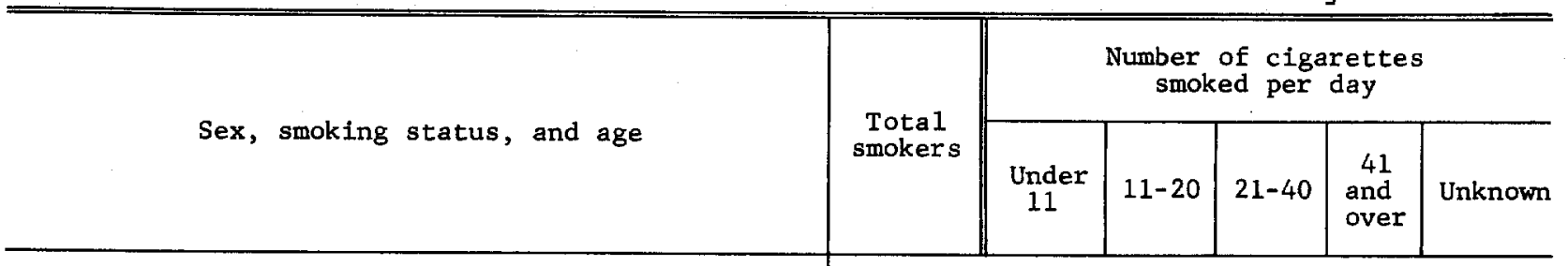

\section{Female}

A11 ages, 17 years and over

17-24 years

25-44 years

45-64 years

65 years and over

Al1 ages, 17 years and over

17-24 years

25-44 years

45-64 years

65 years and over

A11 ages, 17 years and over

17-24 years

25-44 years

45-64 years

65 years and over

A11 ages, 17 years and over

17-24 years

25-44 years--

45-64 years

65 years and over
Percent distribution

Ever smoked-heaviest amount

\begin{tabular}{r||r|r|r|r|r}
100.0 & 34.3 & 42.2 & 19.0 & 2.5 & 2.0 \\
\hline \hline 100.0 & 37.3 & 40.9 & 16.9 & 2.3 & 2.6 \\
100.0 & 30.9 & 42.7 & 22.0 & 3.1 & 1.3 \\
100.0 & 35.3 & 43.5 & 16.8 & 2.0 & 2.4 \\
100.0 & 50.5 & 34.0 & 11.6 & $*$ & $*$
\end{tabular}

Former smokers-heaviest amount

\begin{tabular}{r||r|r|r|r|r}
100.0 & 55.5 & 28.3 & 11.2 & 1.7 & 3.3 \\
\hline 100.0 & 57.8 & 30.8 & 8.9 & $*$ & $*$ \\
100.0 & 53.3 & 30.0 & 12.1 & 2.3 & 2.4 \\
100.0 & 56.3 & 26.4 & 11.4 & $*$ & 4.2 \\
100.0 & 61.0 & 24.1 & $*$ & $*$ & $*$
\end{tabular}

Present smokers-heaviest amount

\begin{tabular}{r||r|r|r|r|r}
100.0 & 29.3 & 45.4 & 20.9 & 2.7 & 1.7 \\
\hline 100.0 & 33.9 & 42.6 & 18.2 & 2.6 & 2.7 \\
100.0 & 26.0 & 45.5 & 24.2 & 3.3 & 1.0 \\
100.0 & 29.7 & 48.1 & 18.2 & 2.0 & 2.0 \\
100.0 & 45.6 & 38.8 & 12.9 & $*$ & $*$
\end{tabular}

Present smokers-present amount

\begin{tabular}{r||r|r|r|r|r}
100.0 & 40.0 & 44.5 & 12.9 & 0.9 & 1.6 \\
\hline 100.0 & 47.8 & 41.1 & 8.0 & $*$ & 2.5 \\
100.0 & 36.0 & 46.3 & 15.5 & 1.1 & 1.2 \\
100.0 & 39.3 & 45.4 & 12.7 & 0.9 & 1.7 \\
100.0 & 57.9 & 33.6 & 6.2 & $*$ & $*$ \\
\hline
\end{tabular}


Table 3. Percent of persons 17 years and over with one or more chronic conditions, by smoking stam tus, number of cigarettes smoked per day, sex, and age: United States, July 1964-June 1965-Con.

[Data are based on household interviews of the civilian, noninstitutional population. The survey design, general qualifications, and information on the reliability of the estimates are given in Appendix I. Definitions of terms are given in Appendix II]

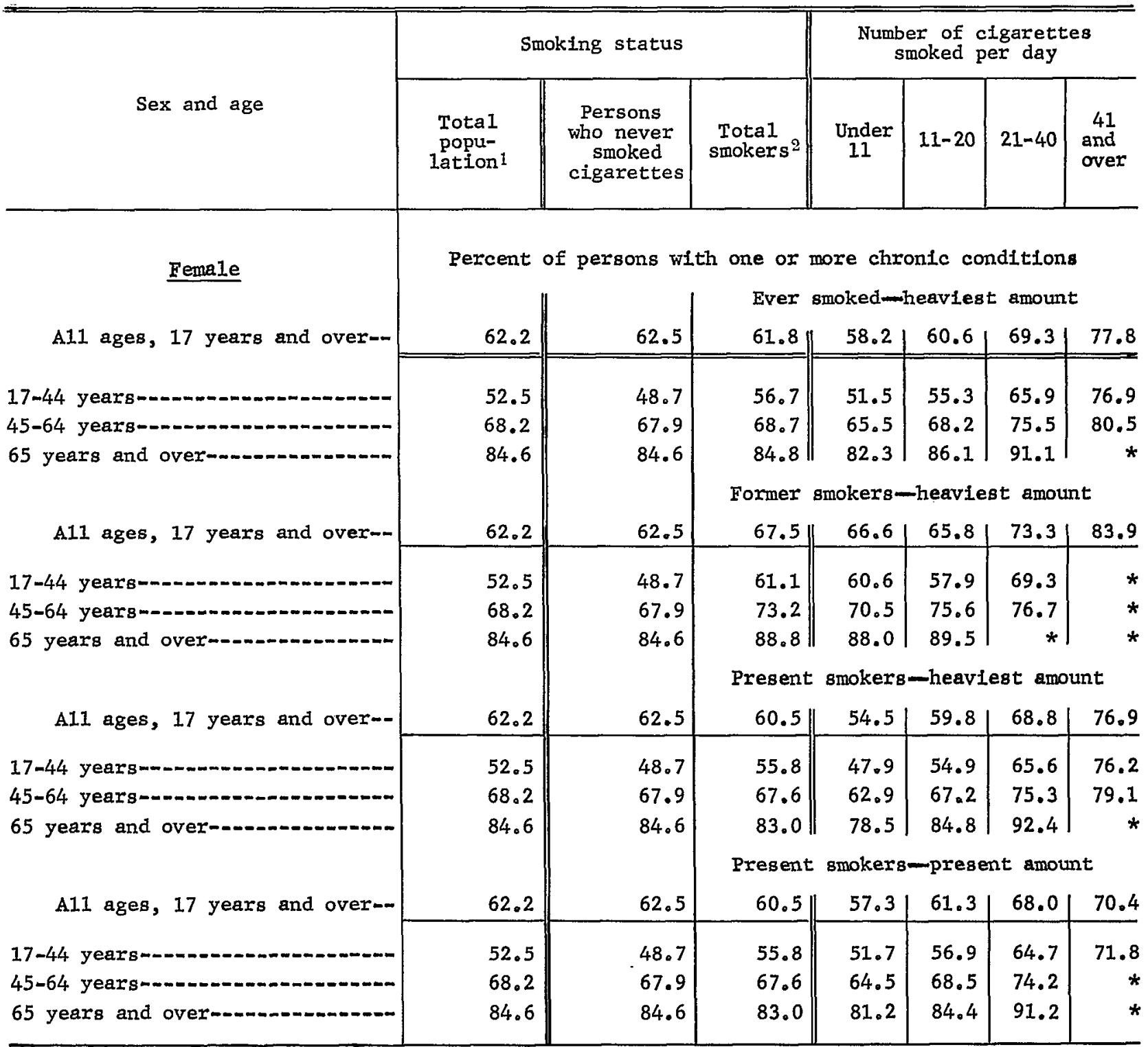

\footnotetext{
1 "Total population" includes the "unknown if ever smoked cigarettes" category.

2 "Total smokers" includes the "unknown number of cigarettes" category.
} 
Table 4. Age-adjusted ${ }^{1}$ percent of persons 17 years and over with one or more chronic conditions and ratios of smokers to "never smokers," by smoking status, number of cigarettes smoked per day, and sex: United States, July 1964-June 1965

[Data are based on household interviews of the civilian, noninstitutional population. The survey design, general qualifications, and information on the reliability of the estimates are given in Appendix I. Definitions of terms are given in Appendix II]

\begin{tabular}{|c|c|c|c|c|c|c|c|}
\hline \multirow[b]{2}{*}{ Sex } & \multicolumn{3}{|c|}{ Smoking status } & \multicolumn{4}{|c|}{$\begin{array}{c}\text { Number of cigarettes } \\
\text { smoked per day }\end{array}$} \\
\hline & $\begin{array}{c}\text { Total } \\
\text { popr- } \\
\text { 1ation'2 }\end{array}$ & $\begin{array}{l}\text { Persons } \\
\text { who never } \\
\text { smoked } \\
\text { cigarettes }\end{array}$ & $\begin{array}{l}\text { Total } \\
\text { smokers }^{3}\end{array}$ & $\begin{array}{c}\text { Under } \\
11\end{array}$ & $11-20$ & $21-40$ & $\begin{array}{l}41 \\
\text { and } \\
\text { over }\end{array}$ \\
\hline
\end{tabular}

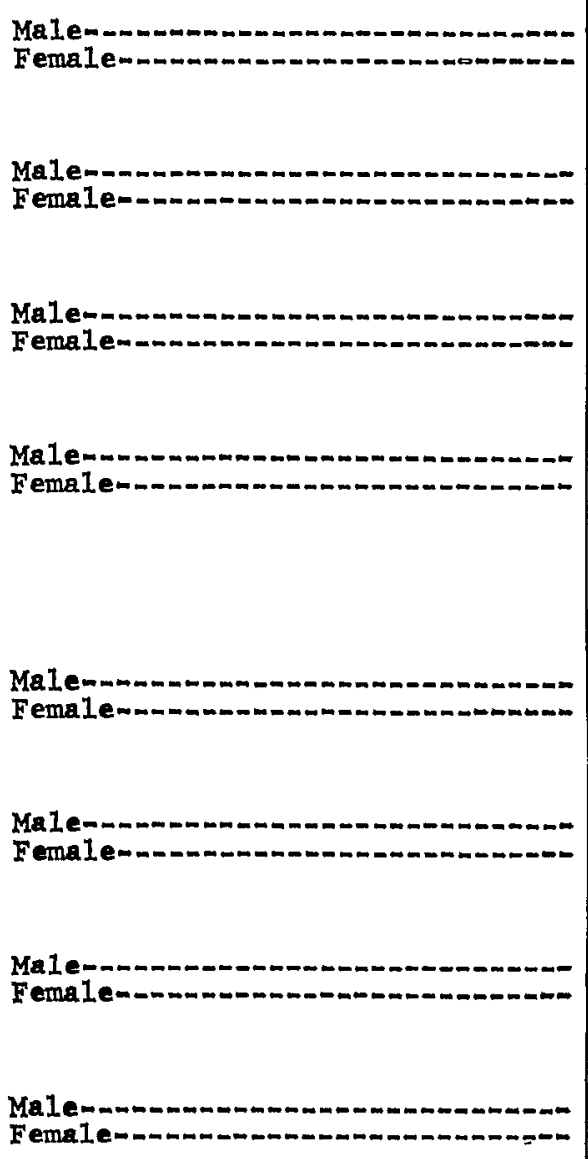

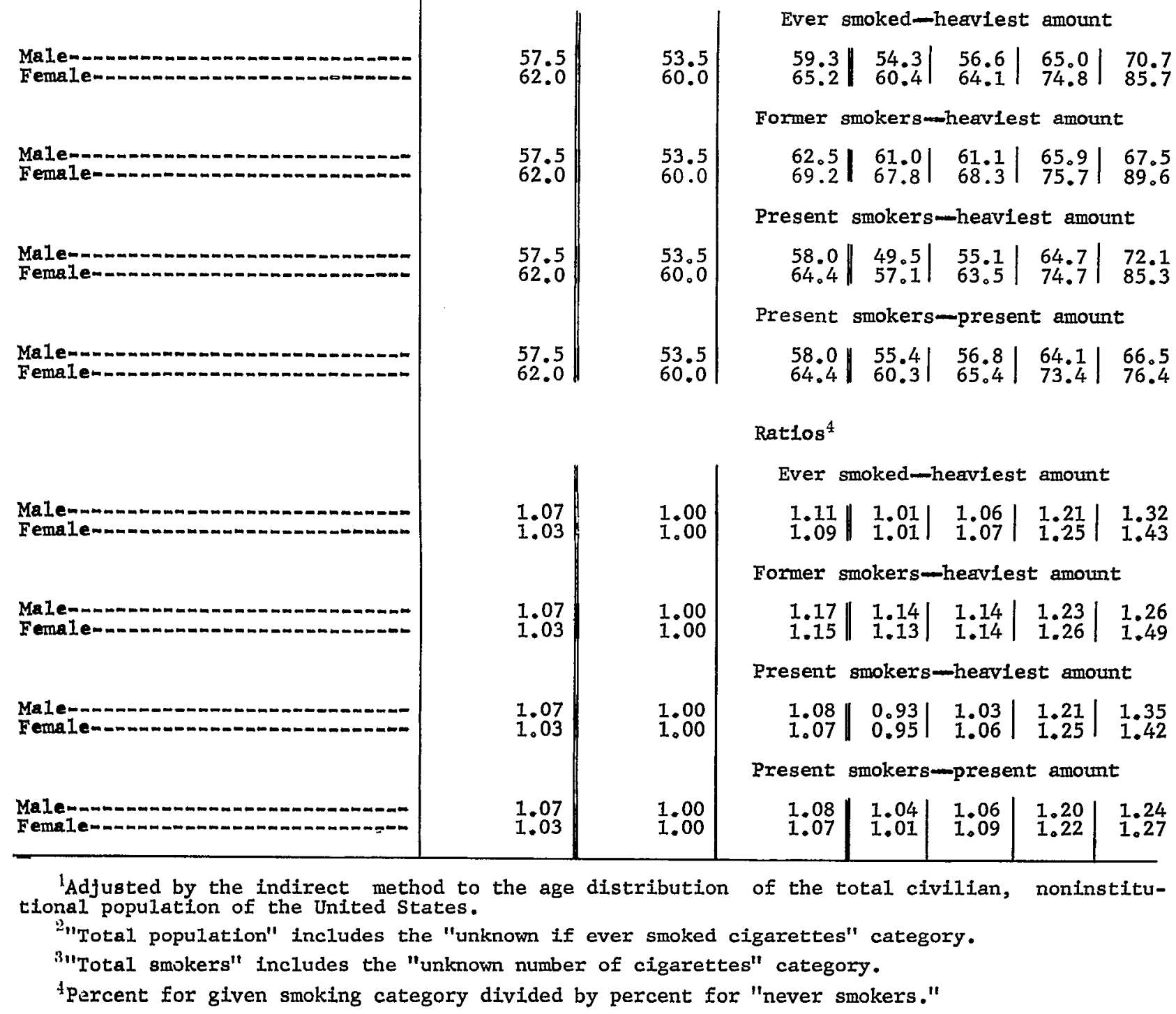

Ever smoked-heaviest amount

Age-adjusted percent of persons with one or more chronic conditions 
Table 5. Age-specific prevalence rates of chronic conditions per 100 males, by cigarette smoking status, selected chronic conditions, and age: United States, July 1964-June 1965

Data are based on household interviews of the civilian, noninstitutional population. The survey design, general qualifications, and information on the reliability of the estimates are given in Appendix I. Definitions of terms are given in Appendix II]

\begin{tabular}{|c|c|c|c|c|c|}
\hline Selected chronic conditions and age & $\begin{array}{l}\text { Total popu- } \\
\text { lation }\end{array}$ & $\begin{array}{c}\text { Persons } \\
\text { who } \\
\text { never } \\
\text { smoked }\end{array}$ & $\begin{array}{l}\text { Persons } \\
\text { who } \\
\text { ever } \\
\text { smoked }\end{array}$ & $\begin{array}{l}\text { Former } \\
\text { smokers }\end{array}$ & $\begin{array}{l}\text { Present } \\
\text { smokers }\end{array}$ \\
\hline
\end{tabular}

\section{Al1 chronic conditions}

A11 ages, 17 years and over

17-44 years--1045-64 year

65 years and over

\section{Heart conditions}

(excluding rheumatic heart disease)

A11 ages, 17 years and over

17-44 years

45-64 years

Arteriosclerotic heart disease, including coronary disease (subcategory of heart conditions)

Al1 ages, 17 years and over 1

45-64 years--

65 years and over-an

Hypertenston without heart involvement

A11 ages, 17 years and over

17-44 years

45-64 years-

65 years and over

Chronic bronchitis and/or emphysema

A11 ages, 17 years and over-

17-44 years

45-64 years

65 years and over
Age-specific prevalence per 100 males

\begin{tabular}{|c|c|c|c|c|}
\hline 119.3 & 112.3 & 122.4 & 150.9 & 111.6 \\
\hline 77.7 & 65.4 & 82.9 & 93.0 & 80.3 \\
\hline 140.6 & 124.2 & 145.9 & 156.2 & 141.2 \\
\hline 240.4 & 229.0 & 249.4 & 261.9 & 237.1 \\
\hline 4.6 & 4.6 & 4.6 & 7.5 & 3.5 \\
\hline 0.7 & $*$ & 0.8 & * & 0.8 \\
\hline 6.3 & 4.7 & 6.8 & 8.7 & 6.0 \\
\hline 16.8 & 16.3 & 17.2 & 19.0 & 15.5 \\
\hline 1.4 & 1.0 & 1.5 & 2.6 & 1.1 \\
\hline 2.4 & 1.5 & 2.7 & 3.7 & 2.2 \\
\hline 3.6 & 3.2 & 3.9 & 4.9 & $3 . C$ \\
\hline 4.1 & 4.4 & 4.0 & 5.3 & 3.5 \\
\hline 1.9 & 1.6 & 2.0 & 2.3 & 2.0 \\
\hline 5.8 & 6.5 & 5.6 & 6.1 & 5.2 \\
\hline 9.3 & 9.6 & 9.1 & 10.0 & 8.1. \\
\hline 1.9 & 1.0 & 2.3 & 2.7 & 2. $\therefore$ \\
\hline 0.8 & $*$ & 1.0 & * & 1.0 \\
\hline 2.8 & * & 3.3 & 3.1 & $3.4 \mathrm{k}$ \\
\hline 4.7 & 2.4 & 6.4 & 6.0 & 6.11 \\
\hline
\end{tabular}


Table 5. Age-specific prevalence rates of chronic conditions per 100 males, by cigarette smoking status, selected chronic conditions, and age: United States, July 1964-June 1965-Con.

[Data are baged on household interviews of the civilian, noninstitutional population. The survey design, general qualifications, and information on the reliability of the estimates are given in Appendix I. Definitions of terms are given in Appendix II]

\begin{tabular}{|c|c|c|c|c|c|}
\hline \multirow[b]{2}{*}{ Selected chronic conditions and age } & \multicolumn{5}{|c|}{ Cigarette smoking status } \\
\hline & $\begin{array}{c}\text { Total popu- } \\
\text { lation }\end{array}$ & $\begin{array}{l}\text { Persons } \\
\text { who } \\
\text { never } \\
\text { smoked }\end{array}$ & $\begin{array}{l}\text { Persons } \\
\text { who } \\
\text { ever } \\
\text { smoked }\end{array}$ & $\begin{array}{l}\text { Former } \\
\text { smokers }\end{array}$ & $\begin{array}{l}\text { Present } \\
\text { smokers }\end{array}$ \\
\hline
\end{tabular}

\section{Chronic sinusitis}

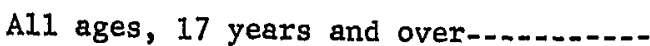

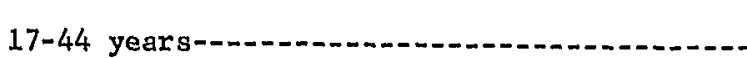

45-64 years

65 ycars and over

Peptic ulcer

Al1 ages, 17 years and over

17-44 years

45-64 years

65 years and over

Arthritis

A11 ages, 17 years and over

17-44 years

45-64 years

65 years and over

Hearing impairments

Al1 ages, 17 years and over

17-44 years-0-n-n

45-64 years--..n-

65 years and over.

Al1 other chronic conditions

Al1 ages, 17 years and over.

17-44 years

45-64 years

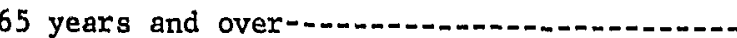

1 No age category for 17-44 years because of
Age-specific prevalence per 100 males

\begin{tabular}{|c|c|c|c|c|}
\hline 10.2 & 8.2 & 11.1 & 11.8 & 10.8 \\
\hline 9.6 & 7.6 & 10.5 & 11.7 & 10.2 \\
\hline 11.2 & 9.1 & 11.9 & 12.0 & 11.9 \\
\hline 10.2 & 8.6 & 11.5 & 11.5 & 11.4 \\
\hline 3.9 & 2.3 & 4.6 & 4.5 & 4.7 \\
\hline 3.1 & 1.6 & 3.8 & 4.3 & 3.6 \\
\hline 5.3 & 3.2 & 6.0 & 4.7 & 6.6 \\
\hline 3.9 & 2.9 & 4.6 & 4.7 & 4.5 \\
\hline 7.1 & 7.3 & 6.9 & 10.4 & 5.6 \\
\hline 1.6 & 1.1 & 1.8 & 2.0 & 1.8 \\
\hline 10.4 & 10.5 & 10.4 & 12.3 & 9.5 \\
\hline 21.4 & 20.7 & 22.0 & 24.1 & 20.0 \\
\hline 8.2 & 8.9 & 7.8 & 10.9 & 6.7 \\
\hline 3.2 & 2.6 & 3.4 & 4.4 & 3.2 \\
\hline 8.9 & 8.5 & 9.0 & 9.8 & 8.6 \\
\hline 27.1 & 27.5 & 26.7 & 26.9 & 26.5 \\
\hline 78.6 & 74.8 & 80.2 & 96.5 & 74.0 \\
\hline 56.7 & 50.0 & 59.5 & 66.7 & 57.7 \\
\hline 89.2 & 80.3 & 92.1 & 98.3 & 89.2 \\
\hline 143.5 & 137.6 & 148.1 & 155.5 & 140.9 \\
\hline
\end{tabular}

No age category for 17-44 years because of sma11 number of cases. 
Table 6. Age-specific prevalence rates of chronic conditions per 100 females, by cigarette smoking status, selected chronic conditions, and age: United States, July 1964-June 1965

[Data are based on household interviews of the civilian, noninstitutional population. The survey design, general qualificationg, and information on the reliability of the estimates are given in Appendix I. Definitions of terms are given in Appendix II]

\begin{tabular}{l|c||c|c|c|}
\hline \hline \multirow{2}{*}{ Selected chronic conditions and age } & \multicolumn{3}{|c}{ Cigarette smoking status } \\
\cline { 2 - 4 } & $\begin{array}{c}\text { Total popu- } \\
\text { lation }\end{array}$ & $\begin{array}{c}\text { Persons } \\
\text { who } \\
\text { never } \\
\text { smoked }\end{array}$ & $\begin{array}{c}\text { Persons } \\
\text { who } \begin{array}{c}\text { ever } \\
\text { smoked }\end{array}\end{array}$ & $\begin{array}{c}\text { Former } \\
\text { smokers }\end{array}$ \\
\hline
\end{tabular}

Al1 chronic conditions

All ages, 17 years and ove

17-44 years

45-64 years

Heart conditions

(excluding rheumatic heart disease)

A11 ages, 17 years and over........-

17-44 years-a-n

45-64 years

65 years and over

Arteriosclerotic heart disease, including coronary disease (subcategory of heart conditions)

A11 ages, 17 years and over 1

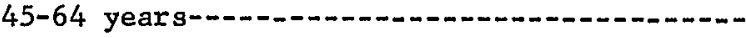

65 years and over

Hypertension without heart involvement

All ages, 17 years and over

17-44 years

45-64 years

65 years and over

Chronic bronchitis and/or emphysema

A11 ages, 17 years and over-.....

17-44 years-...-

45-64 years

65 years and over-
Age-specific prevalence per 100 females

\begin{tabular}{|c|c|c|c|c|}
\hline 149.0 & 155.9 & 139.7 & 164.4 & 133.8 \\
\hline 102.1 & 90.5 & 114.4 & 125.8 & 112.1 \\
\hline 168.5 & 167.5 & 170.3 & 189.8 & 165.1 \\
\hline 279.1 & 280.2 & 276.4 & 324.5 & 253.7 \\
\hline 4.3 & 5.5 & 2.6 & 4.4 & 2.2 \\
\hline 0.7 & 0.6 & 0.8 & * & 0.8 \\
\hline 4.8 & 4.9 & 4.5 & 6.7 & 3.9 \\
\hline 16.8 & 17.0 & 15.6 & 20.2 & 13.4 \\
\hline 0.7 & 0.8 & 0.6 & 1.4 & 0.4 \\
\hline 1.0 & 0.8 & 1.3 & * & 1.0 \\
\hline 2.6 & 2.3 & 3.7 & * & * \\
\hline 8.3 & 10.1 & 5.8 & 7.6 & 5.4 \\
\hline 2.6 & 2.4 & 2.8 & 3.1 & 2.7 \\
\hline 11.7 & 13.1 & 9.8 & 11.5 & 9.4 \\
\hline 22.3 & 22.7 & 20.2 & 23.2 & 18.9 \\
\hline 2.0 & 1.3 & 3.1 & 2.5 & 3.2 \\
\hline 1.5 & 0.7 & 2.4 & 2.1 & 2.5 \\
\hline 2.5 & 1.4 & 4.0 & * & 4.4 \\
\hline 2.9 & 2.5 & 5.4 & * & 5.8 \\
\hline
\end{tabular}


Table 6. Age-specific prevalence rates of chronic conditions per 100 females, by cigarette smokIng status, selected chronic conditions, and age: United States, July 1964-June 1965-Con.

[Data are based on household interviews of the civilian, noninstitutional population. The survey design, general qualifications, and information on the reliability of the estimates are given in Appendix I. Definitions of terms are given in Appendix II]

\begin{tabular}{|c|c|c|c|c|c|}
\hline \multirow[b]{2}{*}{ Selected chronic conditions and age } & \multicolumn{5}{|c|}{ Cigarette smoking status } \\
\hline & $\begin{array}{l}\text { Total popu- } \\
\text { lation }\end{array}$ & $\begin{array}{c}\text { Persons } \\
\text { who } \\
\text { never } \\
\text { smoked }\end{array}$ & $\begin{array}{c}\text { Persons } \\
\text { who } \\
\text { ever } \\
\text { smoked }\end{array}$ & $\begin{array}{l}\text { Former } \\
\text { smokers }\end{array}$ & $\begin{array}{l}\text { Present } \\
\text { smokers }\end{array}$ \\
\hline
\end{tabular}

\section{Chronic sinusitis}

Al1 ages, 17 years and over..............

17-44 years

45-64 years-

65 years and over

\section{Peptic ulcer}

A11 ages, 17 years and over

$17-44$ years

45-64 years

65 years and over

\section{Arthritis}

A11 ages, 17 gears and over

17-44 years

45-64 years

65 years and over

\section{Hearing impairments}

A11 ages, 17 years and over-...
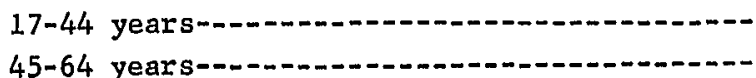

65 years and over

\section{Al1 other chronic conditions}

A11 ages, 17 years and over

\section{7-44 years}

45-64 years

65 years and over
Age-specific prevalence per 100 females

\begin{tabular}{|c|c|c|c|c|}
\hline 12.2 & 11.1 & 13.9 & 14.7 & 13.7 \\
\hline 11.6 & 10.0 & 13.4 & 13.6 & 13.4 \\
\hline 13.5 & 12.5 & 14.9 & 16.6 & 14.4 \\
\hline 11.8 & 11.5 & 14.0 & 14.7 & 13.6 \\
\hline 1.9 & 1.6 & 2.5 & 2.6 & 2.4 \\
\hline 1.5 & 1.1 & 2.0 & 2.3 & 1.9 \\
\hline 2.5 & 2.1 & 3.2 & * & 3.3 \\
\hline 2.3 & 2.0 & 4.7 & $*$ & * \\
\hline 13.0 & 15.4 & 9.7 & 12.8 & 9.0 \\
\hline 3.6 & 3.1 & 4.1 & 4.5 & 4.0 \\
\hline 18.9 & 19.8 & 17.7 & 21.1 & 16.8 \\
\hline 35.3 & 35.5 & 34.5 & 36.5 & 33.7 \\
\hline 5.7 & 7.1 & 3.9 & 4.8 & 3.6 \\
\hline 2.1 & 2.1 & 2.2 & 2.5 & 2.1 \\
\hline 5.5 & 5.5 & 5.6 & 5.9 & 5.5 \\
\hline 19.2 & 20.0 & 15.0 & 15.4 & 14.8 \\
\hline 100.8 & 103.0 & 98.0 & 114.8 & 94.0 \\
\hline 78.5 & 70.7 & 86.9 & 97.0 & 84.8 \\
\hline 108.7 & 107.7 & 110.4 & 122.3 & 107.2 \\
\hline 165.4 & 165.9 & 164.0 & 204.6 & 144.8 \\
\hline
\end{tabular}

${ }^{1}$ No age category for 17-44 years because of sma11 number of cases. 
Table 7. Unadjusted and age-adjusted ${ }^{1}$ prevalence rates for all chronic conditions per 100 persons 17 years and over, by smoking status, number of cigarettes smoked per day, and sex: United States, July 1964-June 1965

[Data are based on household interviews of the civilian, noninstitutional population. The survey design, general qualifications, and information on the reliability of the estimates are given in Appendix I. Definitions of terms are given in Appendix II]

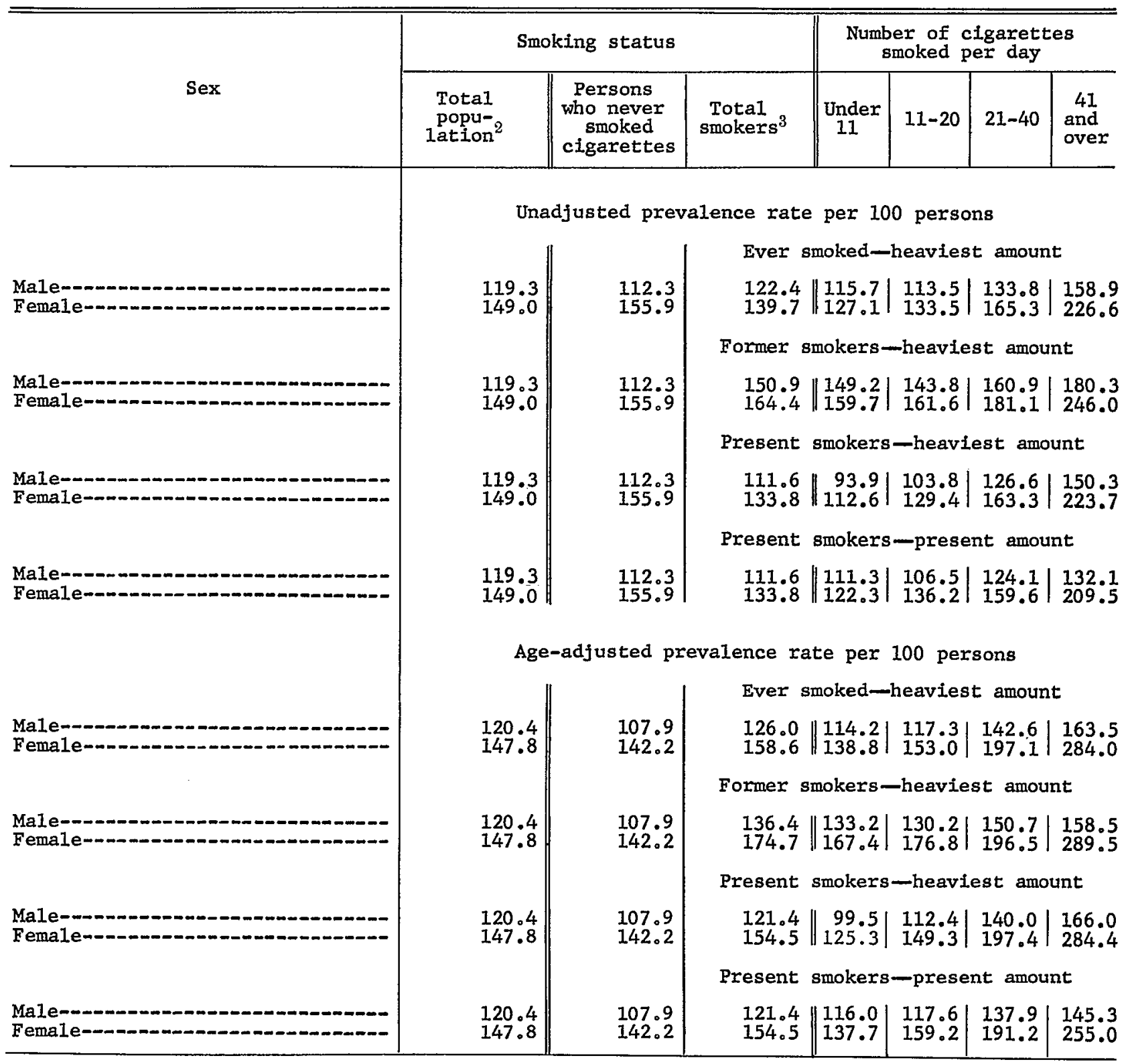

${ }^{1}$ Adjusted by the indirect method to the age distribution of the total civilian, noninstitutional population of the United States.

2 "Total population" includes the "unknown if ever smoked cigarettes" category.

"Total smokers" includes the "unknown number of cigarettes" category. 
Table 8. Unadjusted and age-adjusted ${ }^{1}$ prevalence rates of heart conditions (excluding chronic rheumatic heart disease) 2 pex 100 persons 17 years and over, by smoking status, number of clgarettes smoked per day, and sex: United States, July 1964-June 1965

[Data are based on household interviews of the civilian, noninstitutional population. The survey design, general qualifications, and information on the reliability of the estimates are given in Appendix I. Definitions of terms are given in Appendix II]

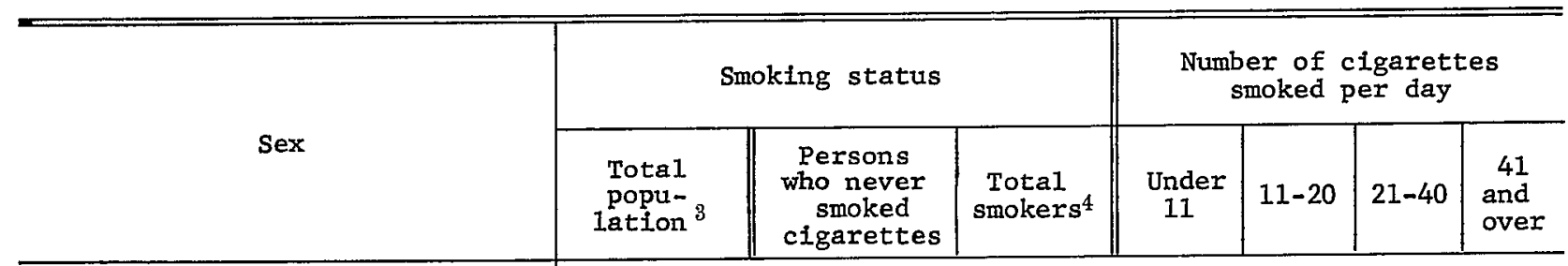

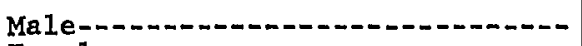

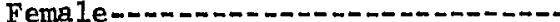

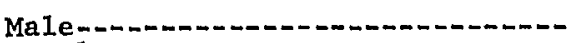

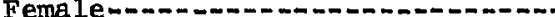

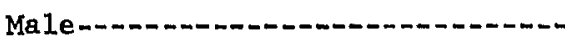

Female

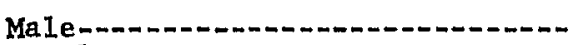

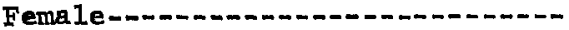

Male.

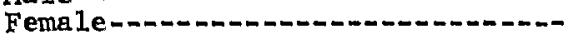

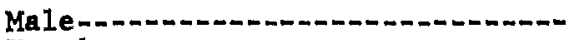

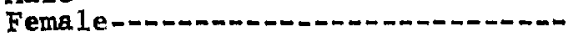

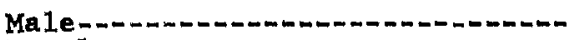

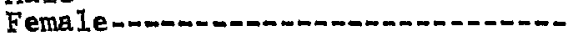

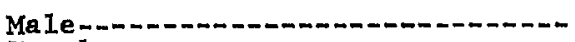

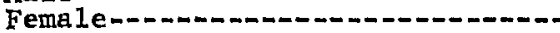

Unadjusted prevalence rate per 100 persons

\begin{tabular}{|c|c|}
\hline $\begin{array}{l}4.6 \\
4.3\end{array}$ & $\begin{array}{l}4.6 \\
5.5\end{array}$ \\
\hline $\begin{array}{l}4.6 \\
4.3\end{array}$ & $\begin{array}{l}4.6 \\
5.5\end{array}$ \\
\hline $\begin{array}{l}4.6 \\
4.3\end{array}$ & $\begin{array}{l}4.6 \\
5.5\end{array}$ \\
\hline & 4.6 \\
\hline
\end{tabular}

Ever smoked-heaviest amount

$$
\begin{array}{l|l|l|l|r}
4.6 & 4.2 & 4.4 & 4.8 & 7.0 \\
2.6 & 2.6 & 2.5 & 2.6 & *
\end{array}
$$

Former smokers-heaviest amount
7.5
4.4
5.9
4.1
7.5
4.5
8.8
11.9

Present smokers-heaviest amount
3.5
2.2
3.2
2.0
3.4
2.2
3.8
5.0

Present smokers-present amount
3.5
2.2
4.9
2.3
3.1
3.1
$\star$

Age-adjusted prevalence rate per 100 persons

\begin{tabular}{|c|c|c|c|c|c|c|}
\hline & & Ever & smoked - & aviest & amoun & \\
\hline $\begin{array}{l}4.7 \\
4.2\end{array}$ & $\begin{array}{l}4.1 \\
4.3\end{array}$ & $\begin{array}{l}5.0 \\
3.9\end{array}$ & $\begin{array}{l}4.0 \\
3.4\end{array} \mid$ & $\begin{array}{l}5.0 \\
3.9\end{array}$ & $\begin{array}{l}6.0 \\
4.7\end{array}$ & 7.9 \\
\hline & & Former & smokers - & eavies & amour & \\
\hline $\begin{array}{l}4.7 \\
4.2\end{array}$ & $\begin{array}{l}4.1 \\
4.3\end{array}$ & $\begin{array}{l}5.9 \\
5.4\end{array}$ & $\begin{array}{l}4.4 \\
4.7\end{array}$ & $\begin{array}{l}5.9 \\
6.0\end{array}$ & $\begin{array}{r}7.6 \\
*\end{array}$ & 8.9 \\
\hline & & Present & smokers & heavie & t amo & \\
\hline $\begin{array}{l}4.7 \\
4.2\end{array}$ & $\begin{array}{l}4.1 \\
4.3\end{array}$ & $\begin{array}{l}4.6 \\
3.5\end{array}$ & $\begin{array}{l}3.8 \\
2.8\end{array}$ & $\begin{array}{l}4.4 \\
3.5\end{array}$ & $\begin{array}{l}5.3 \\
4.5\end{array}$ & $\begin{array}{r}7.0 \\
*\end{array}$ \\
\hline & & Present & smokers & preser & amour & \\
\hline $\begin{array}{l}4.7 \\
4.2\end{array}$ & $\begin{array}{l}4.1 \\
4.3\end{array}$ & $\begin{array}{l}4.6 \\
3.5\end{array}$ & $\begin{array}{l}5.5 \\
3.3\end{array}$ & $\begin{array}{l}4.2 \\
3.7\end{array}$ & $\begin{array}{l}4.5 \\
3.9\end{array}$ & * \\
\hline
\end{tabular}

${ }^{1}$ Adjusted by the indirect method to the age distribution of the total civilian, noninstitutional population of the United States.

"Includes ICD Nos. 420-443, 782.1, 782.2, and 782.4.

"Total population" includes the "unknown if ever smoked cigarettes" category.

"Total smokers" includes the "unknown number of cigarettes" category. 
Table 9. Unadjusted and age-adjusted ${ }^{1}$ prevalence rates of hypertension without heart involvement ${ }^{2}$ per 100 persons 17 years and over, by smoking status, number of cigarettes smoked per day, and sex: United States, July 1964-June 1965

[Data are based on household interviews of the civilian, noninstitutional population. The survey design, general qualifications, and information on the reliability of the estimates are given in Appendix I. Definitions of terms are given in Appendix II]

\begin{tabular}{|c|c|c|c|c|c|c|c|}
\hline \multirow[b]{2}{*}{ Sex } & \multicolumn{3}{|c|}{ Smoking status } & \multicolumn{4}{|c|}{$\begin{array}{c}\text { Number of cigarettes } \\
\text { smoked per day }\end{array}$} \\
\hline & $\begin{array}{c}\text { Total } \\
\text { popu- } \\
\text { lation } 3\end{array}$ & $\begin{array}{l}\text { Persons } \\
\text { who never } \\
\text { smoked } \\
\text { cigarettes }\end{array}$ & $\begin{array}{l}\text { Tota1 } \\
\text { smokers }\end{array}$ & $\begin{array}{c}\text { Under } \\
11\end{array}$ & $11-20$ & $21-40$ & $\begin{array}{l}41 \\
\text { and } \\
\text { over }\end{array}$ \\
\hline
\end{tabular}

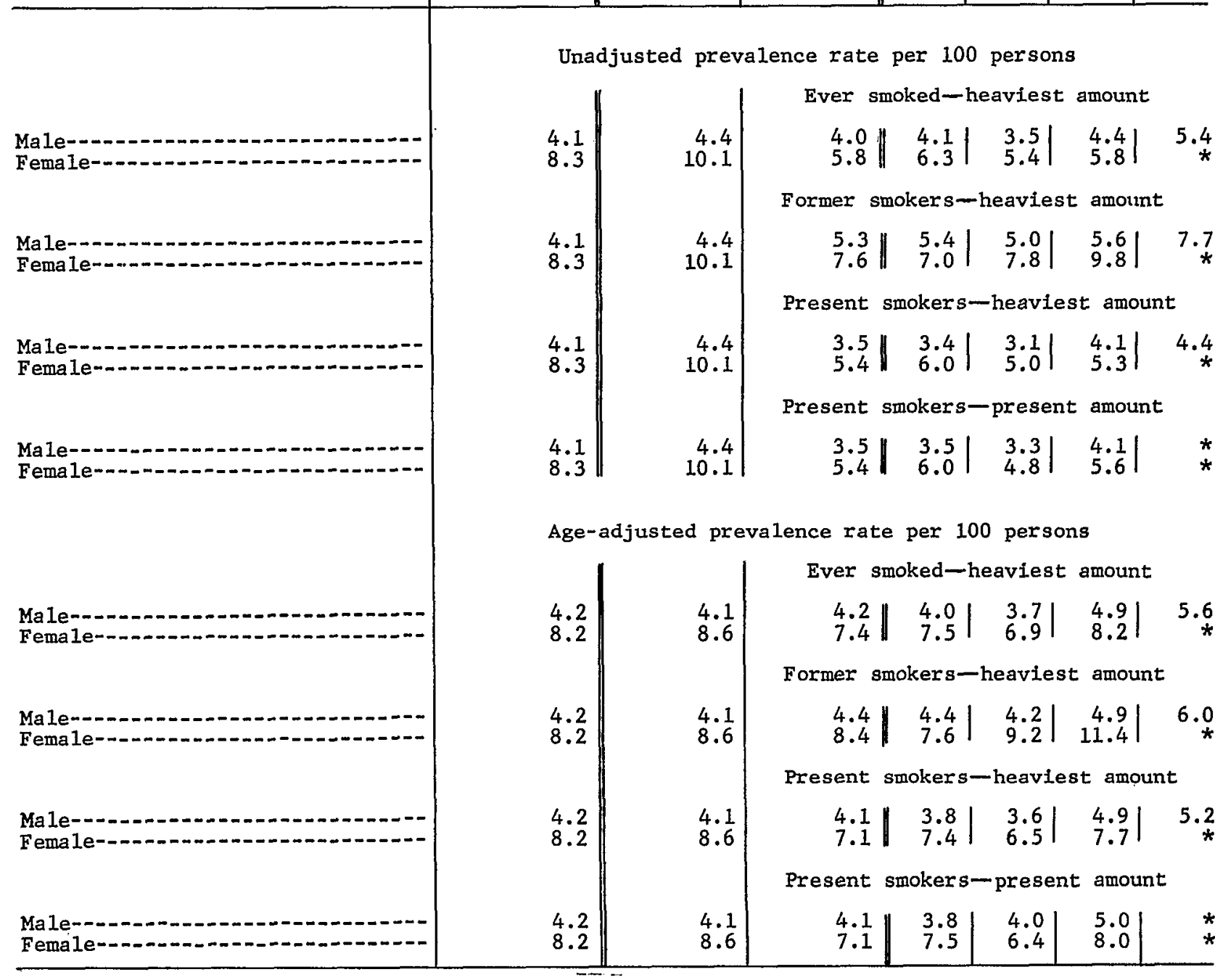

${ }^{1}$ Adjusted by the indirect method to the age distribution of the total civilian, noninstitutional population of the United States.

${ }^{2}$ Includes ICD Nos. 444-447.

"Tota1 population" includes the "unknown if ever smoked cigarettes" category.

4"Total smokers" includes the "unknown number of cigarettes" category. 
Table 10. Unadjusted and age-adjusted ${ }^{1}$ prevalence rates of chronic bronchitis and/or emphysema2 per 100 persons 17 years and over, by smoking status, number of cigarettes smoked per day, and sex: United States, July 1964-June 1965

[Data are based on household interviews of the civilian, noninstitutional population. The survey design, general qualifications, and information on the reliability of the estimates are given in Appendix I. Definitions of terms are given in Appendix II]

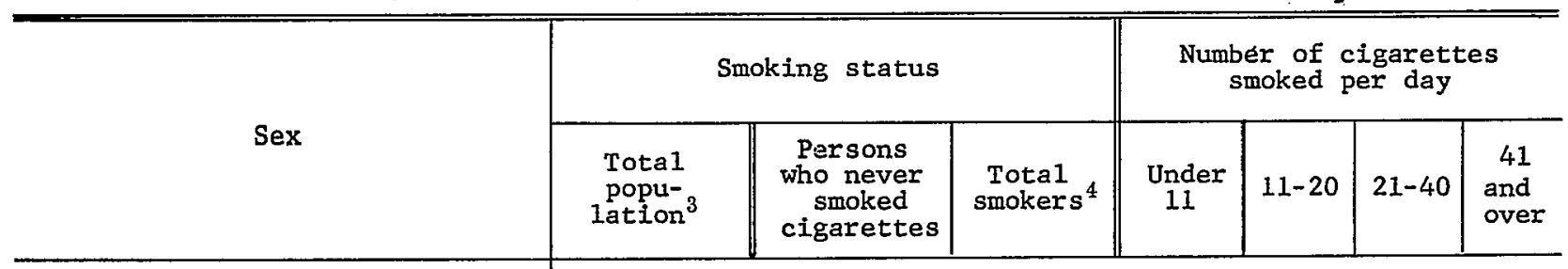

Male-

Female

Male

Male

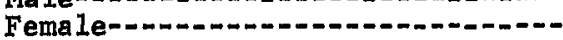

Male-

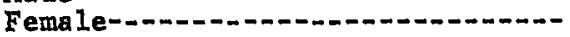

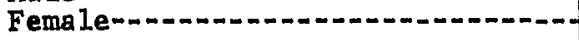

Male-

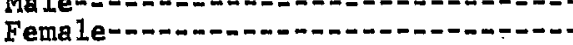

Male-m-nan-

Female-nan-

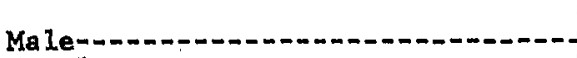

Female-n.-.

Unadjusted prevalence rate per 100 persons

\begin{tabular}{|c|c|c|c|c|c|}
\hline & & Ever $\mathbf{s}$ & red-1 & aviest & amount. \\
\hline $\begin{array}{l}1.9 \\
2.0\end{array}$ & $\begin{array}{l}1.0 \\
1.3\end{array}$ & $\begin{array}{l}2.3 \\
3.1\end{array}$ & $\begin{array}{l}1.2 \\
1.6\end{array}$ & $\begin{array}{l}2.1 \\
3.4\end{array}$ & $\begin{array}{l}3.1 \\
4.4\end{array} \mid$ \\
\hline
\end{tabular}

Former smokers-heaviest amount
2.7
2.1
2.4
$*$
\begin{tabular}{r|r}
4.2 & $*$ \\
$*$ & $*$
\end{tabular}

Present smokers-heaviest amount
3.2.
1.4
$3 . \frac{1}{3} \mid$
2.81
3.7
8.7

Present smokers-present amount

\begin{tabular}{l||l|l|l|l}
2.2 & 2.2 & 2.0 & 2.8 & $*$ \\
3.2 & 1.9 & 3.8 & 5.1 & $*$
\end{tabular}

Age-adjusted prevalence rate per 100 persons

\begin{tabular}{|c|c|c|c|c|c|c|}
\hline \multirow[b]{2}{*}{$\begin{array}{l}1.9 \\
2.0\end{array}$} & \multirow{3}{*}{$\begin{array}{l}1.0 \\
1.2\end{array}$} & \multicolumn{5}{|c|}{ Ever smoked-heaviest amount } \\
\hline & & $\begin{array}{l}2.4 \\
3.4\end{array}$ & $\begin{array}{l}1.2 \\
1.8\end{array} \mid$ & $\begin{array}{l}2.2 \\
4.0\end{array}$ & $\begin{array}{l}3.3 \\
5.2\end{array}$ & $\begin{array}{r}4.1 \\
10.8\end{array}$ \\
\hline & & \multicolumn{5}{|c|}{ Former smokers-heaviest amount } \\
\hline & $\begin{array}{l}1.0 \\
1.2\end{array}$ & $\begin{array}{l}2.5 \\
2.6\end{array}$ & 2.2 & 2.2 & $\begin{array}{r}3.8 \\
*\end{array}$ & * \\
\hline & & \multicolumn{5}{|c|}{ Present smokers-heaviest amount } \\
\hline & $\begin{array}{l}1.0 \\
1.2\end{array}$ & $\begin{array}{l}2.4 \\
3.8\end{array}$ & 1.6 & $\begin{array}{l}2.3 \\
4.0\end{array} \mid$ & $\begin{array}{l}3.1 \\
5.9\end{array} \mid$ & $\begin{array}{r}4.1 \\
11.6\end{array}$ \\
\hline & & Present & smokers & preser & amoun & \\
\hline 1 & $\begin{array}{l}1.0 \\
1.2\end{array}$ & $\begin{array}{l}2.4 \\
3.8\end{array}$ & $\begin{array}{l}2.3 \\
2.1\end{array}$ & $\begin{array}{l}2.2 \\
4.5\end{array}$ & $\begin{array}{l}3.1 \\
6.0\end{array}$ & $\begin{array}{l}* \\
*\end{array}$ \\
\hline
\end{tabular}

${ }^{1}$ Adjusted by the indirect method to the age distribution of the total civilian, noninstitutional population of the United States.

${ }^{2}$ Includes ICD Nos. 502 and 527.1.

"Total population" includes the "unknown if ever smoked cigarettes" category.

"Total smokers" includes the "unknown number of cigarettes" category. 
Table 11. Unadjusted and age-adjusted ${ }^{1}$ prevalence rates of chronic sinusitis ${ }^{2}$ per 100 persons 17 years and over, by smoking status, number of cigarettes smoked per day, and sex: United States, July 1964-June 1965

[Data are based on household interviews of the civilian, noninstitutional population. The survey design, general qualifications, and information on the reliability of the estimates are given in Appendix I. Definitions of terms are given in Appendix II]

\begin{tabular}{|c|c|c|c|c|c|c|c|}
\hline \multirow[b]{2}{*}{ Sex } & \multicolumn{3}{|c|}{ Smoking status } & \multicolumn{4}{|c|}{$\begin{array}{c}\text { Number of cigarettes } \\
\text { smoked per day }\end{array}$} \\
\hline & $\begin{array}{c}\text { Total } \\
\text { popu- } \\
\text { Iation }\end{array}$ & $\begin{array}{l}\text { Persons } \\
\text { who never } \\
\text { smoked } \\
\text { cigarettes }\end{array}$ & $\begin{array}{l}\text { Total } \\
\text { smokers }^{4}\end{array}$ & $\begin{array}{l}\text { Under } \\
11\end{array}$ & $11-20$ & $21-40$ & $\begin{array}{l}41 \\
\text { and } \\
\text { over }\end{array}$ \\
\hline
\end{tabular}

Unadjusted prevalence rate per 100 persons

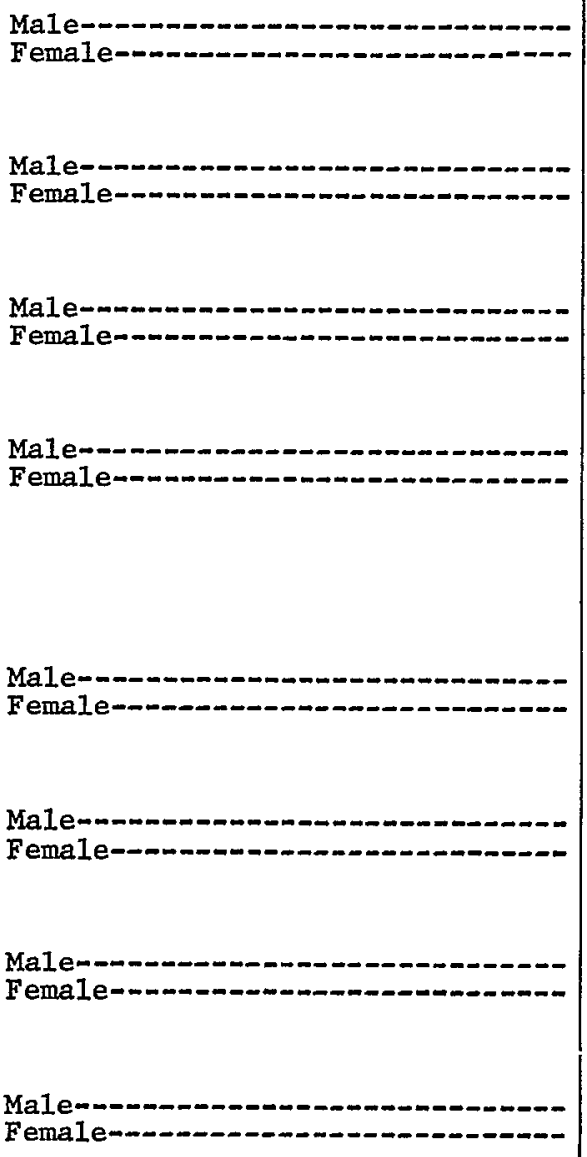

\begin{tabular}{r||r||}
10.2 & \\
12.2 & 8.2 \\
& 11.1 \\
10.2 & \\
12.2 & 8.2 \\
& 11.1 \\
10.2 & \\
12.2 & 8.2 \\
& 11.1 \\
10.2 & \\
12.2 & \\
& \\
& \\
& \\
& \\
& \\
&
\end{tabular}

Ever smoked-heaviest amount

$$
\begin{array}{l||r|r|r|r}
11.1 & 9.0 & 10.6 & 12.7 & 14.6 \\
13.9 & 11.9 & 14.1 & 16.2 & 19.9
\end{array}
$$

Former smokers-heaviest amount

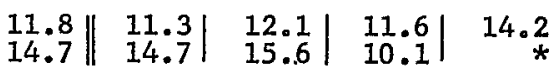

Present smokers-heaviest mount

$$
\begin{array}{r||r|r|r|r}
10.8 & 7.6 & 10.1 & 13.0 & 14.8 \\
13.7 & 10.7 & 13.9 & 17.0 & 19.0
\end{array}
$$

\begin{tabular}{|c|c|c|c|c|c|c|}
\hline \multirow[b]{2}{*}{$\begin{array}{l}10.2 \\
12.2\end{array}$} & \multirow[b]{2}{*}{$\begin{array}{r}8.3 \\
11.1\end{array}$} & \multicolumn{5}{|c|}{ Ever smoked-heaviest amount } \\
\hline & & $\begin{array}{l}11.1 \\
14.0\end{array}$ & $\begin{array}{r}9.0 \\
11.9\end{array}$ & $\begin{array}{l}10.6 \\
14.2\end{array}$ & $\begin{array}{l}12.6 \\
16.3\end{array}$ & $\begin{array}{l}14.5 \\
20.3\end{array}$ \\
\hline & & \multicolumn{5}{|c|}{ Former smokers-heaviest amount } \\
\hline $\begin{array}{l}10.2 \\
12.2\end{array}$ & $\begin{array}{r}8.3 \\
11.1\end{array}$ & $\begin{array}{l}11.6 \\
14.7\end{array}$ & $\begin{array}{l}11.2 \\
14.7\end{array} \mid$ & $\begin{array}{l}11.9 \\
15.6\end{array}$ & $\begin{array}{l}11.4 \\
10.1\end{array} \mid$ & $\begin{array}{r}13.8 \\
*\end{array}$ \\
\hline & & \multicolumn{5}{|c|}{ Present smokers-heaviest amount } \\
\hline $\begin{array}{l}10.2 \\
12.2\end{array}$ & $\begin{array}{r}8.3 \\
11.1\end{array}$ & $\begin{array}{l}10.8 \\
13.8\end{array}$ & $\begin{array}{r}7.7 \\
10.8\end{array}$ & $\begin{array}{l}10.1 \\
14.0\end{array}$ & $\begin{array}{l}13.0 \\
17.3\end{array}$ & $\begin{array}{l}14.8 \\
19.3\end{array}$ \\
\hline & & \multicolumn{5}{|c|}{ Present smokers-present amount } \\
\hline $\begin{array}{l}10.2 \\
12.2\end{array}$ & $\begin{array}{r}8.3 \\
11.1\end{array}$ & $\begin{array}{l}10.8 \\
13.8\end{array}$ & $\begin{array}{r}9.4 \\
11.7\end{array}$ & $\begin{array}{l}10.8 \\
15.0\end{array}$ & $\begin{array}{l}12.9 \\
16.5\end{array}$ & 12.2 \\
\hline
\end{tabular}

Present smokers-present amount

$$
\begin{array}{r||r|r|r|r}
10.8 & 9.3 & 10.8 & 12.9 & 12.3 \\
13.7 & 11.6 & 14.9 & 16.4 & *
\end{array}
$$

Age-adjusted prevalence rate per 100 persons

${ }^{1}$ Adjusted by the indirect method to the age distribution of the total civilian, noninstitutional population of the United States.

${ }^{2}$ Includes ICD No. 513.

"Total population" includes the "unknown if ever smoked cigarettes" category.

" "Total smokers" includes the "unknown number of cigarettes" category. 
Table 12. Unadjusted and age-adjusted ${ }^{1}$ prevalence rates of peptic ulcer $^{2}$ per 100 persons 17 years and over, by smoking status, number of cigarettes smoked per day, and sex: United States, July
1964-June 1965

[Data are based on household interviews of the civilian, noninstitutional population. The survey design, general qualifications, and information on the reliability of the estimates are given in Appendix 1. Definitions of terms are given in Appendix II]

\begin{tabular}{|c|c|c|c|c|c|c|c|}
\hline \multirow[b]{2}{*}{ Sex } & \multicolumn{3}{|c|}{ Smoking status } & \multicolumn{4}{|c|}{$\begin{array}{c}\text { Number of cigarettes } \\
\text { smoked per day }\end{array}$} \\
\hline & $\begin{array}{c}\text { Tota1 } \\
\text { popu- } \\
\text { lation } 3\end{array}$ & $\begin{array}{l}\text { Persons } \\
\text { who never } \\
\text { smoked } \\
\text { cigarettes }\end{array}$ & $\begin{array}{l}\text { Tota1 } \\
\text { smokers }\end{array}$ & $\begin{array}{l}\text { Under } \\
11\end{array}$ & $11-20$ & $21-40$ & $\begin{array}{l}41 \\
\text { and } \\
\text { over }\end{array}$ \\
\hline
\end{tabular}

Unadjusted prevalence rate per 100 persons

Male-_-

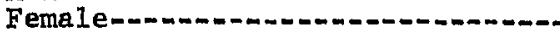

Male-m-n-man-

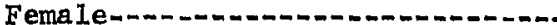

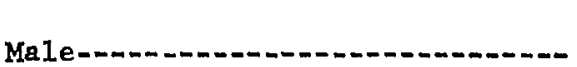

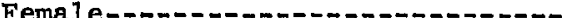

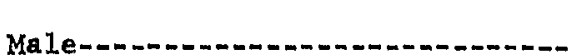

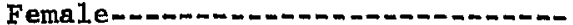

Male-

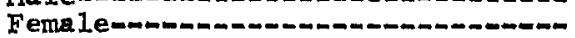

Male

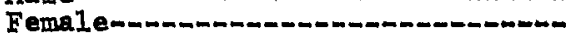

Male-

Female

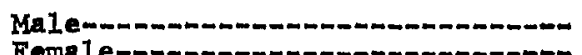

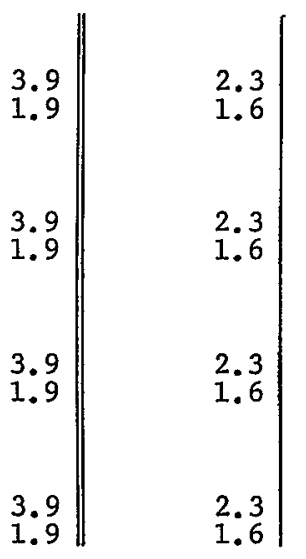

Ever smoked-heaviest amount

$$
\begin{array}{l|l|l|l|r}
4.6 & 3.1 & 4.6 & 5.4 & 5.8 \\
2.5 & 2.2 & 2.4 & 3.0 & *
\end{array}
$$

Former smokers-heaviest amount

$$
\begin{array}{l|l|r|r|r}
4.5 & 3.3 & 4.5 & 6.4 & * \\
2.6 & 2.8 & * & * & *
\end{array}
$$

\begin{tabular}{|c|c|c|c|c|c|c|}
\hline \multirow[b]{2}{*}{$\begin{array}{l}3.9 \\
1.9\end{array}$} & \multirow[b]{2}{*}{$\begin{array}{l}2.4 \\
1.6\end{array}$} & \multicolumn{4}{|c|}{ Ever smoked-heaviest amount } & \multirow[b]{2}{*}{5.6} \\
\hline & & $\begin{array}{l}4.6 \\
2.6\end{array} \mid$ & $\| \quad 3.1 .1$ & $\begin{array}{l}4.6 \\
2.5\end{array} \mid$ & $\begin{array}{l}5.4 \\
3.1\end{array}$ & \\
\hline \multirow{3}{*}{$\begin{array}{l}3.9 \\
1.9\end{array}$} & \multirow{3}{*}{$\begin{array}{l}2.4 \\
1.6\end{array}$} & \multicolumn{4}{|c|}{ Former smokers-heaviest amount } & \\
\hline & & $\begin{array}{l}4.2 \\
2.6\end{array}$ & $\begin{array}{l}3.2 \\
2.8\end{array}$ & $\begin{array}{r}4.2 \\
* 1\end{array}$ & 6.0 & * \\
\hline & & \multicolumn{5}{|c|}{ Present smokers-heaviest amount } \\
\hline & $\begin{array}{l}2.4 \\
1.6\end{array}$ & $\begin{array}{l}4.7 \\
2.5\end{array}$ & $\begin{array}{l}3.0 \\
2.0\end{array} \mid$ & $\begin{array}{l}4.6 \\
2.5\end{array} \mid$ & $\begin{array}{l}5.2 \\
3.4\end{array}$ & $\begin{array}{r}6.6 \\
*\end{array}$ \\
\hline & & Present & smokers - & resent & amount & \\
\hline & $\begin{array}{l}2.4 \\
1.6\end{array}$ & $\begin{array}{l}4.7 \\
2.5\end{array}$ & $\begin{array}{l}4.1 \\
2.1\end{array}$ & $\begin{array}{l}5.1 \\
2.7\end{array}$ & $\begin{array}{l}4.5 \\
3.3\end{array}$ & * \\
\hline
\end{tabular}

Present smokers-heaviest amount

$$
\begin{array}{ll|l|l|r}
4.7 & 2.9 & 4.6 & 5.2 & 6.6 \\
2.4 & 1.9 & 2.4 & 3.2 & *
\end{array}
$$

Present smokers-present amount

\begin{tabular}{l||l|l|l|l}
4.7 & 4.0 & 5.1 & 4.5 & $*$ \\
2.4 & 2.0 & 2.6 & 3.2 & $*$
\end{tabular}

Age-adjusted prevalence rate per 100 persons

${ }^{1}$ Adjusted by the indirect method to the age distribution of the total civilian, noninstitutional population of the United States.

"Includes ICD Nos. 540-542.

"Tota1 population" includes the "unknown if ever smoked cigarettes" category.

"Total smokers" includes the "unknown number of cigarettes" category。 
Table 13. Unadjusted and age-adjusted ${ }^{1}$ prevalence rates of arthritis per 100 persons 17 years and over, by smoking status, number of cigarettes smoked per day, and sex: United States, July 1964-June 1965

[Data are baged on housebold interviews of the civilian, noninstitutional population. The survey design, general qualifications, and information on the relisbility of the estimates are given in Appendix I. Definitions of terms are given in Appendix II]

\begin{tabular}{|c|c|c|c|c|c|c|c|}
\hline \multirow[b]{2}{*}{ Sex } & \multicolumn{3}{|c|}{ Smoking status } & \multicolumn{4}{|c|}{$\begin{array}{c}\text { Number of cigarettes } \\
\text { smoked per day }\end{array}$} \\
\hline & $\begin{array}{l}\text { Total } \\
\text { popu- } \\
\text { lation }\end{array}$ & $\begin{array}{c}\text { Persons } \\
\text { who never } \\
\text { smoked } \\
\text { clgarettes }\end{array}$ & $\begin{array}{l}\text { Total } \\
\text { smoker } s^{4}\end{array}$ & $\begin{array}{c}\text { Under } \\
11\end{array}$ & $11-20$ & $21-40$ & $\begin{array}{l}41 \\
\text { and } \\
\text { over }\end{array}$ \\
\hline
\end{tabular}

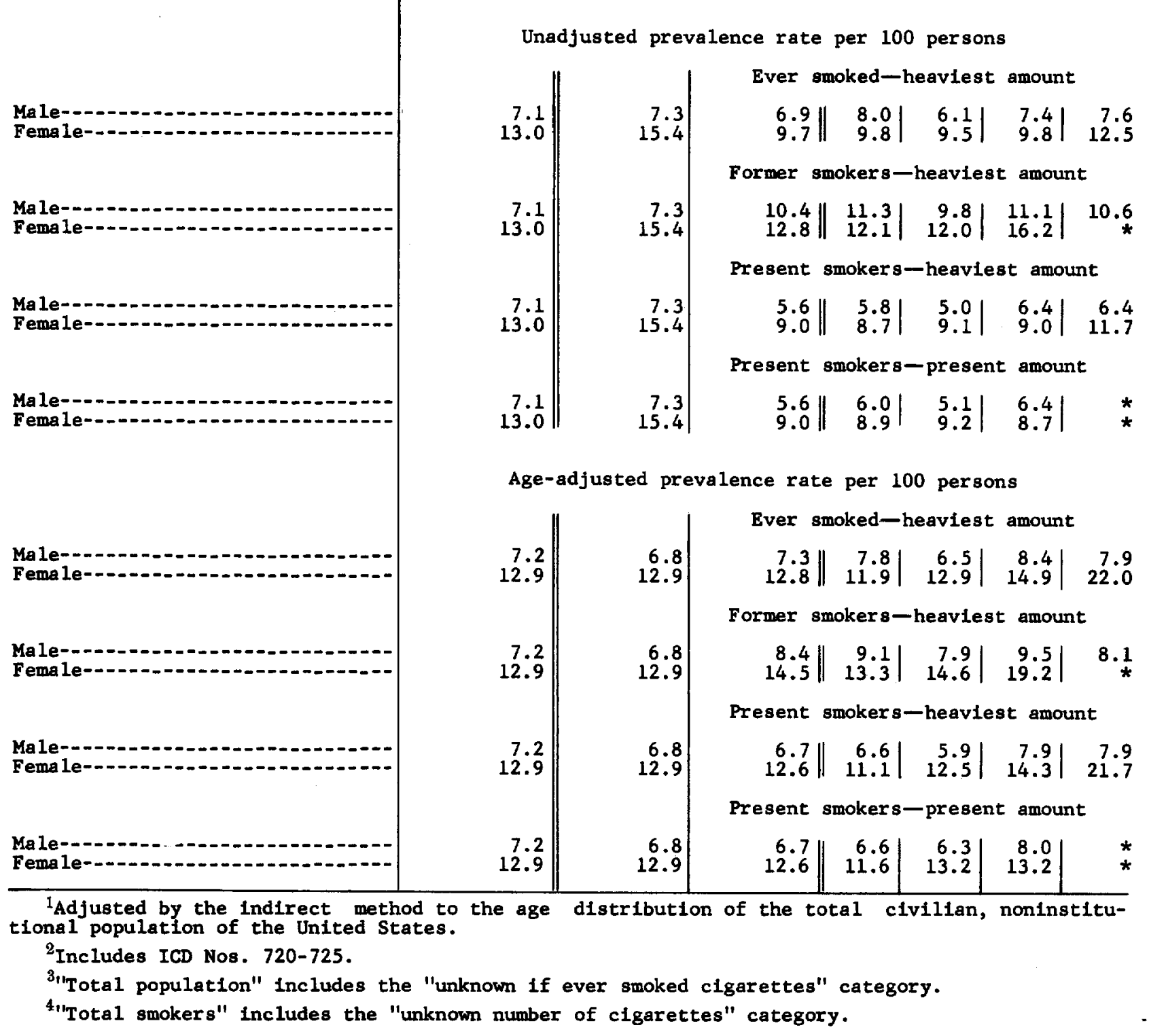


Table 14. Unadjusted and age-adjusted ${ }^{1}$ prevalence rates of hearing impairments ${ }^{2}$ per 100 persons 17 years and over, by smoking status, number of cigarettes smoked per day, and sex: United States, July 1964-June 1965

Data are based on household interviews of the civilian, noninstitutional population. The survey design, generai qualifications, and information on the reliability of the estimates are given in Appendix I. Definitions or terms are given in Appendix I]

\begin{tabular}{|c|c|c|c|c|c|c|c|}
\hline \multirow[b]{2}{*}{ Sex } & \multicolumn{3}{|c|}{ Smoking status } & \multicolumn{4}{|c|}{$\begin{array}{c}\text { Number of cigarettes } \\
\text { smoked per day }\end{array}$} \\
\hline & $\begin{array}{c}\text { Tota1 } \\
\text { popu- } \\
\text { lation }\end{array}$ & $\begin{array}{l}\text { Persons } \\
\text { who never } \\
\text { smoked } \\
\text { cigarettes }\end{array}$ & $\begin{array}{l}\text { Total } \\
\text { smokers }\end{array}$ & $\begin{array}{l}\text { Under } \\
11\end{array}$ & $11-20$ & $21-40$ & $\begin{array}{l}41 \\
\text { and } \\
\text { over }\end{array}$ \\
\hline
\end{tabular}

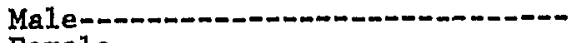
Female-mommonom Male-

Femalem-nommonam

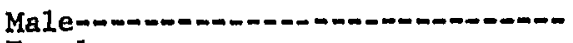

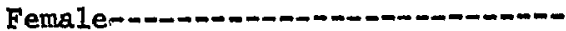

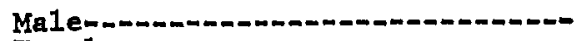

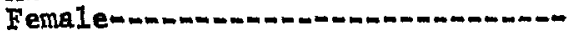

Male

Femal

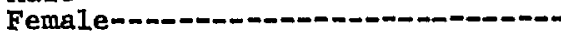

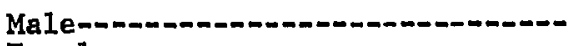

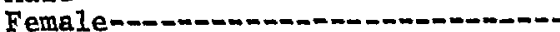

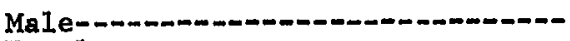

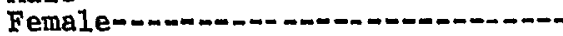

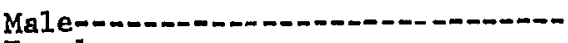

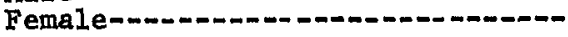

Unadjusted prevalence rate per 100 persons

\begin{tabular}{|c|c|}
\hline $\begin{array}{l}8.2 \\
5.7\end{array}$ & $\begin{array}{l}8.9 \\
7.1\end{array}$ \\
\hline $\begin{array}{l}8.2 \\
5.7\end{array}$ & $\begin{array}{l}8.9 \\
7.1\end{array}$ \\
\hline $\begin{array}{l}8.2 \\
5.7\end{array}$ & $\begin{array}{l}8.9 \\
7.1\end{array}$ \\
\hline $\begin{array}{l}8.2 \\
5.7\end{array}$ & $\begin{array}{l}8.9 \\
7.1\end{array}$ \\
\hline
\end{tabular}

Ever smoked-heaviest amount

$$
\begin{array}{l||l|l|l|r}
7.8 & 8.2 & 7.2 & 8.0 & 9.4 \\
3.9 & 3.7 & 3.8 & 4.1 & *
\end{array}
$$

Former smokers-heavlest amount

$$
\begin{array}{r|r|r|r|r}
10.9 & 10.3 & 10.1 & 11.8 & 12.4 \\
4.8 & 4.7 & 4.6 & * & *
\end{array}
$$

Present smokers-heaviest amount

$$
\begin{array}{l|l|l|l|l|}
6.7 & 6.9 & 6.2 & 7.0 & 8.1 \\
3.6 & 3.2 & 3.7 & 4.1 & *
\end{array}
$$

Present smokers-present amount

\begin{tabular}{|c|c|c|c|c|c|c|}
\hline \multirow[b]{2}{*}{$\begin{array}{l}8.4 \\
5.6\end{array}$} & \multirow[b]{2}{*}{$\begin{array}{l}8.0 \\
5.8\end{array}$} & \multicolumn{4}{|c|}{ Ever smoked-heaviest amount } & \multirow[b]{2}{*}{10.5} \\
\hline & & $\begin{array}{l}8.5 \\
5.4 \|\end{array}$ & $\begin{array}{l}8.0 \\
4.6\end{array}$ & $\begin{array}{l}7.9 \\
5.4\end{array}$ & $\begin{array}{l}9.5 \\
6.3\end{array}$ & \\
\hline & & \multicolumn{5}{|c|}{ Former smokers-heaviest amount } \\
\hline $\begin{array}{l}8.4 \\
5.6\end{array}$ & $\begin{array}{l}8.0 \\
5.8\end{array}$ & $\begin{array}{l}9.1 \\
5.6\end{array}$ & $\begin{array}{l}8.2 \\
5.3\end{array}$ & $\begin{array}{l}8.5 \\
5.8\end{array}$ & $10.7 \mid$ & 10.1 \\
\hline & & \multicolumn{5}{|c|}{ Present smokers-heaviest amount } \\
\hline $\begin{array}{l}8.4 \\
5.6\end{array}$ & $\begin{array}{l}8.0 \\
5.8\end{array}$ & $\begin{array}{l}8.3 \| \\
5.2\end{array}$ & $\begin{array}{l}7.8 \\
4.2\end{array}$ & $\begin{array}{l}7.5 \\
5.3\end{array}$ & $\begin{array}{l}9.1 \\
6.6\end{array} \mid$ & $\begin{array}{r}10.7 \\
*\end{array}$ \\
\hline & & \multicolumn{5}{|c|}{ Present smokers-present amount } \\
\hline $\begin{array}{l}8.4 \\
5.6\end{array}$ & $\begin{array}{l}8.0 \\
5.8\end{array}$ & $\begin{array}{l}8.3 \\
5.2\end{array}$ & $\begin{array}{l}8.0 \\
4.4\end{array}$ & $\begin{array}{l}7.81 \\
5.8\end{array}$ & $\begin{array}{l}9.6 \\
6.3\end{array}$ & $\begin{array}{r}10.2 \\
*\end{array}$ \\
\hline
\end{tabular}

$$
\begin{array}{l|l|l|l|l}
6.7 & 7.3 & 6.1 & 7.1 & 7.7 \\
3.6 & 3.3 & 3.9 & 3.9 & *
\end{array}
$$

Agemadjusted prevalence rate per 100 persons

${ }^{1}$ Adjusted by the indirect method to the age distribution of the total civilian, noninstitutional population of the United States.

"Includes ICD Nos. X06-X09.

"Total population" Includes the "unknown if ever smoked cigarettes" category.

"Total smokers" includes the "unknown number of cigarettes" category. 
Table 15. Unadjusted and age-adjusted ${ }^{1}$ prevalence rates of all other chronic conditions ${ }^{2}$ per 100 persons 17 years and over, by smoking status, number of cigarettes smoked per day, and sex: United States, July 1964-June 1965

[Data are based on household interviews of the civilian, noninstitutional population. The survey design, general qualifications, and information on the reliability of the estimates are given in Appendix I. Definitions of terms are given in Appendix $\mathrm{H}]$

\begin{tabular}{|c|c|c|c|c|c|c|c|}
\hline \multirow[b]{2}{*}{ Sex } & \multicolumn{3}{|c|}{ Smoking status } & \multicolumn{4}{|c|}{$\begin{array}{c}\text { Number of cigarettes } \\
\text { smoked per day }\end{array}$} \\
\hline & $\begin{array}{c}\text { Total } \\
\text { popu- } \\
\text { lation } 3\end{array}$ & $\begin{array}{l}\text { Persons } \\
\text { who never } \\
\text { smoked } \\
\text { cigarettes }\end{array}$ & $\begin{array}{l}\text { Total } \\
\text { smokers }\end{array}$ & $\begin{array}{l}\text { Under } \\
11\end{array}$ & $11-20$ & $21-40$ & $\begin{array}{l}41 \\
\text { and } \\
\text { over }\end{array}$ \\
\hline
\end{tabular}

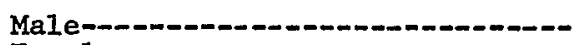

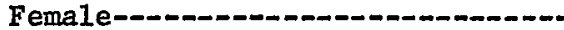

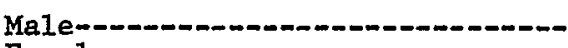

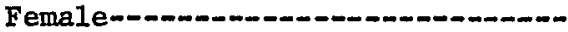

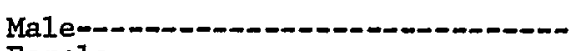

Female-nan-

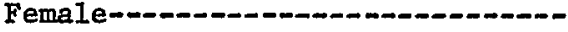

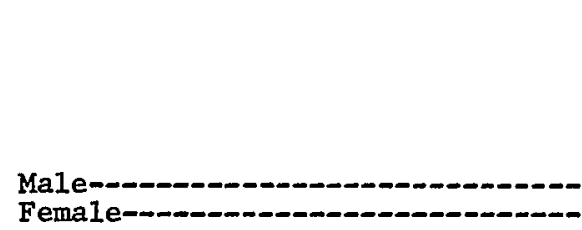

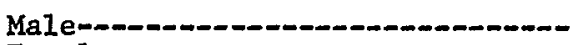

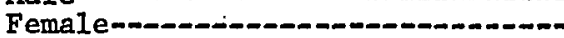

Malem-10

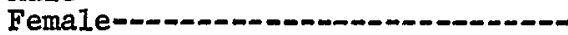

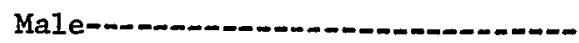
Female

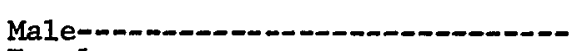

Unadjusted prevalence rate per 100 persons

\begin{tabular}{|c|c|}
\hline $\begin{array}{r}78.6 \\
100.8\end{array}$ & $\begin{array}{r}74.8 \\
103.0\end{array}$ \\
\hline $\begin{array}{r}78.6 \\
100.8\end{array}$ & $\begin{array}{r}74.8 \\
103.0\end{array}$ \\
\hline $\begin{array}{r}78.6 \\
100.8\end{array}$ & $\begin{array}{r}74.8 \\
103.0\end{array}$ \\
\hline $\begin{array}{r}78.6 \\
100.8\end{array}$ & $\begin{array}{r}74.8 \\
103.0\end{array}$ \\
\hline
\end{tabular}

Ever smoked-heaviest amount

\begin{tabular}{l|l|l|l|l}
80.2 & 76.9 & 74.2 & 87.2 & 104.7
\end{tabular} \begin{tabular}{ll|l|l|l}
98.0 & 88.7 & 92.2 & 119.1 & 168.1
\end{tabular}

Former smokers-heaviest amount

\begin{tabular}{r|r|r|r|r}
96.5 & 98.7 & 91.0 & 100.2 & 113.9 \\
114.8 & 111.6 & 111.1 & 132.0 & 174.7
\end{tabular}

Present smokers-heaviest amount

$$
\begin{array}{l||l|l|r|r}
74.0 & 62.7 & 68.8 & 83.7 & 101.0 \\
94.0 & 78.5 & 89.4 & 117.5 & 167.1
\end{array}
$$

Present smokers-present amount

$$
\begin{array}{r|r|r|r|r}
74.0 & 73.5 & 70.4 & 82.8 & 90.2 \\
94.0 & 86.0 & 94.7 & 114.2 & 159.8
\end{array}
$$

\begin{tabular}{|c|c|c|c|c|c|c|}
\hline \multirow[b]{2}{*}{$\begin{array}{r}79.1 \\
100.1\end{array}$} & \multirow[b]{2}{*}{$\begin{array}{l}72.5 \\
95.9\end{array}$} & \multicolumn{5}{|c|}{ Ever smoked-heaviest amount } \\
\hline & & $\begin{array}{r}82.0 \\
107.8\end{array}$ & $\begin{array}{l}76.1 \\
94.8\end{array}$ & $\left|\begin{array}{r}76.1 \\
102.1\end{array}\right|$ & $\left|\begin{array}{r}91.6 \\
135.6\end{array}\right|$ & $\begin{array}{l}107.2 \\
198.2\end{array}$ \\
\hline & & \multicolumn{5}{|c|}{ Former smokers-heaviest amount } \\
\hline $\begin{array}{r}79.1 \\
100.1\end{array}$ & $\begin{array}{l}72.5 \\
95.9\end{array}$ & $\begin{array}{r}89.4 \\
120.3\end{array}$ & $\begin{array}{r}90.4 \\
115.7\end{array}$ & $\begin{array}{r}84.4 \\
118.9\end{array}$ & $\left|\begin{array}{r}95.4 \\
140.4\end{array}\right|$ & $\begin{array}{l}103.4 \\
197.4\end{array}$ \\
\hline & & \multicolumn{5}{|c|}{ Present smokers-heaviest amount } \\
\hline $\begin{array}{r}79.1 \\
100.1\end{array}$ & $\begin{array}{l}72.5 \\
95.9\end{array}$ & $\begin{array}{r}78.9 \\
104.7\end{array}$ & $\begin{array}{l}65.4 \\
85.1\end{array}$ & $\begin{array}{l}73.0 \\
99.5\end{array}$ & $\left|\begin{array}{r}90.3 \\
135.2\end{array}\right|$ & $\begin{array}{l}109.0 \\
199.1\end{array}$ \\
\hline & & Present & lokers- & -present & t amount & \\
\hline $\begin{array}{r}79.1 \\
100.1\end{array}$ & $\begin{array}{l}72.5 \\
95.9\end{array}$ & $\begin{array}{r}78.9 \\
104.7\end{array}$ & $\begin{array}{l}75.8 \\
93.9\end{array}$ & $\begin{array}{r}75.9 \\
106.4\end{array}$ & $\begin{array}{r}89.6 \\
130.5\end{array}$ & $\begin{array}{r}97.1 \\
185.0\end{array}$ \\
\hline
\end{tabular}

Age-adjusted prevalence rate per 100 persons

${ }^{1}$ Adjusted by the indirect method to the age distribution of the total civilian, noninstitutional population of the United States.

${ }^{2}$ Exclusive of conditions shown in tables 6-12 and arteriosclerosis.

3 "Total population" Includes the "unknown if ever smoked cigarettes" category.

4"Total smokers" includes the "unknown number of cigarettes" category. 
Table 16. Incidence of acute conditions per 100 persons 17 years and over per year, by smoking status, number of cigarettes smoked per day, sex, and age: United States, July $1964-J u n e ~ 1965$

[Data are based on household interviews of the civilian, noninstitutional population. The survey design, general qualifications, and information on the reliability of the estimates are given in Appendix I. Definitions of terms are given in Appendix II]

\begin{tabular}{|c|c|c|c|c|c|c|c|}
\hline \multirow[b]{2}{*}{ Sex and age } & \multicolumn{3}{|c|}{ Smoking status } & \multicolumn{4}{|c|}{$\begin{array}{l}\text { Number of cigarettes } \\
\text { smoked per day }\end{array}$} \\
\hline & $\begin{array}{l}\text { Tota1 } \\
\text { popu- } \\
\text { lation } 1\end{array}$ & $\begin{array}{l}\text { Persons } \\
\text { who never } \\
\text { smoked } \\
\text { cigarettes }\end{array}$ & $\begin{array}{l}\text { Total } \\
\text { smokers }\end{array}$ & $\begin{array}{l}\text { Under } \\
11\end{array}$ & $11-20$ & $21-40$ & $\begin{array}{l}41 \\
\text { and } \\
\text { over }\end{array}$ \\
\hline
\end{tabular}

\section{Male}

A11 ages, 17 years and over--

17-44 years--

45-64 years-0-10

65 years and over-a-

A11 ages, 17 years and over--

17-44 years

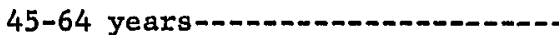

65 years and over.

A11 ages, 17 years and over-17-44 years

45-64 years-_-

65 years and over-an

Al1 ages, 17 years and over-17-44 years 45-64 years--n-men65 years and over-m.n.
Incidence rate per 100 persons per year

Ever smoked-heaviest amount

\begin{tabular}{|r||r|r|r|r|r|r|} 
& & \multicolumn{4}{|c|}{ Ever smoked-heaviest amount } \\
\hline 143.8 & 130.3 & 149.8 & 129.4 & 145.8 & 166.8 & 162.1 \\
\hline \hline 154.2 & 141.4 & 160.1 & 134.0 & 157.4 & 177.3 & 191.3 \\
134.1 & 125.6 & 137.1 & 119.4 & 129.8 & 156.1 & 137.9 \\
123.9 & 105.1 & 138.0 & 132.5 & 136.4 & 139.5 & *
\end{tabular}

Former smokers-heaviest amount

\begin{tabular}{|r||r|r||r|r|r|r|}
\hline 143.8 & 130.3 & 155.9 & 147.9 & 140.9 & 175.4 & 185.5 \\
\hline 154.2 & 141.4 & 170.9 & 165.9 & 140.0 & 196.2 & $*$ \\
134.1 & 125.6 & 137.4 & 119.3 & 125.8 & 170.3 & $*$ \\
123.9 & 105.1 & 162.7 & 154.7 & 177.0 & $*$ & *
\end{tabular}

Present smokers-heaviest amount

\begin{tabular}{|c|c|c|c|c|c|c|}
\hline 143.8 & 130.3 & 147.5 & 117.5 & 147.3 & 164.5 & 152.7 \\
\hline 154.2 & 141.4 & 157.3 & 119.2 & 161.2 & 173.8 & 179.3 \\
\hline 134.1 & 125.6 & 136.9 & 119.5 & 131.5 & 151.4 & 120.1 \\
\hline 123.9 & 105.1 & 113.6 & * & 106.2 & * & * \\
\hline 143.8 & 130.3 & $\begin{array}{r}\text { Present } \\
147.5\end{array}$ & $\begin{array}{l}\text { smoker } \\
135.0\end{array}$ & 147.8 & $\begin{array}{l}\text { nt amot } \\
163.8\end{array}$ & $\begin{array}{l}\text { nt } \\
160.7\end{array}$ \\
\hline 154.2 & 141.4 & 157.3 & 138.2 & 160.8 & 171.7 & 198.5 \\
\hline 134.1 & 125.6 & 136.9 & 139.1 & 128.8 & 154.3 & $*$ \\
\hline 123.9 & 105.1 & 113.6 & 109.2 & 117.8 & * & 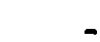 \\
\hline
\end{tabular}


Table 16. Incidence of acute conditions per 100 persons 17 years and over per year, by smoking status, number of cigarettes smoked per day, sex, and age: United States, July 1964-June
1965-Con.

[Data are based on household interviews of the civilian, noninstitutional population. The survey design, general qualifications, and information on the reliability of the estimates are given in Appendix I. Definitions of terms are given in Appendix II]

\begin{tabular}{|c|c|c|c|c|c|c|c|}
\hline Sex and age & $\begin{array}{c}\text { Total } \\
\text { popu- } \\
\text { lation } 1\end{array}$ & $\begin{array}{l}\text { Persons } \\
\text { who never } \\
\text { smoked } \\
\text { cigarettes }\end{array}$ & $\begin{array}{l}\text { Total } \\
\text { smokers }\end{array}$ & $\begin{array}{c}\text { Under } \\
11\end{array}$ & $11-20$ & $21-40$ & $\begin{array}{l}41 \\
\text { and } \\
\text { over }\end{array}$ \\
\hline
\end{tabular}

\section{Female}

Al1 ages, 17 years and over--

17-44 years-45-64 years-_-_-_._._._. 65 years and over-_-

A11 ages, 17 years and over--

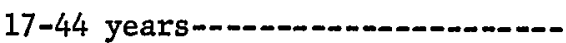
45-64 years

65 years and over-n_.

A11 ages, 17 years and over-17-44 years-n 45-64 years-_-_65 years and over-a.

A11 ages, 17 years and over-m $17-44$ years 45-64 years 65 years and over--n-n-

Incidence rate per 100 persons per year

Ever smoked-heaviest amount

\begin{tabular}{|r||r|r||r|r|r|r|} 
& & \multicolumn{4}{|c|}{ Ever smoked-heaviest amount } \\
\hline 181.6 & 163.3 & 209.1 & 201.0 & 203.3 & 238.4 & 242.9 \\
\hline & & & & & & \\
207.3 & 188.8 & 228.0 & 229.6 & 214.3 & 259.7 & 252.0 \\
156.7 & 145.7 & 173.2 & 154.8 & 177.9 & 189.5 & * \\
139.4 & 133.3 & 182.3 & 159.9 & 223.7 & $*$ & -
\end{tabular}

Former smokers-heaviest amount

\begin{tabular}{|r|r|r||r|r|r|r}
\hline 181.6 & 163.3 & 212.7 & 216.0 & 206.0 & 218.3 & * \\
\hline 207.3 & 188.8 & 220.5 & 226.8 & 205.5 & 241.0 & * \\
156.7 & 145.7 & 202.5 & 206.5 & 192.8 & 185.5 & * \\
139.4 & 133.3 & 200.5 & $*$ & $*$ & $*$ & -
\end{tabular}

Present smokers-heaviest amount

\begin{tabular}{rr||r|r|r|r|r|r}
\hline 181.6 & 163.3 & 208.2 & 194.4 & 203.0 & 240.9 & 237.9 \\
\hline 207.3 & 188.8 & 229.6 & 230.7 & 215.5 & 261.6 & 253.6 \\
156.7 & 145.7 & 165.4 & 128.6 & 175.7 & 190.2 & $*$ \\
139.4 & 133.3 & 173.9 & $*$ & 211.2 & $*$ & -
\end{tabular}

Present smokers-present amount

\begin{tabular}{rr|rr||r|r|r|r}
\hline 181.6 & 163.3 & 208.2 & 203.7 & 208.2 & 227.9 & $*$ \\
\hline 207.3 & 188.8 & 229.6 & 232.0 & 223.1 & 248.1 & * \\
\hline 156.7 & 145.7 & 165.4 & 152.6 & 171.4 & 192.0 & $*$ \\
139.4 & 133.3 & 173.9 & 147.3 & 241.9 & $*$ & \\
\hline
\end{tabular}

\footnotetext{
I"Tota1 population" includes the "unknown if ever smoked cigarettes" category.
}

2 "Total smokers" includes the "unknown number of cigarettes" category. 
Table 18. Unadjusted incidence of acute conditions per 100 persons 17 years and over per year, by cigarette smoking status, selected acute conditions, and sex: United States, July 1964-June 1965

[Data are based on household interviews of the civilian, noninstitutional population. The survey design, general qualifications, and information on the reliability of the estimates are given in Appendix I. Definitions of terms are given in Appendix II]

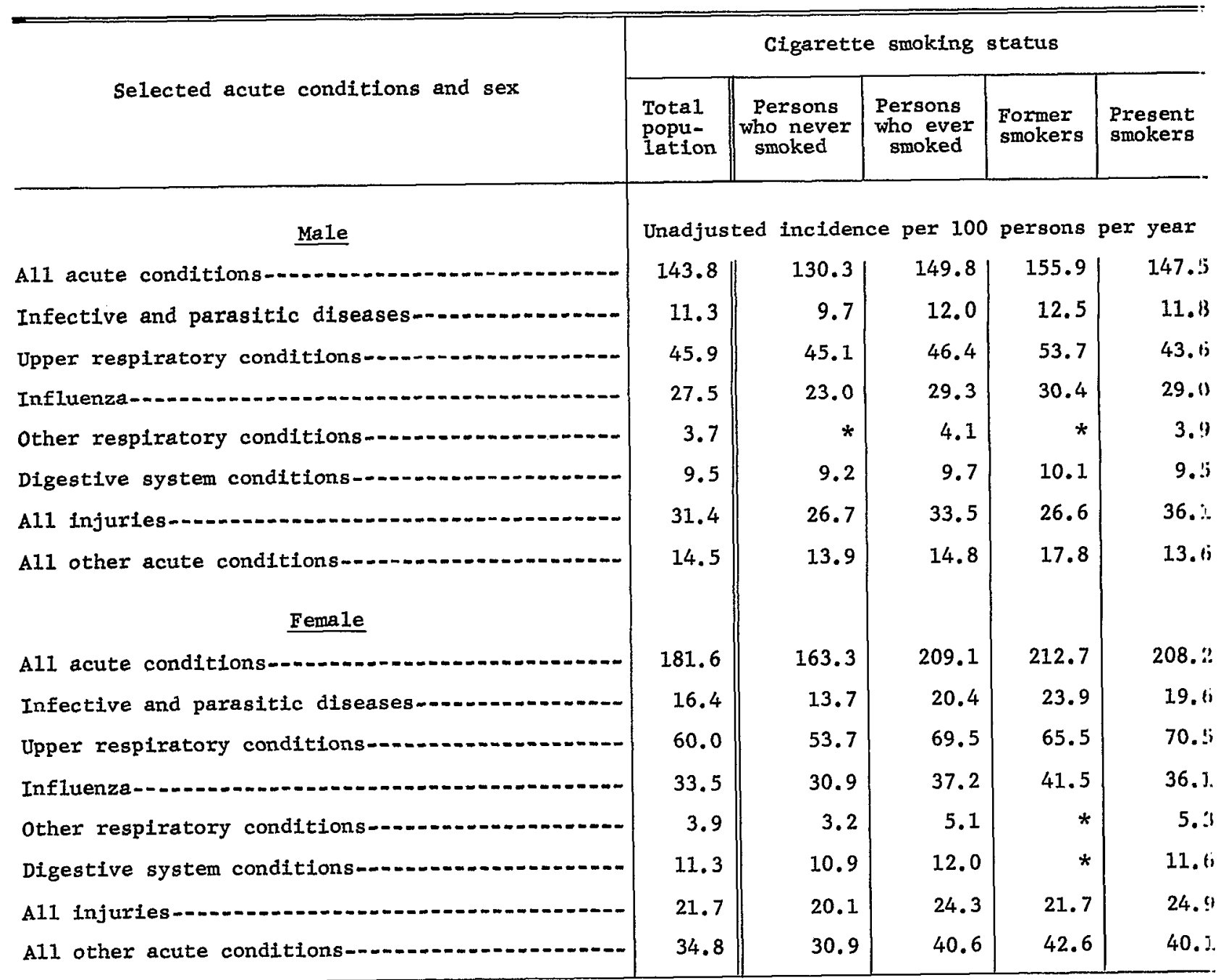


Table 19. Age-adjusted ${ }^{1}$ incidence of acute conditions per 100 persons 17 years and over per year, by cigarette smoking status, selected acute conditions, and sex: United States, July 1964June 1965

[Data are based on household interviews of the civilian, noninstitutional population. The survey design, general qualifications, and information on the reliability of the estimates are given in Appendix I. Definitions of terms are given in Appendix II]

\begin{tabular}{|c|c|c|c|c|c|}
\hline Selected acute conditions and sex & $\begin{array}{l}\text { Total } \\
\text { popu- } \\
\text { lation }\end{array}$ & $\begin{array}{l}\text { Persons } \\
\text { who never } \\
\text { smoked }\end{array}$ & $\begin{array}{l}\text { Persons } \\
\text { who ever } \\
\text { smoked }\end{array}$ & $\begin{array}{l}\text { Former } \\
\text { smokers }\end{array}$ & $\begin{array}{l}\text { Present } \\
\text { smokers }\end{array}$ \\
\hline Male & \multicolumn{5}{|c|}{$\begin{array}{l}\text { Age-adjusted incidence } \\
\text { per } 100 \text { persons per year }\end{array}$} \\
\hline 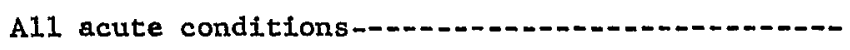 & $143.5 \|$ & 130.8 & 149.2 & 161.5 & 144.8 \\
\hline Infective and parasitic diseases & 11.2 & 9.8 & 11.9 & 13.3 & 11.4 \\
\hline Upper respiratory conditions & 45.8 & 45.0 & 46.4 & 54.9 & 43.2 \\
\hline Influenza & 27.4 & 23.2 & 29.1 & 31.5 & 28.4 \\
\hline 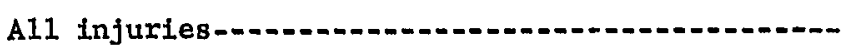 & 31.3 & 26.8 & 33.4 & 27.6 & 35.3 \\
\hline Al1 other acute conditions & 14.4 & 13.9 & 14.7 & 18.8 & 13.2 \\
\hline Femele & & & & & \\
\hline Al1 acute conditions-n. & 181.8 & 167.1 & 203.0 & 210.3 & 201.4 \\
\hline Infective and parasitic diseases & 16.4 & 14.3 & 19.3 & 23.2 & 18.4 \\
\hline Uppex respiratory conditions & 60.0 & 54.3 & 68.3 & 65.1 & 69.2 \\
\hline Influenza-men & 33.6 & 31.8 & 35.9 & 40.8 & 34.6 \\
\hline
\end{tabular}

${ }^{1}$ Adjusted by the indirect method to the age distribution ( 3 categories) of the total civilian, noninstitutional population of the United States. 
Table 20. Number of restricted-activity days per person 17 years and over per year, by smoking status, number of cigarettes smoked per day, sex, and age: United States, July 1964-June 1965

[Data are besed on household interviews of the civilian, noninstitutional population: The survey design, general qualifications, and information on the reliability of the estimates are given in Appendix 1. Definitions of terms are given in Appeadix I] ]

\begin{tabular}{|c|c|c|c|c|c|c|c|}
\hline \multirow[b]{2}{*}{ Sex and age } & \multicolumn{3}{|c|}{ Smoking status } & \multicolumn{4}{|c|}{$\begin{array}{c}\text { Number of clgarettes } \\
\text { omoked per day }\end{array}$} \\
\hline & $\begin{array}{l}\text { Total } \\
\text { popu- } \\
\text { lation }\end{array}$ & $\begin{array}{l}\text { Persons } \\
\text { who never } \\
\text { smoked }\end{array}$ & $\begin{array}{l}\text { Total } \\
\text { amokers }\end{array}$ & $\begin{array}{c}\text { Under } \\
11\end{array}$ & $11-20$ & $21-40$ & $\begin{array}{l}41 \\
\text { and } \\
\text { over }\end{array}$ \\
\hline
\end{tabular}

\section{Male}

A11 ages, 17 years and over---

17-44 years

45-64 years

65 years and over-ares

A11 ages, 17 years and over---

17-44 years-a-

45-64 years-_-_

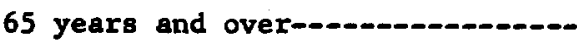

A11 ages, 17 years and over-a-

17-44 years

45-64 years-_-

65 years and over-_.

A11 ages, 17 years and over---

$17-44$ years-1-2.-

45-64 years-

65 years and over-a-
Number of restricted-activity days per person per year

Ever smoked-heaviest amount

\begin{tabular}{|r||r|r|r|r|r|r} 
& & \multicolumn{3}{|c|}{ Ever smoked-heaviest amount } \\
\hline 16.7 & 14.4 & 17.7 & 15.6 & 17.5 & 17.9 & 24.2 \\
\hline 9.7 & 7.5 & 10.6 & 8.2 & 10.1 & 11.7 & 17.2 \\
\hline 21.0 & 15.0 & 22.9 & 18.5 & 23.2 & 23.4 & 30.5 \\
35.6 & 32.9 & 37.9 & 35.3 & 38.4 & 37.6 & 36.3
\end{tabular}

Former smokers-heaviest amount

\begin{tabular}{|r|r|r|r|r|r|r}
\hline 16.7 & 14.4 & 22.2 & 19.4 & 21.4 & 23.0 & 29.2 \\
\hline 9.7 & 7.5 & 11.0 & 11.0 & 8.6 & 13.7 & 14.2 \\
21.0 & 15.0 & 25.3 & 20.4 & 26.2 & 25.8 & 35.1 \\
35.6 & 32.9 & 39.6 & 34.1 & 38.1 & 40.8 & 39.6
\end{tabular}

Present smokers-heaviest amount

\begin{tabular}{r|r|r||r|r|r|r}
\hline 16.7 & 14.4 & 16.0 & 13.0 & 16.3 & 16.6 & 22.3 \\
\hline 9.7 & 7.5 & 10.5 & 6.9 & 10.4 & 11.4 & 17.9 \\
21.0 & 15.0 & 21.8 & 17.0 & 21.9 & 22.6 & 28.1 \\
35.6 & 32.9 & 36.1 & 36.8 & 38.6 & 35.2 & 31.3
\end{tabular}

Present smokers-present amount

\begin{tabular}{|r|r|r|r|r|r|r} 
& & \multicolumn{3}{|c|}{ Present smokers-present amount } \\
\hline 16.7 & 14.4 & 16.0 & 17.7 & 15.4 & 15.6 & 21.0 \\
\hline 9.7 & 7.5 & 10.5 & 9.1 & 10.5 & 11.3 & 19.5 \\
21.0 & 15.0 & 21.8 & 25.2 & 21.4 & 21.2 & 19.5 \\
35.6 & 32.9 & 36.1 & 42.7 & 31.9 & 28.6 & 57.3
\end{tabular}


Table 20. Number of restricted-activity days per person 17 years and over per year, by smoking status, number of cigarettes smoked per day, sex, and age: United States, July 1964-June 1965-Con.

[Data are based an household interviews of the civilian, noninstitutional population. The survey design, general çualifications, and information on the reliability of the estimates are given in Appendix I. Definitions of terms are giken in Appendix II]

\begin{tabular}{|c|c|c|c|c|c|c|c|}
\hline \multirow[b]{2}{*}{ Sex and age } & \multicolumn{3}{|c|}{ Smoking status } & \multicolumn{4}{|c|}{$\begin{array}{c}\text { Number of cigarettes } \\
\text { smoked per day }\end{array}$} \\
\hline & $\begin{array}{c}\text { Total } \\
\text { popu- } \\
\text { lation } 1\end{array}$ & $\begin{array}{l}\text { Persons } \\
\text { who never } \\
\text { smoked }\end{array}$ & $\begin{array}{l}\text { Tota1 } \\
\text { smokers }\end{array}$ & $\begin{array}{l}\text { Under } \\
\text { I1 }\end{array}$ & $11-20$ & $21-40$ & $\begin{array}{c}41 \\
\text { and } \\
\text { over }\end{array}$ \\
\hline
\end{tabular}

Female

Al1 ages, 17 years and over--

17-44 years

45-64 years-n-_-_-_-

65 years and over-...-

A11 ages, 17 years and over---

17-44 years-m-n-

45-64 years-n-

65 years and over-a-

Al1 ages, 17 years and over---

$17-44$ years

45-64 years

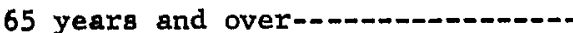

A11 ages, 17 years and over---

17-44 years-m-n

45-64 years-

65 years and over

Number of restricted-activity days per person per year Ever smoked-heaviest amount

\begin{tabular}{|r||r|r|r|r|r|r} 
& & \multicolumn{4}{|c|}{ Ever smoked-heaviest amount } \\
21.8 & 22.0 & 21.5 & 19.0 & 21.0 & 24.5 & 38.8 \\
\hline \hline 15.5 & 13.3 & 17.8 & 15.8 & 17.3 & 20.3 & 34.2 \\
23.7 & 22.6 & 25.3 & 20.0 & 25.8 & 32.4 & 34.5 \\
40.8 & 40.1 & 44.8 & 41.0 & 42.5 & 52.2 & -
\end{tabular}

Former smokers-heaviest amount

\begin{tabular}{r|r|r||r|r|r|r}
21.8 & 22.0 & 25.4 & 22.1 & 29.8 & 22.4 & 45.1 \\
\hline 15.5 & 13.3 & 17.7 & 17.2 & 19.9 & 13.9 & 36.2 \\
23.7 & 22.6 & 30.1 & 22.4 & 43.2 & 32.1 & 63.2 \\
40.8 & 40.1 & 58.2 & 49.5 & 55.4 & 46.6 & -
\end{tabular}

Present smokers-heaviest amount

\begin{tabular}{|r||r|r|r|r|r|r}
21.8 & 22.0 & 20.6 & 17.7 & 19.7 & 24.8 & 37.9 \\
\hline 15.5 & 13.3 & 17.9 & 15.3 & 17.0 & 20.9 & 33.9 \\
23.7 & 22.6 & 24.0 & 18.8 & 23.2 & 32.5 & 52.5 \\
40.8 & 40.1 & 38.5 & 35.6 & 38.6 & 54.5 & -
\end{tabular}

Present smokers-present amount

\begin{tabular}{r|rr|r|r|r|r}
21.8 & 22.0 & 20.6 & 19.8 & 20.7 & 22.4 & 31.3 \\
\hline 15.5 & 13.3 & 17.9 & 17.0 & 17.9 & 19.5 & 35.6 \\
23.7 & 22.6 & 24.0 & 22.6 & 24.2 & 29.3 & $*$ \\
40.8 & 40.1 & 38.5 & 36.6 & 47.1 & $*$ & - \\
\hline
\end{tabular}

1 "Total population" includes the "unknown if ever smoked cigarettes". category.

2 "Total smokers" includes the "unknown number of cigarettes" category. 
Table 21. Number of bed-days per person 17 years and over per year, by smoking status, number of clgarettes smoked per day, sex, and age: United States, July 1964-June 1965

[Data are based on hougehold interviews of the civilian, noninstitutional population. The survey design, general qualifications, and information on the reliability of the estimates are given in Appendix I. Definitions of terms are given in Appendix II]

\begin{tabular}{|c|c|c|c|c|c|c|c|}
\hline \multirow[b]{2}{*}{ Sex and age } & \multicolumn{3}{|c|}{ Smoking status } & \multicolumn{4}{|c|}{$\begin{array}{c}\text { Number of cigarettes } \\
\text { smoked per day }\end{array}$} \\
\hline & $\begin{array}{c}\text { Total } \\
\text { popu- } \\
\text { lation } 1\end{array}$ & $\begin{array}{l}\text { Persons } \\
\text { who never } \\
\text { smoked } \\
\text { c1garettes }\end{array}$ & $\begin{array}{l}\text { Tota } 1 \\
\text { smoker } \mathbf{s}^{2}\end{array}$ & $\begin{array}{l}\text { Under } \\
11\end{array}$ & $11-20$ & $21-40$ & $\begin{array}{l}41 \\
\text { and } \\
\text { over }\end{array}$ \\
\hline
\end{tabular}

Male

A11 ages, 17 years and over--

17-44 years

45-64 year 8

65 years and over....

A11 ages, 17 years and over--

17-44 years-

45-64 years--

65 years and over

A11 ages, 17 years and over--

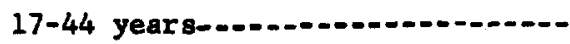

45-64 years--_-

65 years and over.

A11 ages, 17 years and over--

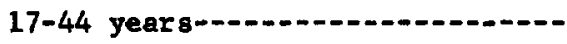

45-64 years-1

65 years and over
Number of bed-days per person per year

Ever smoked-heaviest amount

\begin{tabular}{|r|r|r|r|r|r|r} 
& & \multicolumn{6}{|c|}{ Ever smoked-heaviest amount } \\
\hline \hline 5.7 & 5.3 & 5.9 & 5.7 & 5.9 & 5.8 & 7.5 \\
\hline 3.5 & 2.7 & 3.9 & 3.4 & 3.7 & 4.1 & 6.0 \\
6.4 & 4.6 & 6.9 & 6.6 & 7.2 & 6.8 & 8.2 \\
13.2 & 13.4 & 13.0 & 11.9 & 13.1 & 13.7 & 13.5
\end{tabular}

Former smoker s-heaviest amount

\begin{tabular}{|c|c|c|c|c|c|c|}
\hline 5.7 & 5.3 & 7.4 & 7.2 & 6.9 & 7.8 & 9.4 \\
\hline 3.5 & 2.7 & 3.6 & 3.8 & 2.8 & 5.1 & * \\
\hline 6.4 & 4.6 & 8.4 & 8.4 & 8.5 & 8.3 & 12.0 \\
\hline 13.2 & 13.4 & 13.3 & 12.1 & 12.4 & 14.1 & 15.0 \\
\hline
\end{tabular}

Present smokers-heaviest amount

\begin{tabular}{|c|c|c|c|c|c|c|}
\hline 5.7 & 5.3 & 5.3 & 4.7 & $\begin{array}{r}\text { neavle } \\
5.6\end{array}$ & 5.2 & 6.7 \\
\hline 3.5 & 2.7 & 4.0 & 3.3 & 3.9 & 3.9 & 6.8 \\
\hline 6.4 & 4.6 & 6.3 & 5.2 & 6.7 & 6.3 & 6.1 \\
\hline 13.2 & 13.4 & 12.7 & 11.6 & 13.7 & 13.4 & * \\
\hline
\end{tabular}

Present smokers-present amount

\begin{tabular}{|c|c|c|c|c|c|c|}
\hline 5.7 & 5.3 & 5.3 & 6.5 & 5.0 & 4.4 & 7.8 \\
\hline 3.5 & 2.7 & 4.0 & 3.7 & 3.8 & 3.8 & 8.4 \\
\hline 6.4 & 4.6 & 6.3 & 8.6 & 6.1 & 5.0 & * \\
\hline 13.2 & 13.4 & 12.7 & 15.9 & 10.5 & 8.5 & * \\
\hline
\end{tabular}


Table 21. Number of bed-days per person 17 years and over per year, by smoking status, number of cigarettes smoked per day, sex, and age: United States, July 1964-June 1965-Con.

[Data are based on household interviews of the civilian, noninstitutional population. The survey design, general qualifications, and information on the reliability of the estimates are given in Appendix I. Definitions of terms are given in Appendix II]

\begin{tabular}{|c|c|c|c|c|c|c|c|}
\hline \multirow[b]{2}{*}{ Sex and age } & \multicolumn{3}{|c|}{ Smoking status } & \multicolumn{4}{|c|}{$\begin{array}{c}\text { Number of cigarettes } \\
\text { smoked per day }\end{array}$} \\
\hline & $\begin{array}{c}\text { Tota1 } \\
\text { popu- } \\
\text { lation } 1\end{array}$ & $\begin{array}{l}\text { Persons } \\
\text { who never } \\
\text { smoked } \\
\text { cigarettes }\end{array}$ & $\begin{array}{l}\text { Total } \\
\text { smokers }\end{array}$ & $\begin{array}{l}\text { Under } \\
11\end{array}$ & $11-20$ & $21-40$ & $\begin{array}{l}41 \\
\text { and } \\
\text { over }\end{array}$ \\
\hline
\end{tabular}

Female

A11 ages, 17 years and over--

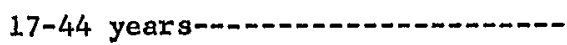

45-64 years-n-

65 years and over

A11 ages, 17 years and over-$17-44$ years

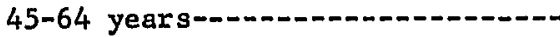
65 years and over-a

A11 ages, 17 years and over-17-44 years-1-ne 45-64 years-.... 65 years and over-

A11 ages, 17 years and over-17-44 years 45-64 years65 years and over-an

Number of bed-days per person per year

Ever smoked-heaviest amount

\begin{tabular}{|c|c|c|c|c|c|c|}
\hline 8.1 & 8.3 & $\begin{array}{r}\text { Ever sm } \\
7.9\end{array}$ & $\begin{array}{r}6.6 \\
6.6 \\
\end{array}$ & $\begin{array}{r}\text { aviest } \\
7.5\end{array}$ & $\begin{array}{r}\text { amount } \\
9.8 \\
\end{array}$ & 17.2 \\
\hline 6.0 & 5.4 & 6.7 & 5.9 & 6.5 & 7.6 & 14.9 \\
\hline 8.5 & 8.0 & 9.2 & 6.9 & 8.8 & 13.8 & 25.2 \\
\hline 15.1 & 15.1 & 15.2 & 11.4 & 13.4 & 24.0 & - \\
\hline 8.1 & 8.3 & \multicolumn{5}{|c|}{ Former smokers - heaviest amount } \\
\hline 6.0 & 5.4 & 6.7 & 6.1 & 7.2 & 4.9 & 27.8 \\
\hline 8.5 & 8.0 & 11.8 & 9.1 & 15.2 & 15.4 & \\
\hline 15.1 & 15.1 & 22.2 & 12.4 & 23.4 & & \\
\hline
\end{tabular}

Present smokers-heaviest amount

\begin{tabular}{|c|c|c|c|c|c|c|}
\hline 8.1 & 8.3 & 7.5 & 6.1 & 7.0 & 9.7 & 15.5 \\
\hline 6.0 & 5.4 & 6.7 & 5.8 & 6.4 & 7.8 & 13.2 \\
\hline 8.5 & 8.0 & 8.5 & 5.7 & 7.8 & 13.6 & 24.0 \\
\hline 15.1 & 15.1 & 11.8 & 10.8 & 10.4 & 22.4 & - \\
\hline
\end{tabular}

Present smokers-present amount

\begin{tabular}{|c|c|c|c|c|c|c|}
\hline 8.1 & 8.3 & 7.5 & 7.5 & 7.0 & 9.1 & 14.2 \\
\hline 6.0 & 5.4 & 6.7 & 7.0 & 6.2 & 7.3 & 20.0 \\
\hline 8.5 & 8.0 & 8.5 & 7.6 & 8.2 & 13.6 & * \\
\hline 15.1 & 15.1 & 11.8 & 13.0 & 11.2 & $*$ & - \\
\hline
\end{tabular}

1"Total population" includes the "unknown if ever smoked cigarettes" category.

"Tota1 smokers" includes the "unknown number of cigarettes" category. 
Table 22. Number of work-1oss days per currently employed person 17 years and over per year, jy smoking status, number of cigarettes smoked per day, sex, and age: Inited States, July 196;́June 1965

[Data are based on household interviews of the civilian, noninstitutional population. The survey design, general qualifications, and information on the reliability of the estimates are given in Appendix I. Definitions of terms are given in Appendix II]

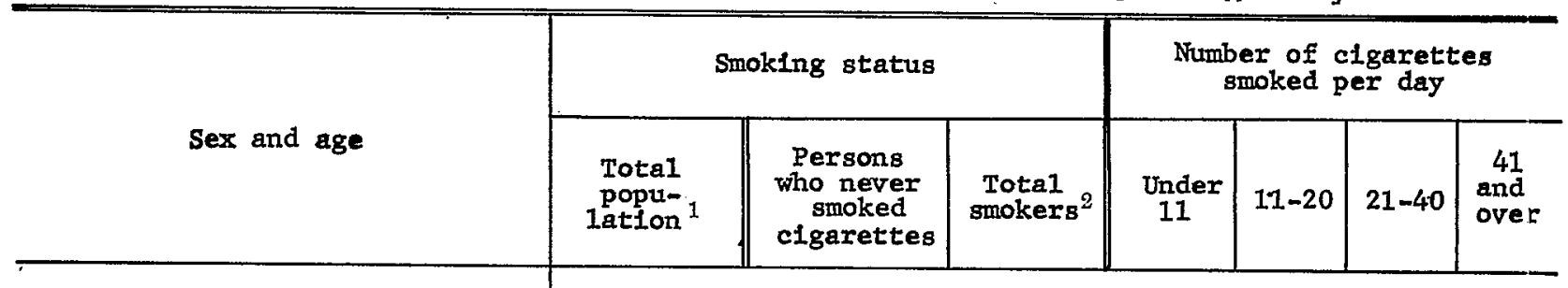

Male.

Al1 ages, 17 years and overm

17-44 years 65 years and over

A11 ages, 17 years and overm

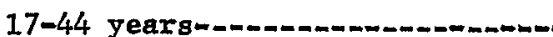
45-64 years

65 years and ove

A11 ages, 17 years and overm-

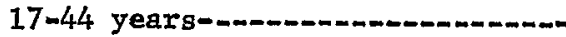
45-64 yearsm-n_-n_m

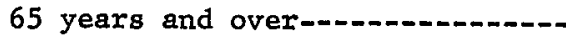

A11 ages, 17 years and over--

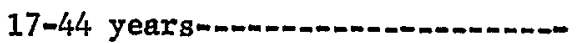
45-64 yearsm-and

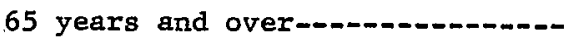

Number of work-10ss days per currently employed person per year

Ever smoked-heavlest amount

\begin{tabular}{|c|c|c|c|c|c|c|}
\hline 5.7 & 4.6 & $\begin{array}{r}\text { Ever } 8 \\
6.1\end{array}$ & $\begin{array}{r}\text { ked-h } \\
4.8\end{array}$ & 6.0 & $\begin{array}{r}\text { amount } \\
6.7\end{array}$ & 8,4 \\
\hline 4.1 & 3.4 & 4.4 & 3.0 & 4.6 & 4.9 & 5,7 \\
\hline 7.8 & 5.6 & 8.5 & 7.0 & 8.2 & 9.2 & 11,1 \\
\hline 9.8 & 9.8 & 9.8 & 10.4 & 7.5 & 12.9 & 20,9 \\
\hline
\end{tabular}

Former smokersmheaviest amount

\begin{tabular}{rr||r|r|r|r|r}
5.7 & 4.6 & 6.8 & 6.1 & 6.1 & 8.2 & 10.9 \\
\hline 4.1 & 3.4 & 3.6 & 3.4 & 2.6 & 5.0 & 5.3 \\
7.8 & 5.6 & 9.8 & 7.7 & 9.6 & 11.4 & 13.3 \\
9.8 & 9.8 & 10.3 & 16.8 & 5.5 & $*$ & $*$
\end{tabular}

Present smokers-heaviest amount

\begin{tabular}{|r|r|r|r|r|r|r}
\hline 5.7 & 4.6 & 5.9 & 3.9 & 6.0 & 6.3 & 7.5 \\
\hline 4.1 & 3.4 & 4.7 & 2.9 & 5.1 & 4.9 & 5.8 \\
7.8 & 5.6 & 7.9 & 6.4 & 7.5 & 8.5 & 9.9 \\
9.8 & 9.8 & 9.4 & $*$ & 8.8 & 16.1 & $*$ \\
& & & Present smokers mpresent amount \\
\hline 5.7 & 4.6 & 5.9 & 5.3 & 5.9 & 6.4 & 7.5 \\
\hline 4.1 & 3.4 & 4.7 & 3.5 & 5.1 & 4.8 & 6.9 \\
7.8 & 5.6 & 7.9 & 8.3 & 7.6 & 8.5 & 7.6 \\
9.8 & 9.8 & 9.4 & 9.9 & $*$ & 23.7 & $*$
\end{tabular}


Table 23. Age-adjusted ${ }^{1}$ number of disability days per person 17 years and over per year, oy smoking status, number of cigarettes smoked per day, type of disability day, and sex: United

States, July 1964-June 1965

[Data are based on household interviews of the civilian, noninstitutional population. The survey design, general qualifications, and information on the reliability of the estimates are given in Appendix I. Definitions of terms are given in Appendix II]

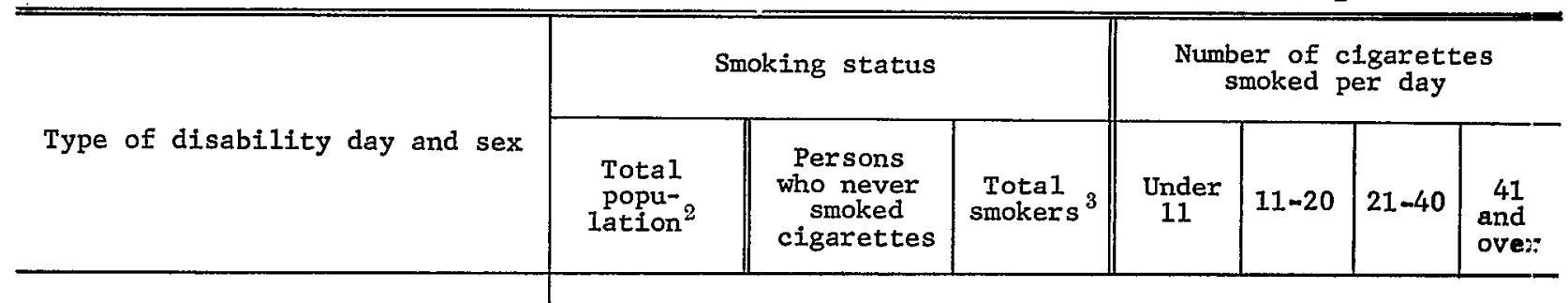

\section{Days of restricted activity}

Male

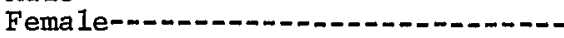

Male-

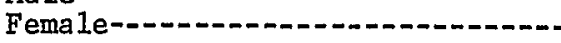

Male-

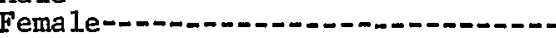

Male-10.0-

Female-n-m-non

Days of bed disability

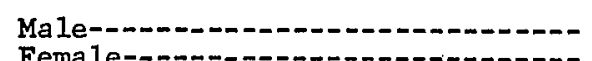

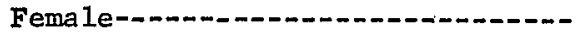

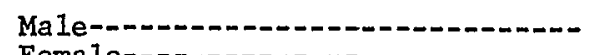

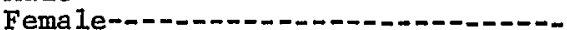

Male-n-10-0.-

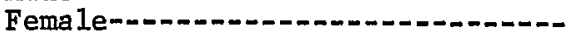

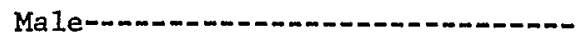

Femalem-n-nan-
Age-adjusted number of disability days per person per year

\begin{tabular}{|c|c|}
\hline $\begin{array}{l}16.9 \\
21.6\end{array}$ & $\begin{array}{l}13.8 \\
20.0\end{array}$ \\
\hline $\begin{array}{l}16.9 \\
21.6\end{array}$ & $\begin{array}{l}13.8 \\
20.0\end{array}$ \\
\hline $\begin{array}{l}16.9 \\
21.6\end{array}$ & $\begin{array}{l}13.8 \\
20.0\end{array}$ \\
\hline $\begin{array}{l}16.9 \\
21.6\end{array}$ & $\begin{array}{l}13.8 \\
20.0\end{array}$ \\
\hline $\begin{array}{l}5.8 \\
8.1\end{array}$ & $\begin{array}{l}5.1 \\
7.5\end{array}$ \\
\hline $\begin{array}{l}5.8 \\
8.1\end{array}$ & $\begin{array}{l}5.1 \\
7.5\end{array}$ \\
\hline $\begin{array}{l}5.8 \\
8.1\end{array}$ & $\begin{array}{l}5.1 \\
7.5\end{array}$ \\
\hline $\begin{array}{l}5.8 \\
8.1\end{array}$ & $\begin{array}{l}5.1 \\
7.5\end{array}$ \\
\hline
\end{tabular}

Ever smoked-heaviest amount

$$
\begin{array}{l|l|l|l|l}
18.3 & 15.4 & 18.2 & 19.2 & 25.0 \\
24.5 & 20.8 & 24.3 & 29.5 & 49.2
\end{array}
$$

Former smokers-heaviest amount

$$
\begin{array}{l||l|l|l|l|l}
19.9 & 17.3 & 19.3 & 21.5 & 25 & 5 \\
27.1 & 23.2 & 32.8 & 24.4 & 53 & 7
\end{array}
$$

Present smokers-heaviest amount

$$
\begin{array}{l||l|l|l|l}
17.5 & 13.9 & 17.8 & 18.4 & 24.7 \\
23.9 & 19.8 & 22.9 & 30.3 & 48.7
\end{array}
$$

Present smokers-present amount

$$
\begin{array}{l||l|l|l|l}
17.5 & 18.5 & 17.1 & 17.4 & 23.3 \\
23.9 & 22.5 & 24.3 & 27.2 & 38.4
\end{array}
$$

Ever smoked-heaviest amount

$$
\begin{array}{l||r|r|r|r}
6.2 & 5.6 & 6.2 & 6.2 & 7.8 \\
9.1 & 7.2 & 8.8 & 11.8 & 21.9
\end{array}
$$

Former smokers-heaviest amount

$$
\begin{array}{r||r|r|r|r}
6.7 & 6.5 & 6.3 & 7.4 & 8.4 \\
10.4 & 8.2 & 12.1 & 11.2 & 34.3
\end{array}
$$

Present smokers-heaviest amount

$$
\begin{array}{r||r|r|r|r}
5.8 & 5.0 & 6.1 & 5.9 & 7.6 \\
8.8 & 6.9 & 8.2 & 11.9 & 19.7
\end{array}
$$

Present smokers-present amount

\begin{tabular}{l|l|l|r|r}
5.8 & 6.8 & 5.6 & 5.0 & 8.8 \\
8.8 & 8.5 & 8.3 & 11.0 & 17.4
\end{tabular}


Table 23. Age-adjusted ${ }^{1}$ number of disabtlity days per person 17 years and over per year, by smoking status, number of cigarettes smoked per day, type of disability day, and sex: United States, July 1964-June 1965-Con.

Data are based on household interviews of the civilian, noninstitutional population. The survey design, general qualifications, and information on the reliability of the estimates are given in Appendix I. Definitions of terms are given in Appendix II]

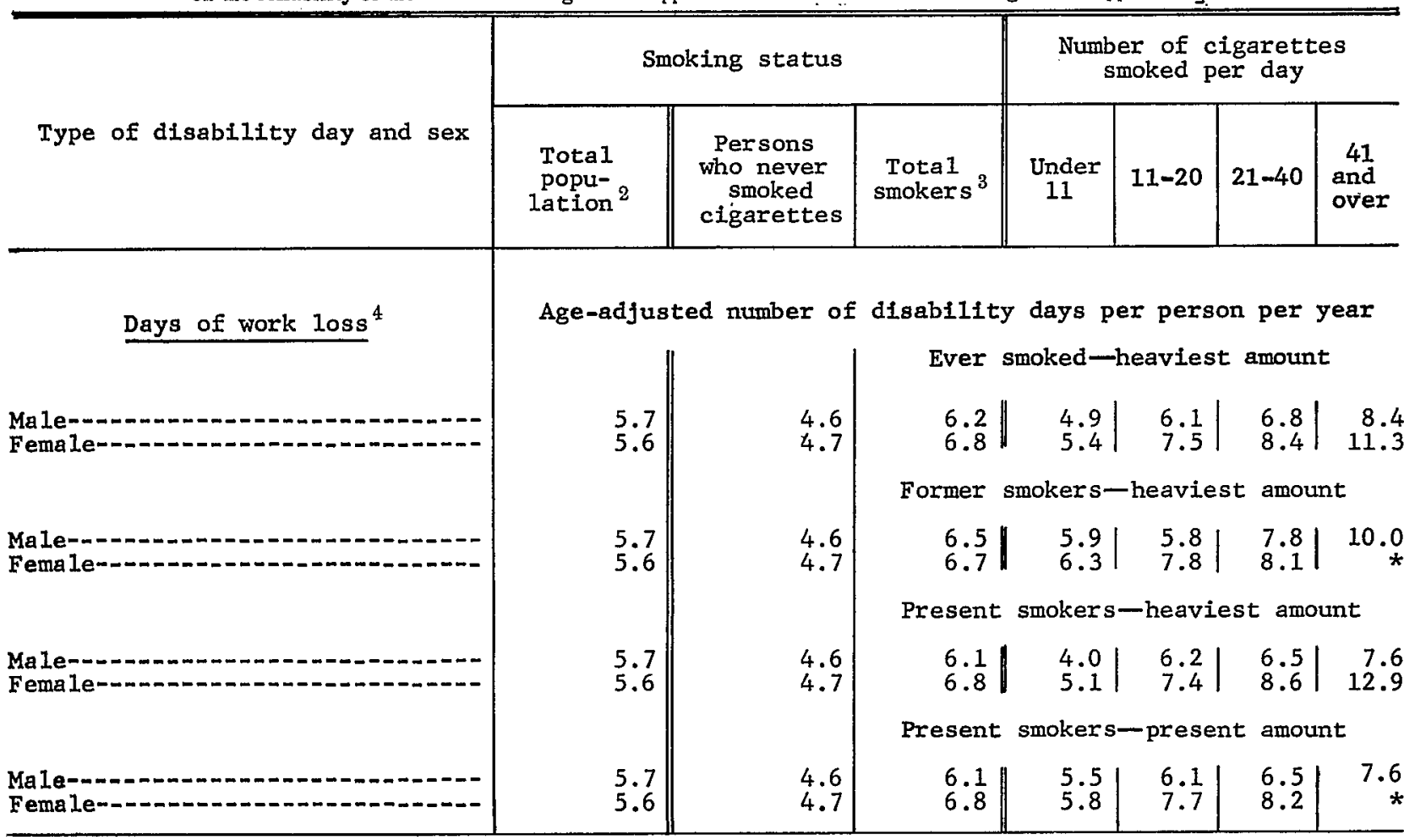

${ }^{1}$ Adjusted by' the indirect method to the age distribution of the total civilian, noninstitutional population of the United States.

"Total population" Includes the "unknown if ever smoked cigarettes" category.

3 "Total smokers" includes the "unknown number of cigarettes" category.

"Based on currently employed population. 


\section{APPENDIX 1 \\ TECHNICAL NOTES ON METHODS}

\section{Background of This Report}

This report is one of a series of statistical reports prepared by the National Health Survey. It is based on information collected in a continuing nationwide sample of households in the Health Interview Survey, a major part of the program.

The Health Interview Survey utilizes a questionnaire which, in addition to personal and demographic characteristics, obtains information on illnesses, injuries, chronic conditions and impairments, and other health topics. As data relating to each of these various broad topics are tabulated and analyzed, separate reports are issued which cover one or more of the specific topics. The present report is based on the consolidated sample for 52 weeks of interviewing ending June 1965.

The population covered by the sample for the Health Interview Survey is the civilian, noninstitutional population of the United States living at the time of the interview. The sample does not include members of the Armed Forces, U.S. nationals living in foreign countries, or crews of vessels.

\section{Statistical Design of the \\ Health Interview Survey}

General plan.-The sampling plan of the survey follows a multistage probability design which permits a continuous sampling of the civilian population of the United States. The first stage of this design consists of drawing a sample of 357 from about 1,900 geographically defined primary sampling units (PSU's) into which the United States has been divided. A PSU is a county, a group of contiguous counties, or a standard metropolitan statistical area.

With no loss in general understanding, the remaining stages can be combined and treated in this discussion as an ultimate stage. Within PSU's, then, ultimate stage units called segments are defined in such a manner that each segment contains an expected nine households. A segment consists of a cluster of neighboring households or addresses. Two general types of segments are used: (1) area segments which are defined geographically, and (2) B segments which are defined from a list of addresses from the Decennial Census and Survey of Construction. Each week a random sample of about 90 segments is drawn. In the approximately 800 households in these segments, hoursehold members are interviewed concerning factors related to health.

Since the household members interviewed each we ek are a representative sample of the population, sampies for successive weeks can be combined into larger samples. Thus the design permits both continucus measurement of characteristics of high incidence or prevalence in the population and, through the larger consolidated samples, more detailed analysis of less common characteristics and smaller categories. The continuous collection has administrative and operational advantages as well as technical assets, since it permits field work to be handled with an experienced, stable staff.

Sample size and geographic detail. - The nation al sample plan for the 12-month period ending June 191,5 included about 134,000 persons from 42,000 householdls in about 4,700 segments.

The overall sample was designed in such a fashicn that tabulation could be provided for each of the majcr geographic regions and for urban and rural sectors of the United States.

Collection of data. - Field operations for the household survey are performed by the Bureau of the Census under specifications established by the National Center for Health Statistics. In accordance with thes? specifications the Bureau of the Census selects th: sample, conducts the field interviewing as an agent of the Center, and performs a manual edit and coding of the questionnaires. The Health Interview Survey, using Center electronic computers, carries out further editing: and tabulates the edited data.

Estimating methoas. -Each statistic produced by the survey-for example, the number of persons witt one or more chronic conditions in a specified periodis the result of two stages of ratio estimation. In the first of these, the control factor is the ratio of the 1960 decennial population count to the 1960 estimated population in the National Health Survey's first-stage sample of PSU's. These factors are applied for some 25 color-residence classes.

Later, ratios of sample-produced estimates of the population to official Bureau of the Census figures for current population in about 60 age-sex-color classes are computed and serve as second-stage factors for ratio estimating.

The effect of the ratio estimating process is to make the sample more closely representative of the 
population by age, sex, color, and residence, thus reducing sampling variance.

As noted, each week's sample represents the population living during that week and characteristics of this population. Consolidation of samples over a time period, say a calendar quarter, produces estimates of average characteristics of the U.S. population for that calendar quarter. Similarly, population data for a year are averages of the four quarterly figures.

For statistics measuring the number of occurrences during a specified time period, such as the incidence of acute conditions, a similar computational procedure is used, but the statistics are interpreted differently. For these items, the questionnaire asks for the respondent's experience over the 2 calendar weeks prior to the week of interview. In such instances the estimated quarterly total for the statistic is simply 6.5 times the average 2-week estimate produced by the 13 successive samples taken during the period. The annual total is the sum of the four quarters. Thus, the experience of persons interviewed auring a year-experience which actually occurred for each person in a 2-calendar-week interval prior to week of interview-is treated as though it measured the total of such experience during the year. Such interpretation leads to no significant bias.

\section{General Qualifications}

Nonresponse. - Data were adjusted for nonresponse by a procedure which imputes to persons in a household which was not interviewed the characteristics of persons in households in the same segment which were interviewed. The total noninterview rate was 5 percent-1 percent was refusal, and the remainder was primarily due to the failure to find any eligible household respondent after repeated trials.

The interview process. - The statistics presented in this report are based on replies secured in interviews of persons in the sampled households. Each person 19 years of age and over, available at the time of interview, was interviewed individually. Proxy respondents within the household were employed for children and for adults not available at the time of the interview, provided the respondent was closely related to the person about whom information was being obtained.

There are limitations to the accuracy of diagnostic and other information collected in household interviews. For diagnostic information, the household respondent can, at best, pass on to the interviewer only the information the physician has given to the family. For conditions not medically attended, diagnostic information is often no more than a description of symptoms. However, other facts, such as the number of disability days caused by the condition, can be obtained more accurately from household members than from any other source since only the persons concerned are in a position to report this information.
Rounding of numbers. - The original tabulations on which the data in this report are based show all estimates to the nearest whole unit. All consolidations were made from the original tabulations using the estimates to the nearest unit. In the final published tables the figures are rounded to the nearest thousand, although these are not necessarily accurate to that detail. Devised statistics, such as rates and percent distributions, are computed after the estimates on which these are based have been rounded to the nearest thousand.

Population figures. - Some of the published tables include population figures for specified categories. Except for certain overall totals by age and sex, which are adjusted to independent estimates, these figures are based on the sample of households in the National Health Survey. These are given primarily to provide denominators for rate computation, and for this purpose they are more appropriate for use with the accompanying measures of health characteristics than other population data that may be available. In some instances these will permit users to recombine published data into classes more suitable to their specific needs. With the exception of. the overall totals by age and sex, mentioned above, the population figures differ from corresponding figures (which are derived from different sources) published in reports of the Bureau of the Census. For population data for general use, see the official estimates presented in Bureau of the Census reports in the $\mathrm{P}-20, \mathrm{P}-25$, and $\mathrm{P}-60$ series.

Age-adjusting. - The direct method of age-adjusting is used in most of the Health Interview Survey reports. However, because of the small size of some of the age-specific smoking and health categories in these data and the wide fluctuation of some of the age-specific rates, the indirect method of age-adjusting ${ }^{1}$ is utilized in this report as shown below.

Age-adjusted rate, indirect method ${ }^{1}=\frac{\frac{C_{s}}{P_{s}}}{\frac{\Sigma\left(m_{s 2} P_{u 2}\right)}{\Sigma P_{v 2}}} \times \frac{C_{u}}{P_{u}}$,

where: $C_{3}=$ number of conditions in standard population

$P_{s}=$ number of persons in standard population

$\boldsymbol{m}_{\mathbf{s}}=$ specific rate for age group of standard population

$C_{\mathbf{u}}=$ number of conditions in community

$P_{\mathrm{u}}=$ number of persons in community

$P_{u s}=$ population of specific age group in community

\footnotetext{
1For a more detailed discussion of the indirect method, see $T e c h$ niques of Vital Statistics, National Office of Vital Statistics. Washington, U.S. Government Printing Office, 1959, pp. 69-71.
} 
Type B.-Incidence-type statistics for which the period of reference in the questionnalre is 2 weeks.

Since the estimates are based on a sample, they will differ somewhat from the figures that would have been obtained if a complete census had been taken using the same schedules, instructions, and interviewing personnel and procedures. As in any survey, the results are also subject to measurement error.

The standard error is primarily a measure of sampling variability, that is, the variations that might occur by chance because only a sample of the population is surveyed. As calculated for this report, the standard error also reflects part of the variation which arises in the measurement process. It does not include estimates of any biases which might lie in the data. The chances are about 68 out of 100 that an estimate from the sample would differ from a complete census by less than the standard error. The chances are about 95 out of 100 that the difference would be less than twice the standard error and about 99 out of 100 that it would be less than $2 \not z$ times as large.

The relative standard error of an estimate is obtained by dividing the standard error of the estimate by the estimate itself, and it is expressed as a percentage of the estimate. Included in this Appendix are charts from which the relative standard errors can be determined for estimates shown in the report. In order to derive relative errors which would be applicable to a wide variety of health statistics and which could be prepared at a moderate cost, a number of approximations were required. As a result, the charts provide an estimate of the approximate relative standard error rather than the precise error for any specific aggregate or percentage.

Three classes of statistics for the health survey are identified for purposes of estimating variances.

Narrow range. - This class consists of (1) statistics which estimate a population attribute, e.g., the number of persons in a particular income group, and (2) statistics for which the measure for a single individual for the period of reference is usually either 0 or 1 , on occasion may take on the value 2 , and very rarely, 3 .

Medium range. - This class consists of other statistics for which the measure for a single individual for the period of reference will rarely lie outside the range 0 to 5 .

Wide range. - This class consists of statistics for which the measure for a single individual for the period of reference frequently will range from 0 to a number in excess of 5 , e.g., the number of days of bed disability experienced during the year.

In addition to classifying variables according to whether they are narrow-, medium-, or wide-range, statistics in the survey are further defined as:

Type A.-Statistics on prevalence and incidence data for which the period of reference in the questionnaire is 12 months.
Only the charts on sampling error applicable to data contained in this report are presented.

General rules for determining relative sampling errors. The "guide" on page 59 , together with the following rules, will enable the reader to determine approximate relative standard errors from the charts for estimates presented in this report.

Rule 1. Estimates of aggregates: Approximatert1ative standard errors for estimates of aggregates, such as the number of persons with a given characteristic, are obtained from appropriate curves on payre 60. The number of persons in the total U.S. population or in an age-sex class of the total population is adjusted to official Bureau of the Census figures and is nut subject to sampling error.

Rule 2. Estimates of percentages in apercent distribution: Relative standard errors for percentages in a percent distribution of 1 total are obtained from appropriate curve:; on page 61 . For values which do not fall on one of the curves presented in the chart, visual interpolation will provide a satisfactory approximation.

Rule 3. Estimates of rates where the numerator. is a subclass of the denominator: This rule applies for prevalence rates or where a unit of the numerator occurs, with few exceptions, only once in the year for any one unit in the denominator. For example, in computing the rate of orthopedic impairments per 1,000 population, the numerator consisting of persons with the impairment is a subclass of the denominator which includes all persons in the population. Such rates if converted to rates per 100 may be treated as though they were percentages, and the relative standard errors obtained from the chart, P4AN-M. Rates per 1,000 or on any other base, must first be converted to rates per 100; then the percentage chart will provide the relative standard error per 100.

Rule 4. Estimates of ratios of rates and rates where the numerator is not a subclass of the denominator: This rule applies where a unit of the numerator often occurs more than once for any one unit in the denominator. For example, in the computation of the number of persons injured per 1,000 currently employed persons per year, it is possible that a person in the denominator 
could have sustained more than one of the injuries included in the numerator. Approximate relative standard errors for rates of this kind may be computed as follows:

(a) Where the denominator is the total U.S. population, or includes all persons in one or more of the age-sex groups of the total population, the relative error of the rate is equivalent to the relative error of the numerator which can be obtained directly from the appropriate chart. (b) In other cases, obtain the relative standard error of the numerator and of the denominator from the appropriate curve. Square each of these relative errors, add the resulting values, and extract the square root of the sum. This procedure will result in an upper bound and often will overstate the error.

The following guide indicates the appropriate rules and charts to be used in deriving relative standard errors for estimates shown in this report.

\section{Guide to Use of Relative Standard Error Charts}

The code shown below identifies the appropriate curve to be used in estimating the relative standard error of the statistic described. The four components of each code describe the statistic as follows: (1)
$\mathrm{A}=$ aggregate, $\mathrm{P}=$ percentage; (2) the number of calendar quarters of data collection; (3) the type of the statistic; and (4) the range of the statistic as described on page 58 .

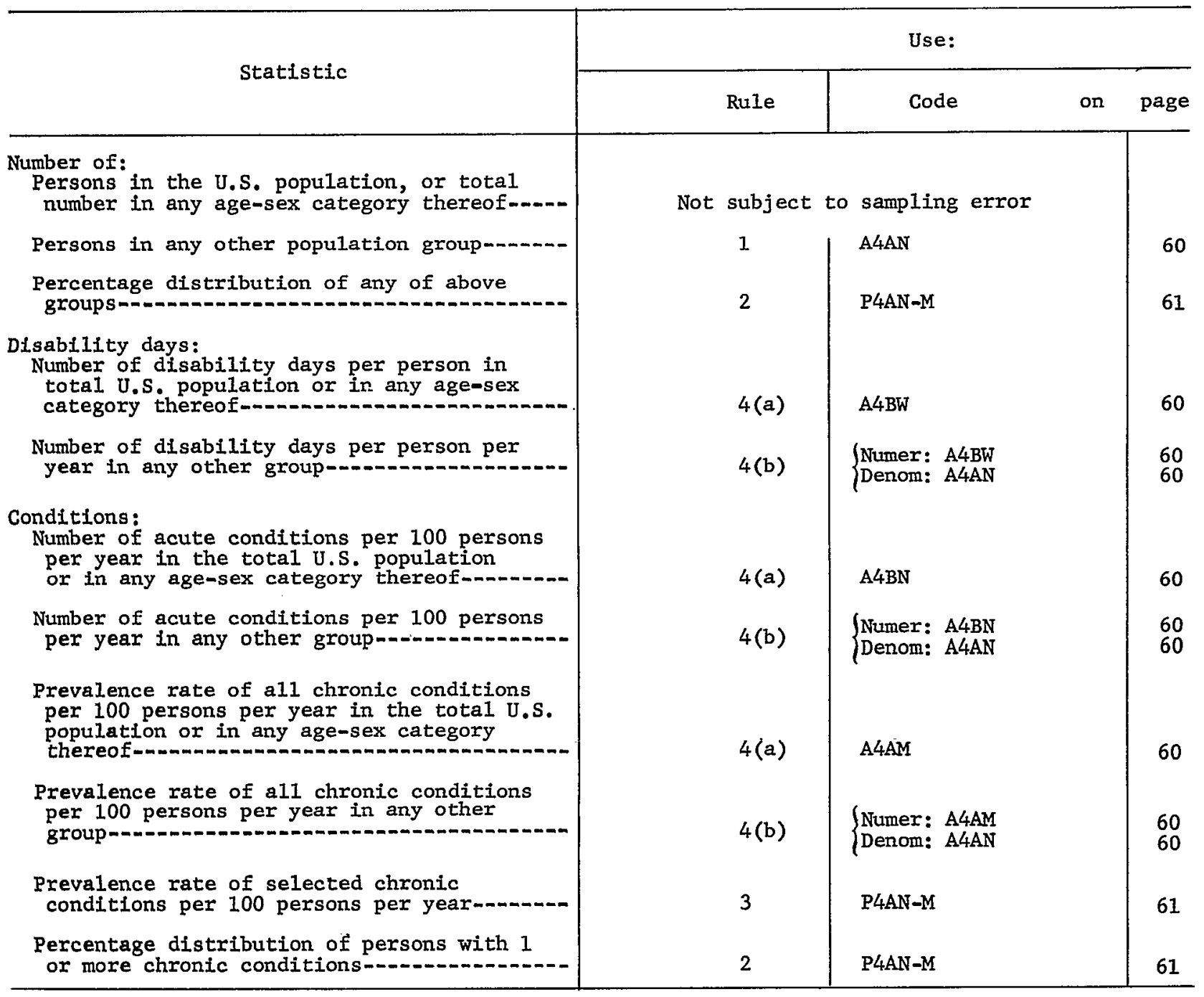


Relative standard errors for aggregates based on four quarters of data collection for data of all types and ranges

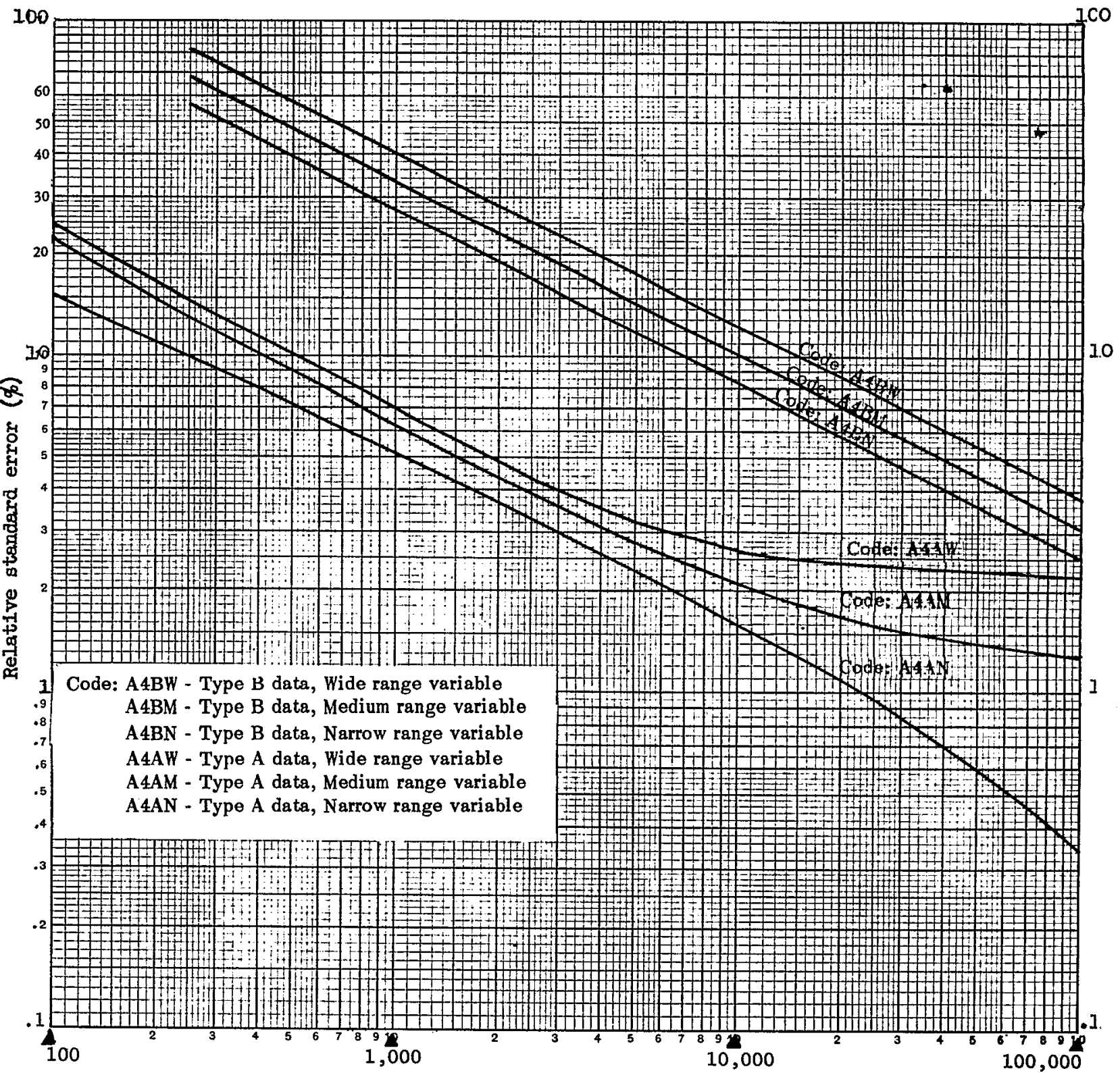

Size of estimate (in thousands)

Example of use of chart: An aggregate of 2,000,000 (on scale at bottom of chart) for a Narrow range Type A statistic (code: A4AN) has a relative standard error of 3.6 percent, (read from scale at left side of chart), or a standard error of 72,000 (3.6 percent of $2,000,000$ ). For a Wide range Type B statistic (code: A4BW), an aggregate of 6,000,000 has a relative error of 16.0 percent or a standard error of 960,000 (16 percent of $6,000,000$ ). 
Relative standard errors for percentages based on four quarters of data collection

for type A data,

(Base of percentage shown on curves in millions)

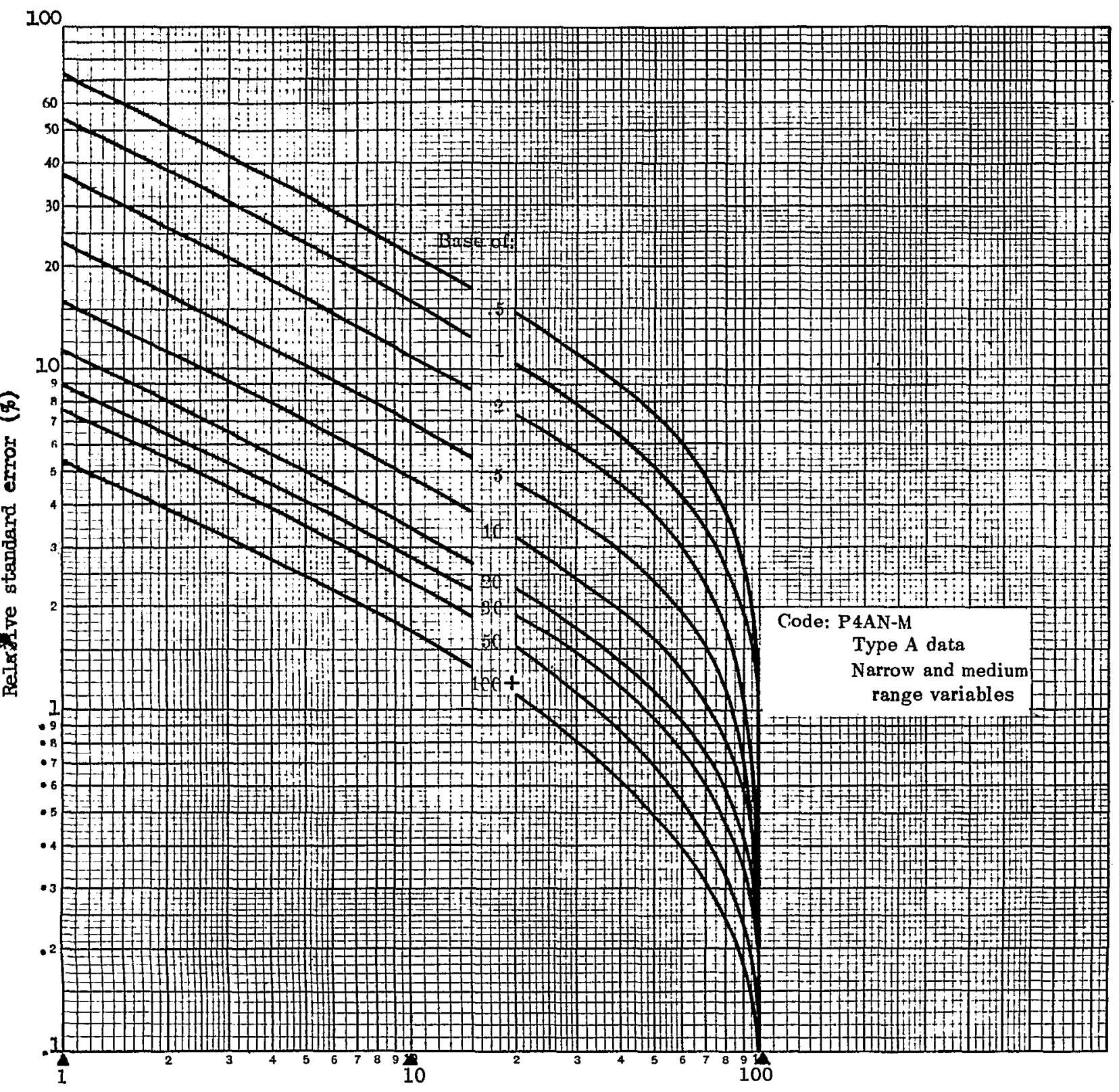

Estimated percentage

Example of use of chart: An estimate of 20 percent (on scale at bottom of chart) based on an estimate of $10,000,000$ has a relative standard error of 3.2 percent (read from the Bcale at the left side of the chart), the point at which the curve for a base of 10,000,000 intersects the vertical Iine for 20 percent. The standard error in percentage points is equal to 20 percent $\times 3.2$ percent or 0.64 percentage points. 


\section{APPENDIX II}

\section{DEFINITIONS OF CERTAIN TERMS USED IN THIS REPORT}

\section{Terms Related to Cigarette Smoking}

Nonsmoker. - A person who has never smoked more than 100 cigarettes (5 packs of cigarettes) during his entire life is considered to have never smoked cigarettes. Persons who have never smoked cigarettes will also be referred to as "never smokers."

Ever smoked cigarettes.-Persons who have smoked more than 100 (5 packs) cigarettes in their entire life are classifled as having ever smoked and are further described as present smokers and former smokers. Also referred to as "ever smokers."

Present cigarette smoker.-Any person who reported a current rate of cigarette smoking is classified as a present smoker. The rate may range from less than 1 cigarette per day to 99 or more cigarettes per day. If a person has stopped smoking cigarettes only temporarily because of illness, economic reasons, or the like, he is still considered a present smoker.

Former cigarette smoker.-Any person who has smoked at least 100 cigarettes during his entire life, but reports smoking no cigarettes at the present time is classified as a former smoker.

Heaviest smoking rate. - A person's heaviest smoking rate is the daily rate of consumption during the period when he was smoking the most. The period of heaviest smoking can range from a short time to many years.

Present smoking rate.-A person's present smoking rate is the number of cigarettes he reports to be smoking per day at the time of the interview.

Time since last smoked. - This is a measure of the interval of time since a former smoker last smoked cigarettes fairly regularly.

\section{Terms Relating to Chronic Conditions}

Condition.-A morbidity condition, or simply a condition, is any entry on the questionnaire which describes a departure from a state of physical or mental well-being. It results from a positive response to one of a series of "illness-recall" questions. In the coding and tabulating process, conditions are selected or classified according to a number of different criteria, such as, whether they were medically attended; whether they resulted in disability; whether they were acute or chronic; or according to the type of disease, injury, impairment, or symptom reported. For the purposes of each published report or set of tables, only those conditions recorded on the questionnaire which satisfy certain stated criteria are included.

Conditions, except impairments, are coded by type according to the International Classification of Diseases with certain modifications adopted to make the code more suitable for a household-interview-type survey.

Chronic condition. - A condition is considered to be chronic if (1) it is described by the respondent in terms of one of the chronic diseases on the "Check List of Chronic Conditions" or in terms of one of the types of impairments on the "Check List of Impairments," or (2) the condition is described by the respondent as having been first noticed more than 3 months before the week of the interview.

Impairment.-Impairments are chronic or permanent defects, resulting from disease, injury, or congenital malformation. They represent decrease or loss of ability to perform various functions, particularly those of the musculoskeletal system and the sense organs. All impairments are classified by means of a special supplementary code for impairments. Hence, code numbers for impairments in the International Classification of Diseases are not used. In the Supplementary Code impairments are grouped according to the type of functional impairment and etiology. The impairment classification is shown in Health Statistics from the National Health Survey, Series B, No. 35.

Persons with chronic conditions. - The estimated number of persons with chronic conditions is based on the number of persons who at the time of the interview were reported to have one or more chronic conditions.

Prevalence of conditions. - In general, prevalence of conditions is the estimated number of conditions of a specified type existing at a specified time or the average number existing during a specified interval of time. The prevalence of chronic conditions is defined as the number of chronic cases reported to be present or assumed to be present at the time of the interview; those assumed to be present at the time of the interview are cases described by the respondent in terms of one of the chronic diseases on the "Check List of 
Chronic Conditions" and reported to have been present at some time during the 12-month period prior to the interview.

\section{Terms Relating to Acute Conditions}

Acute condition. - An acute condition is defined as a condition which has lasted less than 3 months and which has involved either medical attention or restricted activity. Because of the procedures used to estimate incidence, the acute conditions included in this report are the conditions which had their onset during the 2 weeks prior to the interview week and which involved either medical attention or restricted activity during that 2 -week period. However, it excludes certain conditions which are always classified as chronic (listed below) even though the onset occurred within 3 months.

Conditions always classified as chronic:

$\begin{array}{ll}\begin{array}{l}\text { Asthma } \\ \text { Hay fever }\end{array} & \begin{array}{l}\text { Stomach ulcer } \\ \text { Any other chronic stomach } \\ \text { trouberculosis }\end{array} \\ \begin{array}{l}\text { Chronic bronchitis } \\ \text { Kidney stones or chronic } \\ \text { trouble }\end{array} & \begin{array}{c}\text { kidney trouble } \\ \text { Rhthritis or rheumatism }\end{array} \\ \text { Heumatic fever } & \text { Mental illness } \\ \text { Hardening of the arteries } & \text { Diabetes } \\ \text { High blood pressure } & \text { Thyroid trouble or goiter } \\ \text { rieart trouble } & \text { Any allergy } \\ \text { Stroke } & \text { Epilepsy } \\ \text { Trouble with varicose } & \text { Chronic nervous trouble } \\ \text { veins } & \text { Cancer } \\ \text { Hemorrhoids or piles } & \text { Chronic skin trouble } \\ \text { Tumor, cyst, or growth } & \text { Hernia or rupture } \\ \text { Chronic gallbladder or } & \text { Prostate trouble } \\ \text { liver trouble } & \text { Paralysis of any kind } \\ \text { Deafness or serious } & \text { Repeated trouble with } \\ \text { trouble with hearing } & \text { back or spine } \\ \text { Serlous trouble with } & \text { Club foot } \\ \text { seeing, even when } & \text { Permanent stiffness or } \\ \text { wearing glasses } & \text { any deformity of the foot, } \\ \text { Cleft palate } & \text { leg, fingers, arm, or } \\ \text { Any speech defect } & \text { back } \\ \text { Missing fingers, hand, } & \text { Condition present since } \\ \text { or arm-toes, foot, or leg } & \text { birth } \\ \text { Palsy } & \end{array}$

Acute conditions are classified according to the International Classification of Diseases, 1955 Revision, with certain modifications adopted to make the code more suitable for a household-interview survey. In this report, all tables which have data classified by type of condition employ a seven-category regrouping. The International Classification code numbers included in each category are shown below:
International Classification Code Number

(excluding chronic inclusions)

Infective and parasitic

diseases -.

Upper respiratory conditions-- $\quad 470-475,511,517$

Influenza -

Other respiratory conditions-- $\quad 490-501,518-525,527$, 783

Digestive system conditions---

$530-539,543-553$, $570,571,573-587$, 784,785

Injuries -

N800-N885, N890N895, N900-N994, N996-N999

All other acute conditions--.--

All other acute code numbers

Onset of conaition. - A condition is considered to have had its onset when it was first noticed. This could be the time the person first felt sick or became injured, or it could be the time when the person or his family was first told by a physician that he had a condition of which he was previously unaware.

Incidence of conditions.-The incidence of conditions is the estimated number of conditions having their onset in a specified time period. As previously mentioned, minor àcute conditions involving neither restricted activity nor medical attention are excluded from the statistics. The incidence data shown in some reports are further limited to various subclasses of conditions, such as "incidence of conditions involving bed disability."

\section{Terms Relating to Disability Days}

Disability. - Disability is a general term used to describe any temporary or long-term reduction of a person's activity as a result of an acute or chronic condition.

Disability days are classified according to whether they are days of restricted activity, bed-days, hospital days, work-loss days, or school-loss days. All hospital days are, by definition, days of bed disability; all days of bed disability are, by definition, days of restricted activity. The converse form of these statements is, of course, not true. Days lost from work are special 
terms which apply to the working population only, but these too are days of restricted activity. Hence, "days of restricted activity" is the most inclusive term used to describe disability days.

Restricted-activity day.-A day of restricted activity is a day when a person cuts down on his usual activities for the whole of that day because of an illness or an injury. The term "usual activities" for any day means the things that the person would ordinarily do on that day. For children under school age, "usual activities" depend upon whatever the usual pattern is for the child's day which will, in turn, be affected by the age of the child, weather conditions, and so forth. For retired or elderly persons, "usual activities" might consist of almost no activity, but cutting down on even a small amount for as much as a day would constitute restricted activity. On Sundays or holidays "usual activities" are taken to be the things the person usually does on such days-going to church, playing golf, visiting friends or relatives, or staying at home and listening to the radio, reading, looking at television, and so forth.

Restricted activity does not imply complete inactivity, but it does imply only the minimum of "usual activities." A special nap for an hour after lunch does not constitute cutting down on usual activities, nor does the elimination of a heavy chore, such as cleaning ashes out of the furnace or hanging out the wash. If a farmer or housewife carries on only the minimum of the day's chores, however, this is a day of restricted activity.

A day spent in bed or a day home from work or school because of illness or injury is, of course, a restricted-activity day.

Bed-disability day.-A bed-disability day, sometimes for brevity referred to as a "bed-day," is a day on which a person was kept in bed either all or most of the day because of an illness or an injury. "All or most of the day" is defined as more than half of the daylight hours. All hospital days are included as bed-disability days even if the patient was not actually in bed at the hospital.

Work-loss day.-A day lost from work is a normal working day on which a person did not work at his job or business because of a specific illness or injury. If the person's regular work day is less than a whole day and the entire work day was lost, it would be counted as a whole work day lost. The number of days lost from work is determined only for persons 17 years of age or over who reported that at any time during the 2 -week period covered by the interview they either worked at or had a job or business. These are defined as currently employed persons.

\section{Demographic and Economic Terms}

Age.-The age recorded for each person is the agi? at last birthday. Age is recorded in single years anil grouped in a variety of distributions depending upon the purpose of the table.

Currently employed persons. - Currently employed persons are all persons 17 years of age or over whis reported that at any time during the 2-week perioil covered by the interview they either worked at or hail a job or business. Current employment includes paill work as an employee of someone else; self-employment in business, farming, or professional practice; and un.. paid work in a family business or farm. Persons who were temporarily absent from their job or business because of a temporary illness, vacation, strike, or bacl weather are considered as currently employed if they expected to work as soon as the particular event causing: their absence no longer existed.

Freelance workers are considered as having $\varepsilon$ job if they had a definite arrangement with one or more employers to work for pay according to a weekly or monthly schedule, either full-time or part-time. Excluded from the currently employed population are such persons who have no definite employment schedule but who work only when their services are needed.

Also excluded from the currently employed popula tion are (1) persons who were not working, even though having a job or business, but were on layoff or looking for work, (2) persons receiving revenue from an enterprise in whose operation they did not participate, (3) persons doing housework or charity work for which they received no pay, and (4) seasonal workers during the unemployment season.

The number of currently employed persons estimated by the National Health Survey (NHS) will differ from the estimates prepared by the Current Population Survey (CPS), Bureau of the Census, for several reasons. In addition to sampling variability they include three primary conceptual differences, namely: (1) NHS estimates are for persons 17 years of age or over; CPS estimates are for persons 14 years of age or over. (2) NHS uses a 2-week-reference period while CPS uses a 1-week-reference period. (3) NHS is a continuing survey with separate samples taken weekly, while CPS is a monthly sample taken for the survey week which includes the 12 th of the month. 


\section{OUTLINE OF REPORT SERIES FOR VITAL AND HEALTH STATISTICS}

Public Health Service Publication No. 1000

Sirit's 1. Programs and collection procedures.-Reports which describe the general programs of the National Center for Health Statistics and its offices and divisions, data collection methods used, definitions, and other material necessary for understanding the data.

Sirti's 2. Data evaluation and methods research. - Studies of new statistical methodology including: experimental tests of new survey methods, studies of vital statistics collection methods, new analytical techniques, objective evaluations of reliability of collected data, contributions to statistical theory.

Sirril's 3. Analytical studies. - Reports presenting analytical or interpretive studies based on vital and health statistics, carrying the analysis further than the expository types of reports in the other series.

Sirvits \%. Documents and committee reports. - Final reports of major committees concerned with vital and health statistics, and documents such as recommended model vital registration laws and revised birth and death certificates.

Siric's 10. Data from the Health Interview Survey. - Statistics on illness, accidental injuries, disability, use of hospital, medical, dental, and other services, and other health-related topics, based on data collected in a continuing national household interview survey.

Sirit's 11. Data from the Health Examination Survey. - Data from direct examination, testing, and measurement of national samples of the population provide the basis for two types of reports: (1) estimates of the medically defined prevalence of specific diseases in the United States and the distributions of the population with respect to physical, physiological, and psychological characteristics; and (2) analysis of relationships among the various measurements without reference to an explicit finite universe of persons.

Sirie's 12. Data from the Institutional Population Surveys. - Statistics relating to the health characteristics of persons in institutions, and on medical, nursing, and personal care received, based on national samples of establishments providing these services and samples of the residents or patients.

Sirit's 13. Data from the Hospital Discharge Survey. - Statistics relating to discharged patients in short-stay hospitals, based on a sample of patient records in a national sample of hospitals.

Sirics 20. Data on mortality. - Various statistics on mortality other than as included in annual or monthly reports-special analyses by cause of death, age, and other demographic variables, also geographic and time series analyses.

Siriı's 21. Data on natality, marriage, and divorce. - Various statistics on natality, marriage, and divorce other than as included in annual or monthly reports-special analyses by demographic variables, also geographic and time series analyses, studies of fertility.

S'rit's 22. Data from the National Natality and Mortality Surveys. - Statistics on characteristics of births and deaths not available from the vital records, based on sample surveys stemming from these records, including such topics as mortality by socioeconomic class, medical experience in the last year of life, characteristics of pregnancy, etc.

For it list of titles of reports published in these series, write to: Office of Information

National Center for Health Statistics

U.S. Public Health Service

Washington, D.C. 20201 